Portland State University

PDXScholar

Summer 8-16-2017

\title{
Ozone Interaction with Indoor Building Materials and HVAC Filters
}

Omed Akber Abbass

Portland State University

Follow this and additional works at: https://pdxscholar.library.pdx.edu/open_access_etds

Part of the Engineering Commons

Let us know how access to this document benefits you.

\section{Recommended Citation}

Abbass, Omed Akber, "Ozone Interaction with Indoor Building Materials and HVAC Filters" (2017).

Dissertations and Theses. Paper 3771.

https://doi.org/10.15760/etd.5655

This Dissertation is brought to you for free and open access. It has been accepted for inclusion in Dissertations and Theses by an authorized administrator of PDXScholar. Please contact us if we can make this document more accessible: pdxscholar@pdx.edu. 
Ozone Interaction with Indoor Building Materials and HVAC Filters

by

\title{
Omed Akber Abbass
}

A dissertation submitted in partial fulfillment of the requirements for the degree of

\author{
Doctor of Philosophy \\ in \\ Mechanical Engineering
}
Dissertation Committee: Elliott Gall, Chair David Sailor, Co-Chair
Faryar Etesami Andrea DeBarber Douglas Hall

Portland State University 2017 
(C) 2017 Omed Akber Abbass 


\begin{abstract}
As modern life develops, humans spend most of their time inside buildings. Understanding the effects of different building materials that exist indoors on indoor air quality is crucial to ensure comfort, health, and productivity of building occupants. Indoor air quality (IAQ) is an important field of building science that focuses on studying the existence of different compounds indoors. These compounds include: airborne particles such as dust, volatile organic compounds (VOCs) such as carbonyls, reactive gases such as radon, ozone and others. Ozone is a strong oxidant gas that has adverse effects on human health, and is highly reactive with building materials that exist indoors. This reaction may reduce its concentration indoors, but may produce other by-products that could be more harmful for human health than ozone itself.

In this dissertation, ozone reaction with different building materials is investigated in four studies. The first includes studying the effect of indoor carpet fiber type on ozone removal and carbonyl emissions. This study provides valuable data and knowledge about the importance of selecting carpet type and its effect on indoor environment. In the second study, different indoor plants were tested to evaluate their ability to remove ozone. The results from this study show wide variation between plants tested on ozone removal. Also, the ability of plants as ozone removal agent changes as light levels change. The third part studies ozone removal efficiency of HVAC filters previously installed in air handling units located on green and white membrane roofs of a commercial building. Detailed filter surface analysis using scanning electron microscope (SEM) was performed to understand the nature of deposits on these filters. The reason for differences in ozone removal efficiency of two filters in comparison with new filter is
\end{abstract}


also discussed. The fourth study investigated ozone removal and carbonyl emissions from three different VOC content indoor latex paints. The outcomes from this research show that zero VOC latex paint has the most ozone effective removal capacity and this paint is the least carbonyl emitter.

The research presented in this dissertation adds new data, valuable knowledge, and expands the understanding of the importance of selecting indoor materials to raise indoor air quality and make the buildings' indoor environment healthier and safer. 


\section{Acknowledgments}

I do like to show my deep appreciation to my advisor Professor Dr. David Sailor for his continuous support during this study. Also for Dr. Elliott Gall for his valuable contribution and notes during some tests and revisions during writing journal papers. Also for other committee members: Dr. Andrea DeBarber for her effort in chemistry lab. Also, Dr. Faryar Etesami for his friendly encouragement, and Dr. Douglas Hall for being part of the dissertation committee. Special thanks to Dr. Gerald Recktenwald for his useful advice and support during different stages of study at mechanical engineering department.

My deep appreciation for people who provided technical insights in different stages of building the test apparatus specially Wentai Luo, Tom Bennett. Many thanks to Mike chuning to facilitate building some parts in in mechanical engineering department workshop. Also for MELT team for their support as well.

I would like to acknowledge the funding, and support from The Higher Committee for Education Development in Iraq (HCED) to provide a scholarship to pursue doctorate study.

Lastly, a special thanks to my family who joined me through this study trip. My wife, Asmaa, for her continues encouragement, love, and support. Also, to my lovely children, Yousif, Mina, Lina, and Younis, who made every moment in my life happier and full of energy.

Portland, Oregon, USA.

July 2017 


\section{Table of Contents}

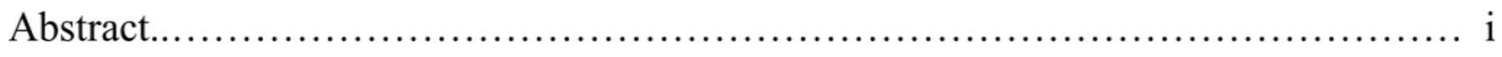

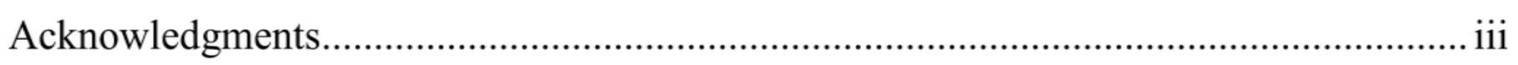

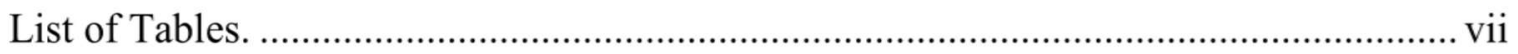

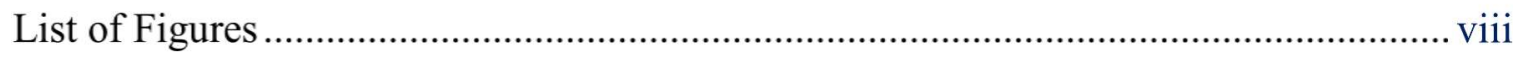

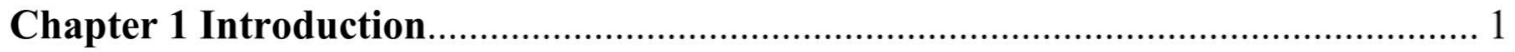

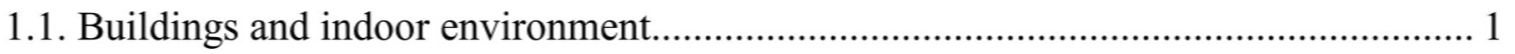

1.2. Ozone and indoor and outdoor sources............................................................ 2

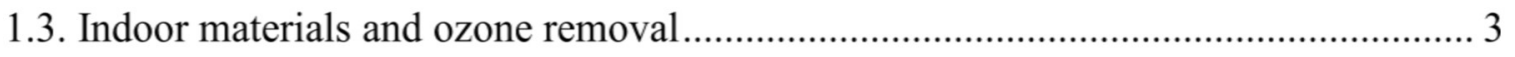

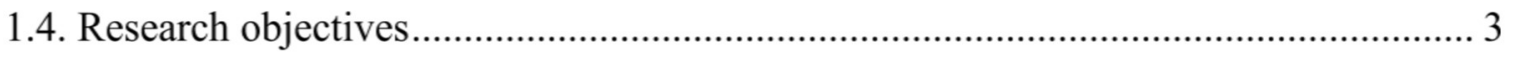

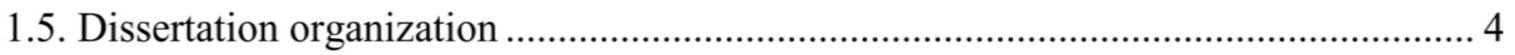

Chapter 2 Paper 1: Effect of fiber material on ozone removal and carbonyl production from carpets............................................................... 8

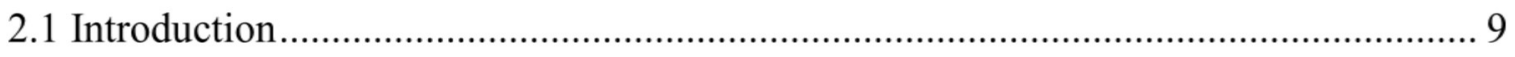

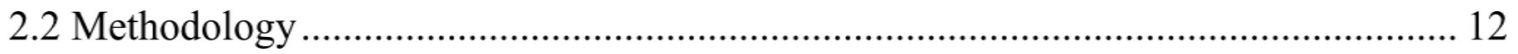

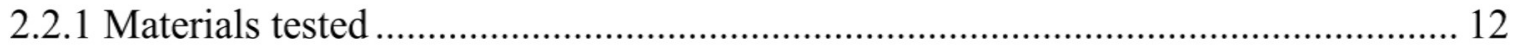

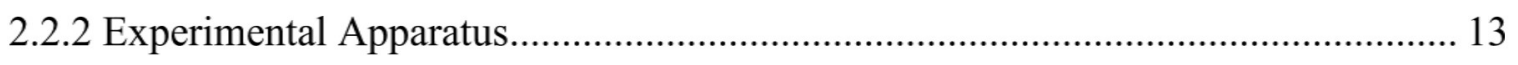

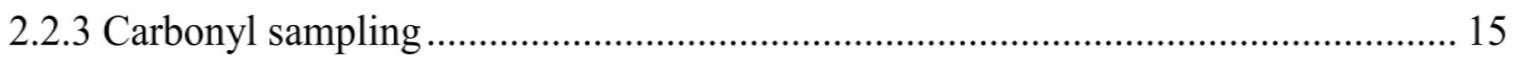

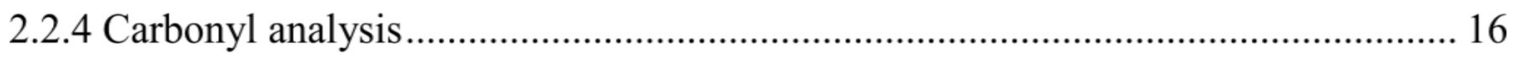

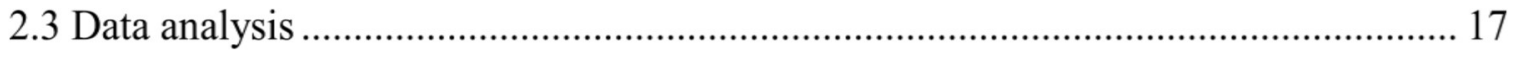

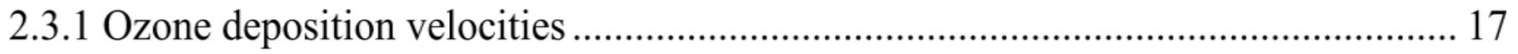

2.3.2 Carbonyl emissions and molar yield calculation ............................................. 18

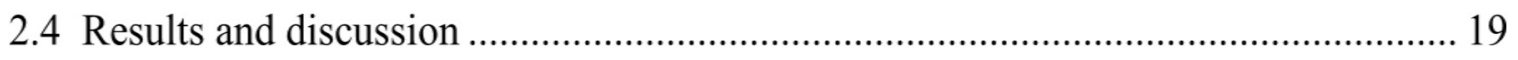

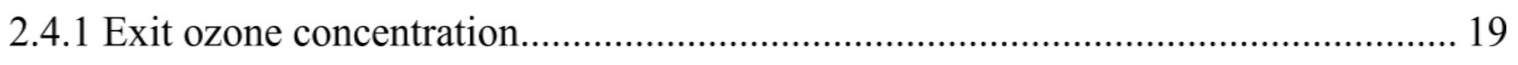

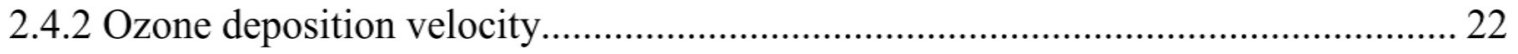

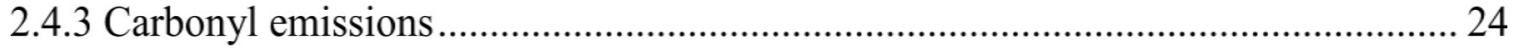

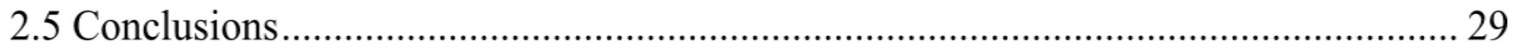

Chapter 3 Paper 2: Effectiveness of indoor plants for passive removal of indoor

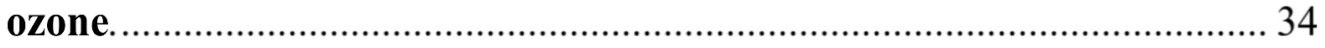

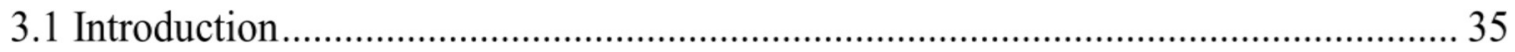

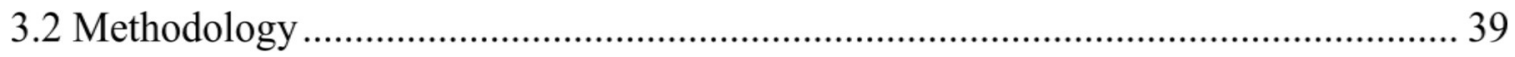




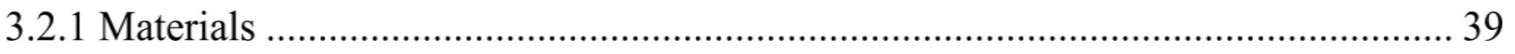

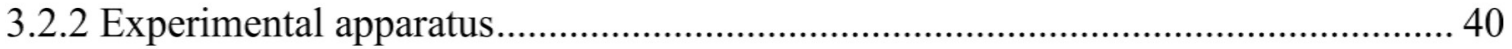

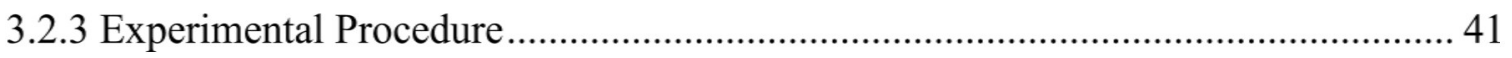

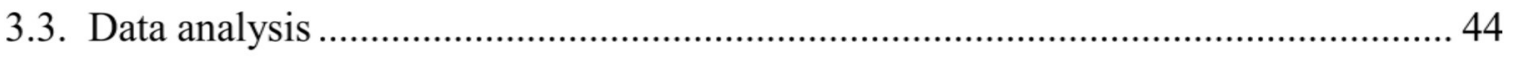

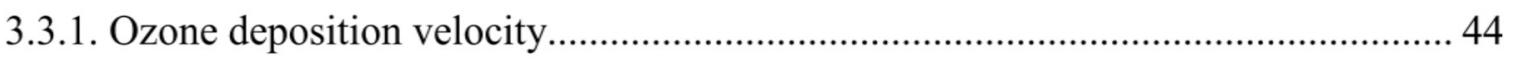

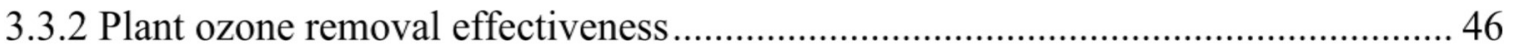

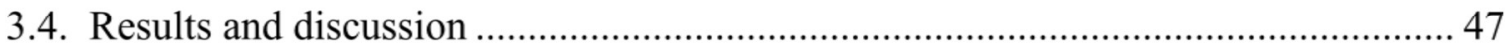

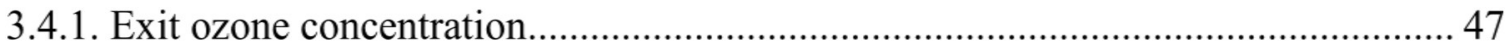

3.4.2. Ozone deposition velocity ............................................................................ 49

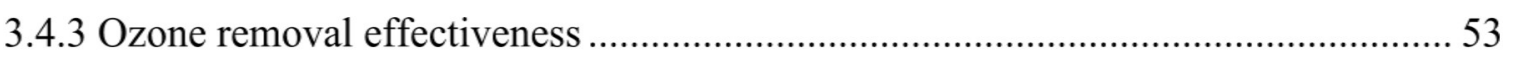

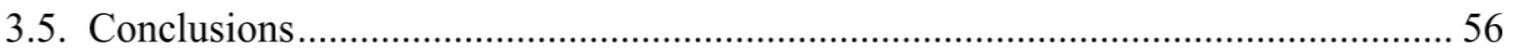

Chapter 4 Paper 3: Ozone removal efficiency and surface analysis of green and

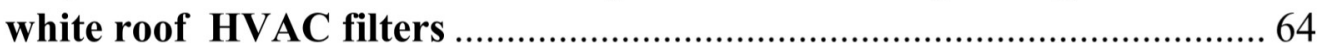

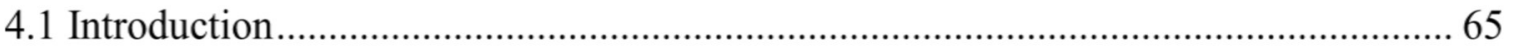

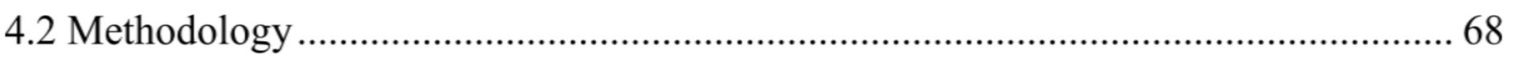

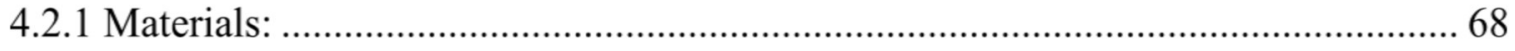

4.2.2 Field site

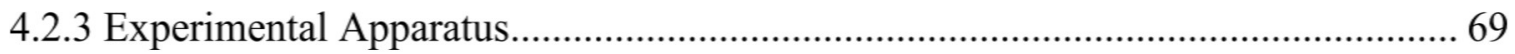

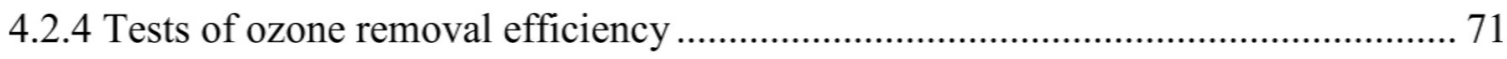

4.2.5 Physical and Chemical analysis of filters ....................................................... 73

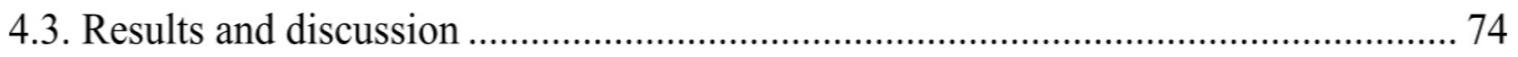

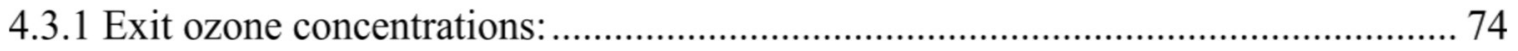

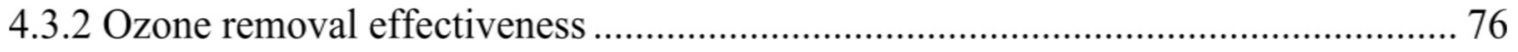

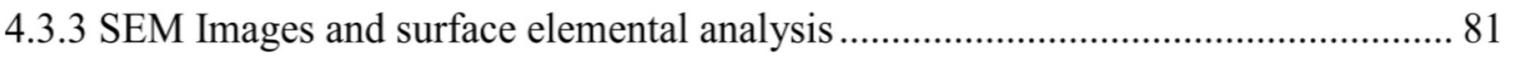

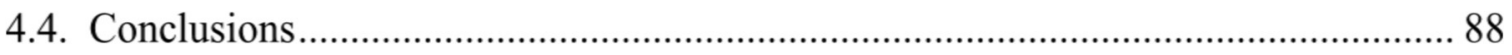

Chapter 5 Paper4: Ozone deposition velocity, TVOC, and carbonyl emissions from freshly indoor latex painted surfaces ……………………........................... 94

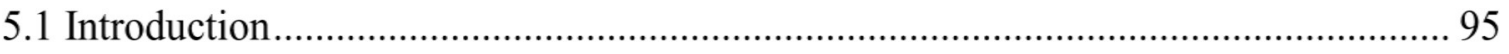

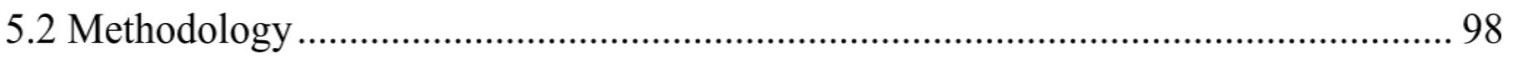

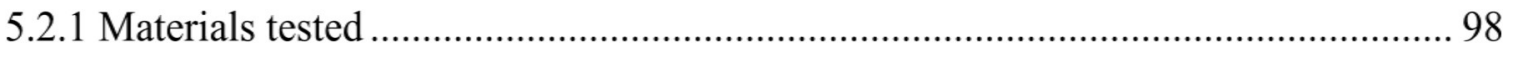

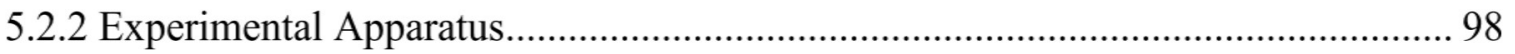

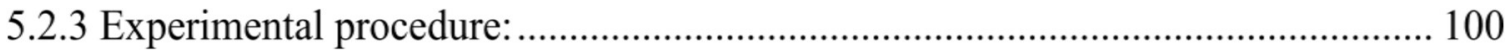


5.2.3.1 Total VOC and Carbonyls sampling and analysis ........................................... 101

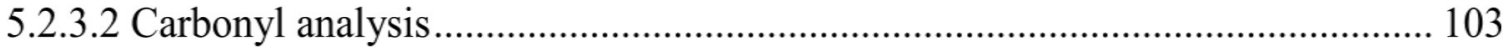

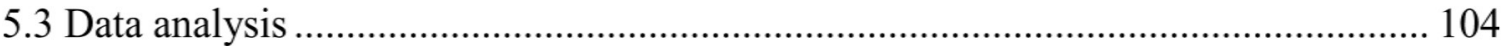

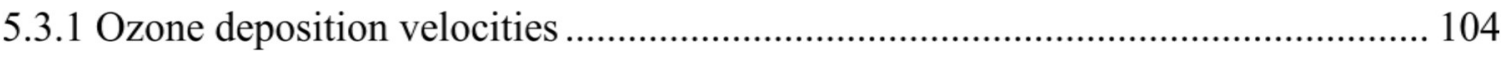

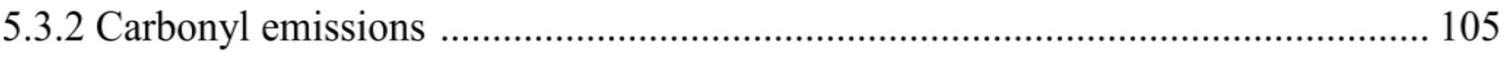

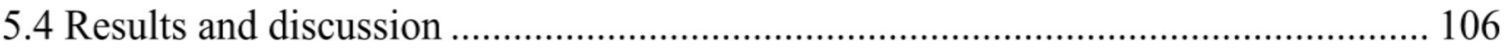

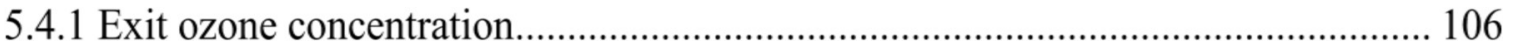

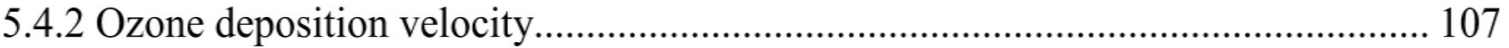

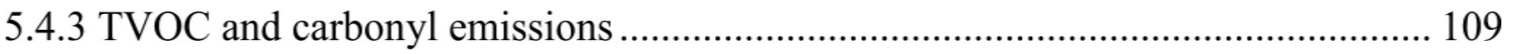

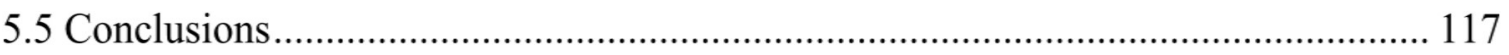

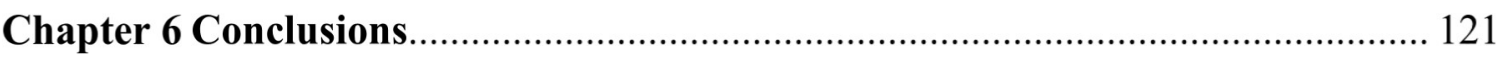

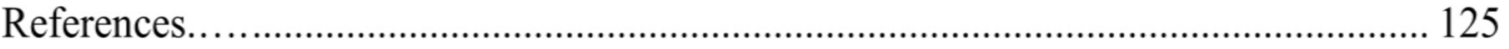




\section{List of Tables}

Table 1.1: Summary of characteristics of carpet samples investigated in this study .........13

Table 3.1: List of indoor plants used in tests of ozone removal rate.................................40

Table 3.2: Peak photosynthetic active radiation (PAR) and solar radiation intensity values recorded in different indoor locations .................................................................44

Table 4.1: Summary of experiments for testing of ozone removal to and surface composition of filter samples

Table 4.2: Elemental analysis data in normalized weight percent for different filter fibers and deposits gained using EDS analyzer ................................................. 88

Table 5.1: List of characteristics of paints investigated in this study...................................98

Table 5.2: List of paint tests and measurements made in each experiment........................101 


\section{List of Figures}

Figure 2.1: Schematic diagram of the experimental apparatus ......................14

Figure 2.2: The change of exit ozone concentration with time for the six carpet types. ...21

Figure 2.3: Ozone removal percentage at steady-state for carpet samples.........................22

Figure 2.4: Ozone deposition velocities for different carpets used in the study ................23

Figure 2.5: Primary and secondary light carbonyl emissions from carpet samples ...........25

Figure 2.6: Primary and secondary heavy aldehyde emissions from carpet samples.........27

Figure 2.7: Molar yields for secondary carbonyl emissions from carpet samples..............29

Figure 3.1: Schematic diagram of the experimental apparatus.......................41

Figure 3.2: Experimental timeline for tests of ozone uptake to each type of plant ...........43

Figure 3.3: Empty chamber, inlet, and outlet ozone concentration for Peace Lily plant...48

Figure 3.4: Change of transient ozone deposition velocity for all plants with number of

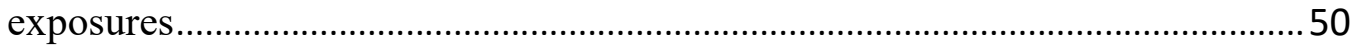

Figure 3.5: Comparison of change of steady state ozone deposition velocity for the plants

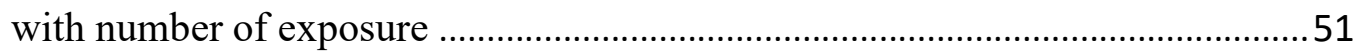

Figure 3.6: Ozone deposition velocity change of the five plants with exposure to light...53

Figure 3.7: Effectiveness of ozone removal versus the ratio of plant leaf area to space

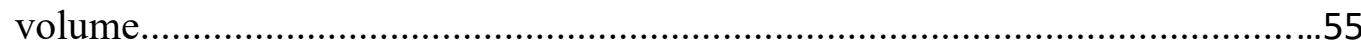

Figure 3.8: A photo shows a sample of the plants used in tests, and the glass beaker used

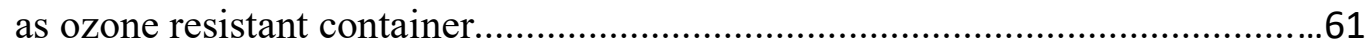

Figure 3.9: A photo shows the experimental apparatus for ozone removal tests..............61

Figure 3.10: Change of ozone concentration with time. The figures show the exit ozone concentrations of inlet, empty chamber, and three exposures of the plants used in

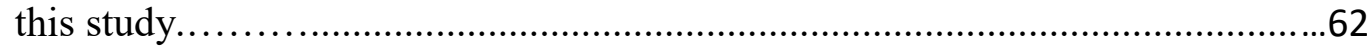

Figure 3.11: Effectiveness of ozone removal versus the ratio of plant leaf area to space volume.

Figure 4.1: Schematic diagram of the experimental apparatus.... .70

Figure 4.2: Inlet and exit ozone concentrations for green, white membrane roof, and unused filter samples 
Figure 4.3: Ozone removal effectiveness for green, white membrane, and unused (new) filter samples

Figure 4.4: Steady state ozone removal effectiveness for green (GR), white membrane (WM) roofs, and new (unused) filters . 79

Figure 4.5: Relative humidity effect on ozone removal effectiveness for green, white membrane roof, and unused filters samples 80

Figure 4.6: SEM images for green roof filter samples non-ozonated at different magnification...

Figure 4.7: SEM images for white membrane roof filter samples non-ozonated at different magnification.

Figure 4.8: SEM images for unused filter samples non-ozonated at different magnification. .83

Figure 4.9: SEM images show locations where elemental analysis was performed..........84

Figure 4.10: EDS elemental analysis graphs of filter fibers and deposits........................87

Figure 4.11: Plan view for the roof of the commercial building ..............................92

Figure 4.12: A photo shows the green roof (left) and white membrane roof (right)........92

Figure 4.13: A photo shows the Teflon filter holder with gaskets, connection bolts and sample of filter used in ozone removal tests..............................................93

Figure 5.1: Schematic diagram of the experimental apparatus........................ 100

Figure 5.2: Ozone concentration change with time for paint tests.....................107

Figure 5.3: Transient ozone deposition velocity for paint samples..............................108

Figure 5.4: Steady state ozone deposition velocities for three paint sample....................109

Figure 5.5: Total VOC measurements change with time for ozonated and non-ozonated painted samples............................................................. 111

Figure 5.6: Specific emission rates change with time for all paint samples.................114

Figure 5.7: Average specific emission rates for all paint samples............................116

Figure 5.8: Photo of high pressure liquid chromatography / Mass spectroscopy (HPLC/MS). 


\section{Chapter 1}

\section{Introduction}

\subsection{Buildings and indoor environment}

Studies show that people in urban locations of the United States typically spend about $90 \%$ of their time indoors (Klepeis et. al. 2001, Jenkins \& Nazzaroff 1992). While this fact is true for the population in general, the elderly living in assisted living facilities likely spend an even more time indoors (Bentayeb et. al. 2013). In order to ensure building occupants' comfort, health, and productivity, many standards and codes have been written and implemented, like standard 55 by American Society of Heating, Refrigerating and Air-Conditioning Engineers (ASHRAE, 2013), to ensure limits for specific parameters like temperature and relative humidity. While these two factors are important parameters affecting human comfort, indoor air quality (IAQ) is another important factor that affects comfort, health and productivity of building occupants. According to ASHRAE, better indoor air quality will raise productivity and satisfaction of a building's occupants. On the other hand, poor IAQ will reduce work time, and increase health issues of occupants (ASHRAE, 2009). According to Environmental Protection Agency (EPA), poor air quality costs United States tens of billions of dollars as loss in productivity and health care (Zhao 2006, USEPA 1997).

IAQ studies air suspended particles like smoke and dust, and gas phase compounds such as volatile organic compounds (VOCs), ozone, radon, and other gaseous. One important gaseous pollutant that has adverse effects on human health is ozone $\left(\mathrm{O}_{3}\right)$. 


\subsection{Ozone and indoor and outdoor sources}

Ozone is a strong oxidant gas that is considered as a trigger for many health problems, especially for children, elderly, and people with lung issues like asthma (EPA 2017). Because of that, EPA has set limits on ozone exposure, including a recent 8-hour standard of 70ppb (EPA 2015). Outdoor ground level ozone forms as a result of photochemical reaction between oxygen, nitrogen oxides $\left(\mathrm{NO}_{\mathrm{x}}\right)$ emitted from motor vehicles, and VOCs emitted from industrial activities, in presence of sunlight, forming ozone (Lei et. al. 2007). This reaction is mostly seen in industrialized and heavily populated cities like Houston, Los Angeles, Mexico City, Beijing, and others. High concentrations of ozone outdoors will lead eventually to the transmission of ozone to the indoor environment by infiltration through building envelopes, and ventilation by HVAC systems (Walker et. al. 2009).

Research shows that most of human exposure to ozone is from outdoor sources (Weschler 2000). However, there are indoor ozone sources that may increase the concentration inside buildings. These include high voltage electrical equipment like laser printers, photocopiers, and UV light based air cleaners which are also indoor sources of harmful ozone (Boelter\&Davidson 1997, Tuomi et. al. 2000). Some equipment indoors can produce ozone at levels even higher than what is infiltrated through the building skin (Lamble 2011). Existence of ozone indoors has many health risks that are mostly related to respiratory malfunction (Brauer and Brook 1997), lung aging (Lippmann 1989), and increase in mortality, even at levels that are below than EPA standards (Bell et. al. 2006). As the fact that ozone existence indoors has serious health risks, it is important to study 
the possible ways to reduce its concentration indoors by investigating materials that can react with ozone, reducing its concentration inside buildings.

\subsection{Indoor materials and ozone removal}

As ozone is a strong oxidant gas, it reacts with different materials that exist in indoor environments. This includes metals in HVAC ducts (Morrison et. al 1998), organic fibers in carpets and filter fabrics (Morrison \&Nazzaroff 2002, Zhao et. al. 2007), indoor painted surfaces (Gall et. al. 2013), even human skin and hair (Wisthaler \&Weschler 2010, Pandrangi \&Morrison 2008). In addition, ozone reacts with primary VOC emissions (chemical compounds released from these indoor materials). As a result of this reaction, ozone is consumed and its concentration will be decreased indoors. However, many studies show that there are by-products known as secondary emissions, like VOCs, aldehydes and ketones that are emitted as a result of this reaction that could pose more serious health risk than ozone itself (Weschler 2000). Some of these compounds are carcinogenic (formaldehyde) or respiratory irritants (heavy aldehydes). It is obvious that existence of ozone indoors has many health related issues, as a result, additional research is needed to improve our understanding and knowledge in this field, and to shed more light on how to improve indoor air quality by understanding how ozone interacts with different building materials and the byproducts from this interaction.

\subsection{Research objectives}

During the period of study, a comprehensive set of tests was performed on different indoor materials to identify answers for questions that were not addressed in previous research. The objectives of this study include: 
1 - Evaluate the effect of indoor carpet fiber type on ozone removal and primary and secondary aldehyde emissions. From this part, a conclusion can be made about the carpet fiber type that is the most appropriate to remove ozone with less harmful byproduct emissions.

2- Investigate passive ozone removal using five common indoor plants, and study the effect of light intensity on ozone removal activity. Data from this section are used to estimate ozone removal effectiveness of indoor plants in a hypothetical indoor space.

3- Evaluate ozone removal efficiency of HVAC filters taken from air handling units on vegetated green roof, and white membrane roof. Filter surface study using a scanning electron microscope (SEM) is conducted to understand the role of organic deposits originating from vegetated green roof and captured by HVAC filters on ozone level in air provided to a commercial building.

4- Estimate ozone removal and aldehyde emissions from gypsum board freshly painted with three latex paints identified based on their VOC content as: normal VOC, low VOC, and zero VOC. From this part, the difference in ozone removal capability and primary and secondary emission rates is calculated to assess the effect of freshly painted surface on indoor environment.

\subsection{Dissertation organization}

The remainder of this dissertation is organized in four chapters that include research paper transcripts elaborating on literature review, methods of experiments, results and findings for each of the research question. Chapter 2 deals with the effect on carpet fiber material on ozone removal and aldehyde emissions from carpets used in indoor surfaces. This research paper is published in Atmospheric Environment (Abbass et. al. 2017). 
Chapter 3 presents details about the effectiveness of indoor plants on removing ozone from indoor spaces. This paper is published in Building and Environment (Abbass et. al. 2017b). Chapter 4 shows the results of experiments of ozone removal efficiency of HVAC filters taken from green and white membrane roofs. This manuscript will be submitted to Building and Environment. In chapter 5, the last research question is addressed to investigate ozone removal and carbonyl emissions from three indoor latex paints. This manuscript is in preparation to be submitted to Building and Environment. The dissertation concludes with a chapter summarizing the findings of this work.

\section{References}

Abbass, O. A., Sailor, D. J., \& Gall, E. T. (2017). Effect of fiber material on ozone removal and carbonyl production from carpets. Atmospheric Environment, 148, 42-48.

Abbass, O. A., Sailor, D. J., \& Gall, E. T. (2017b). Effectiveness of indoor plants for passive removal of indoor ozone. Building and Environment, 119, 62-70.

Bell, M. L., Peng, R.D., Cominici, F. (2006). The exposure-response curve for ozone and risk of mortality and the adequacy of current ozone regulations. Environmental Health Perspectives 114(4): 532-536.

Bentayeb, M., Billionnet, C., Baiz, N., Derbez, M., Kirchner, S., \& Annesi-Maesano, I. (2013). Higher prevalence of breathlessness in elderly exposed to indoor aldehydes and VOCs in a representative sample of French dwellings. Respiratory medicine, 107(10), 1598-1607.

Brauer, M., \& Brook, J. R. (1997). Ozone personal exposures and health effects for selected groups residing in the Fraser Valley. Atmospheric Environment, 31(14), 21132121. http://dx.doi.org/10.1016/S1352-2310(96)00129-X

EPA, (2017). Ozone Pollution. An online content from U.S. Environmental Protection Agency website. Retrieved online on Jun (2017) from: https://www.epa.gov/ozonepollution

EPA, (2015). NAAQS Table. An online content from U.S. Environmental Protection Agency website. Retrieved online on Dec. (2016) from: https://www.epa.gov/criteria-airpollutants/naaqs-table 
Gall ET, Darling E, Siegel J, Morrison G, Corsi R, (2013). Evaluation of three common green building materials for ozone removal, and primary and secondary emissions of aldehydes. Atmospheric Environment 77, 910-918.

Iain Walker, Max Sherman and William W. Nazaroff (2009) "Ozone Reductions Using Residential Building Envelopes.” A report prepared by: Lawrence Berkeley National Laboratory.

Indoor Air Quality Guide Best Practices for Design, Construction, and Commissioning. (2009). American Society of Heating, Refrigerating and Air-Conditioning Engineers (ASHRAE). Online article retrieved from: https://www.ashrae.org/resources-publications/bookstore/indoor-air-quality-guide

Jenkins, P. L. and Nazaroff, W. W. "Activity patterns of Californians: Use of and proximity to indoor pollutant sources", Atmospheric Environment. (1992) Vol. 26, pp. 2141-2148.

Klepeis NE, Nelson WC, Ott WR, Robinson JP, Tsang AM, Switzer P, Behar JV, Hern SC, Engelmann WH, (2001). The National Human Activity Pattern Survey (NHAP): a resource for assessing exposure to environmental pollutants. J. Expo Anal Environ Epidemiol, 11 (3), 231-52.

Lamble, S. P. (2011). Ozone uptake rates and secondary product emissions of green building materials. Master Thesis, Missouri University of Science and Technology. Paper 4926.

Lei, W., Foy, B. D., Zavala, M., Volkamer, R., \& Molina, L. T. (2007). Characterizing ozone production in the Mexico City Metropolitan Area: a case study using a chemical transport model. Atmospheric Chemistry and Physics, 7(5), 1347-1366.

Lippmann, M. (1989). Health effects of ozone a critical review. Journal of the Air Pollution Control Association, 39(5), 672-695.

Morrison GC, Nazzarof WW, (2002). Ozone Interaction with Carpet: Secondary Emissions of Aldehydes, Environmental Science and Technology, 36, 2185-2192.

Morrison, G. C., Nazaroff, W. W., Cano-Ruiz, J. A., Hodgson, A. T., \& Modera, M. P. (1998). Indoor air quality impacts of ventilation ducts: ozone removal and emissions of volatile organic compounds. Journal of the Air \& Waste Management Association, 48(10), 941-952.

Pandrangi, L. S., \& Morrison, G. C. (2008). Ozone interactions with human hair: ozone uptake rates and product formation. Atmospheric Environment, 42(20), 5079-5089.

Standard 55 (2013). Thermal Environmental Conditions for Human Occupancy (ANSI Approved). Retrieved from:

http://www.techstreet.com/ashrae/products/1868610?utm_source=promotion\&utm_medi 
um=landingpage\&utm_campaign $=86179 \& u t m \_t e r m=86179 \& u t m \_$content $=86179 \&$ ashra e_auth_token=

Tuomi, T., Engström, B., Niemelä, R., Svinhufvud, J., \& Reijula, K. (2000). Emission of ozone and organic volatiles from a selection of laser printers and photocopiers. Applied Occupational and Environmental Hygiene, 15(8), 629-634.

Weschler, C. J. (2000). Ozone in indoor environments: concentration and chemistry. Indoor air, 10(4), 269-288.

Weschler, C. J. (2000). Ozone in indoor environments: concentration and chemistry. Indoor air, 10(4), 269-288.

Wisthaler, A., \& Weschler, C. J. (2010). Reactions of ozone with human skin lipids: sources of carbonyls, dicarbonyls, and hydroxycarbonyls in indoor air. Proceedings of the National Academy of Sciences, 107(15), 6568-6575.

Zhao, P. (2006). Ozone interactions with HVAC filters (Doctoral dissertation). University of Texas at Austin. Retrieved online from:

https://repositories.lib.utexas.edu/bitstream/handle/2152/2965/zhaod81284.pdf

Zhao, P., Siegel, J. A., \& Corsi, R. L. (2007). Ozone removal by HVAC filters. Atmospheric Environment, 41(15), 3151-3160. 


\title{
Chapter 2
}

\section{Paper 1: Effect of fiber material on ozone removal and carbonyl production from carpets}

\author{
Omed A. Abbass, David J. Sailor, and Elliott T. Gall
}

Published in Atmospheric Environment 148 (2017) 42-48

\begin{abstract}
Indoor air quality is affected by indoor materials such as carpets that may act as sources and/or sinks of gas-phase air pollutants. Heterogeneous reactions of ozone with carpets may result in potentially harmful products. In this study, indoor residential carpets of varying fiber types were tested to evaluate their ability to remove ozone, and to assess their role in the production of aldehydes when exposed to elevated levels of ozone. Tests were conducted with six types of new unused carpets. Two sets of experiments were conducted, the first measured ozone removal and ozone deposition velocities, and the second measured primary carbonyl production and secondary production as a result of exposure to ozone. The tests were conducted using glass chambers with volume of $52 \mathrm{~L}$ each. Air exchange rates for all tests were $3 \mathrm{~h}^{-1}$. The ozone removal tests show that, for the conditions tested, the polyester carpet sample had the lowest ozone removal (40\%), while wool carpet had the greatest ozone removal (65\%). Most carpet samples showed higher secondary than primary carbonyl emissions, with carpets containing polypropylene fibers being a notable exception. Carpets with polyester fibers had both the highest primary and secondary emissions of formaldehyde among all samples tested. While it is difficult to make blanket conclusions about the relative air quality merits of
\end{abstract}


various carpet fiber options, it is clear that ozone removal percentages and emissions of volatile organic compounds can vary drastically as a function of fiber type.

\subsection{Introduction}

The existence of ozone indoors and its effect on indoor air quality has received significant attention in the research literature. In the absence of high-tension voltage equipment such as laser printers, copiers and UV light based air purifiers, infiltration of polluted ambient air through the building envelope and transmission through the ventilation system is the main source of ozone indoors. The ratio of indoor to outdoor ozone concentrations has been documented to be in the range of $0.2-0.7$ for most buildings in the United States (Weschler, 2000). The reason for the lower indoor ozone concentrations is twofold. First, air passing through building envelope materials or ventilation system ductwork and filters undergoes surface oxidation reactions (Fick et al 2004; Stephens et al. 2012). Additionally, ozone that does penetrate into the indoor environment interacts with building materials such as carpets both through deposition associated with surface chemistry, and also through reaction with volatile organic compounds emitted by sources that include indoor building materials. This interaction can lead to harmful by-products that may be more harmful than the ozone itself (Lamble et al., 2011; Wisthaler and Weschler, 2010). However, it should be noted that the average person in the US spends $89 \%$ of their time indoors (Klepeis et al., 2001); thus, despite lower indoor ozone concentrations, it can be argued that the chronic exposure to ozone is likely to be greater indoors than outdoors (Weschler 2006). 
Materials high in organic content, such as carpets, wood, fabrics, and paint can offgas carboxylic acids, volatile organic compounds (VOCs), and compounds that participate in chemistry that may lead secondary organic aerosol formation (Uhde and Salthammer, 2007; Waring and Siegel, 2013) each of which may subsequently interact with ozone. Non-organic compounds such as glass and metals are known for their limited interaction with ozone, while other materials such as gypsum, brick, and concrete interact with ozone exclusively through surface chemistry, without producing organic byproducts.

Carpeting is a particularly common floor covering in the United States, although less common in Asia and Europe (Weschler, 2009). According to California Department of Resources Recycling and Recovery (CalRecycle, 2016), nylon fiber carpet is used in about $50 \%$ of the carpet sold in United States, while polypropylene fiber carpet is approximately $30 \%$ of market share. Because of the high surface area to volume ratio in an indoor space, carpets have the potential to significantly affect indoor air quality. This has led to a number of studies to explore the relationships among carpets, indoor ozone, and indoor air quality.

Researchers have suggested that when building materials are exposed to ozone, secondary emissions of carbonyls may increase considerably. For example, Weschler et al. (1992) used a 20-m ${ }^{3}$ stainless steel room furnished with four types of new carpets. The carpets, with either nylon fibers or a combination of nylon and olefin fibers, were tested under ozone concentrations of $0,30-50$ and $400 \mathrm{ppb}$. Weschler found that the emissions of formaldehyde, acetaldehyde, and aldehydes with 5 to 10 carbon atoms increased significantly in the presence of ozone. Coleman et al., (2008) found that secondary 
emissions of VOCs are higher than primary emissions when aircraft cabin materials, including carpet specimens from aircraft cabins, are exposed to ozone. Morrison et al. (2002) conducted a study to investigate the production of aldehydes from two residential nylon fiber carpets, and two commercial carpets with olefin fibers when exposed to 100 ppb ozone. The results showed that for $\mathrm{C} 1-\mathrm{C} 13$ carbonyls, especially nonanal, emissions increased significantly during exposure to ozone. One of the few studies conducted in situ was that of Wang and Morrison (2006), who investigated secondary aldehyde emissions from four indoor surfaces in four houses. Living room carpets were one of the surfaces included in study. A Teflon chamber was used to take air samples after exposing the material on site to $100-150 \mathrm{ppb}$ ozone. The results showed that newer carpets have higher secondary emissions than older carpets, but regardless of age, carpets are one of the major sources of aldehyde emissions indoors. Lamble et al (2011) explored the ozone removal and carbonyl emissions of nineteen sustainable "green" building materials including two recycled nylon carpets using a stainless steel test chamber. They found that carpets were among the materials with the highest ozone deposition velocities (4.0 to 5.0 $\mathrm{m} \mathrm{h}^{-1}$ ). Gall et al. (2013) performed full scale tests of three common indoor materials: recycled carpets, ceiling tiles, and recycled drywall painted with a low VOC paint. They found that ozone deposition velocity for carpets were the highest among the three building materials with values ranging from $5.5-8.0 \mathrm{~m} \mathrm{~h}^{-1}$ for relative humidity in the range of $25 \%-75 \%$. The aldehyde analysis results from that study showed that carpet was the indoor material with highest aldehyde emissions, especially for nonanal. Gall et al. conclude that care must be taken in choosing green materials because of potentially high primary and secondary emissions of aldehydes. 
The body of research describing the interaction of indoor ozone and carpets shows carpets are an important material contributing to indoor air pollution, particularly with respect to indoor ozone removal and carbonyl emissions. Most previous research, however, has focused on carpets with nylon and olefin fibers. However, carpets are commonly made from other fibers including wool, polyester, polypropylene and other synthetic fibers, and, there is scant data available regarding these different types of carpet fibers.

The present research aims to fill this research gap by studying the effect of six environmentally friendly carpet fiber materials on ozone removal by calculating the ozone deposition velocities, and determining emissions of carbonyls in the absence and presence of ozone (primary and secondary emissions, respectively). This investigation also expands on prior studies through measurement and reporting of a number of carbonyl species for carpet fibers not previously investigated in studies of ozone-carpet interaction.

\subsection{Methodology}

\subsubsection{Materials tested}

In this research, six types of commercial and residential carpets were tested. These carpets are marketed as environmentally friendly because they contain recycled fibers, or they are made from raw materials prepared from plant source polymers (e.g., DupontTM Sorona ${ }^{\circledR}$ version of triexta). Some of the tested carpet samples are made of synthetic materials such as nylon. All carpet samples were unused prior to testing. The detailed description of carpet samples is given in Table 1.1. 
Table 2.1. Summary of characteristics of carpet samples investigated in this study.

\begin{tabular}{|c|c|c|c|c|}
\hline Code $^{\#}$ & Brand & Fiber material & Cut type & Green attribute \\
\hline Triexta & Karastan & $100 \% \mathrm{BCF}^{*}$ Triexta & Cut pile & $\begin{array}{l}\text { Made of DuPont }{ }^{\mathrm{TM}} \text { Sorona } \\
\text { renewable polymer }\end{array}$ \\
\hline Poly-triexta & Mohawk & $\begin{array}{l}75 \% \mathrm{BCF}^{*} \text { Polyester, } \\
25 \% \mathrm{BCF}^{*} \text { Triexta }\end{array}$ & Cut pile & Contains $50 \%$ recycled content \\
\hline PP & Royal & $100 \%$ Polypropylene & Cut pile & - \\
\hline Polyester & Mohawk & $\begin{array}{l}100 \% \mathrm{PET}^{* *} \mathrm{BCF}^{*} \\
\text { polyester }\end{array}$ & Cut-loop pile & Partly made of recycled bottles \\
\hline Nylon & Stainmaster & $100 \%$ Nylon & Multi-level loop & - \\
\hline Wool & Unbranded & $100 \%$ Wool & Level loop & - \\
\hline
\end{tabular}

\# An abbreviated code is given each carpet studies based on the fiber type

* bulked continuous filament

** polyethylene terephthalate

\subsubsection{Experimental Apparatus}

Figure 2.1 shows the experimental apparatus used in this study. It consists of an air supply system, two glass chambers (constructed per ISO 16000-9), each with a volume of 52 L, ozone generator (UVP, model SOG-2), and ozone analyzers (2B Technologies, model 106-L). Compressed air from the laboratory air supply was purified by using oil and water filters to remove any droplets that may exist in the air stream. Then, a gas drying unit was used to dehumidify the air prior to passing it through an activated carbon filter to remove any VOCs present in inlet air (verified through subsequent inlet air sampling for carbonyls). The filtered air stream was then humidified to the required relative humidity by using a by-pass valve controlled impinger. The temperature and relative humidity of the supply air was measured and recorded at one minute intervals using a 12-bit temperature and relative humidity sensor from Onset (model S-THBM002). The temperature of the laboratory was monitored and maintained within the range of $21^{\circ} \mathrm{C} \pm 1{ }^{\circ} \mathrm{C}$, and the relative humidity was $50 \% \pm 2 \%$. The purified air was divided into two streams, one to supply an un-ozonated control chamber, and the other to pass through an ozone generator. Two mass flow controllers (OMEGA FMA 5523) were 
used to supply a constant flow rate of air to each branch of the flow system. The UVbased ozone generator was used to generate ozone concentrations in the range of 40-400 ppb. All connectors and fittings were either stainless steel or Teflon to minimize reactivity with ozone.

The ozone deposition velocity tests were conducted using a single chamber, while the carbonyl emissions tests used one chamber as a control and one for testing. The air pressure inside the chambers was kept at a slight positive pressure relative to the laboratory to prevent air leakage into the chambers. For monitoring ozone, two portable photometric ozone analyzers were used to monitor and record ozone concentrations upstream and downstream the ozonated test chamber with one-minute interval.

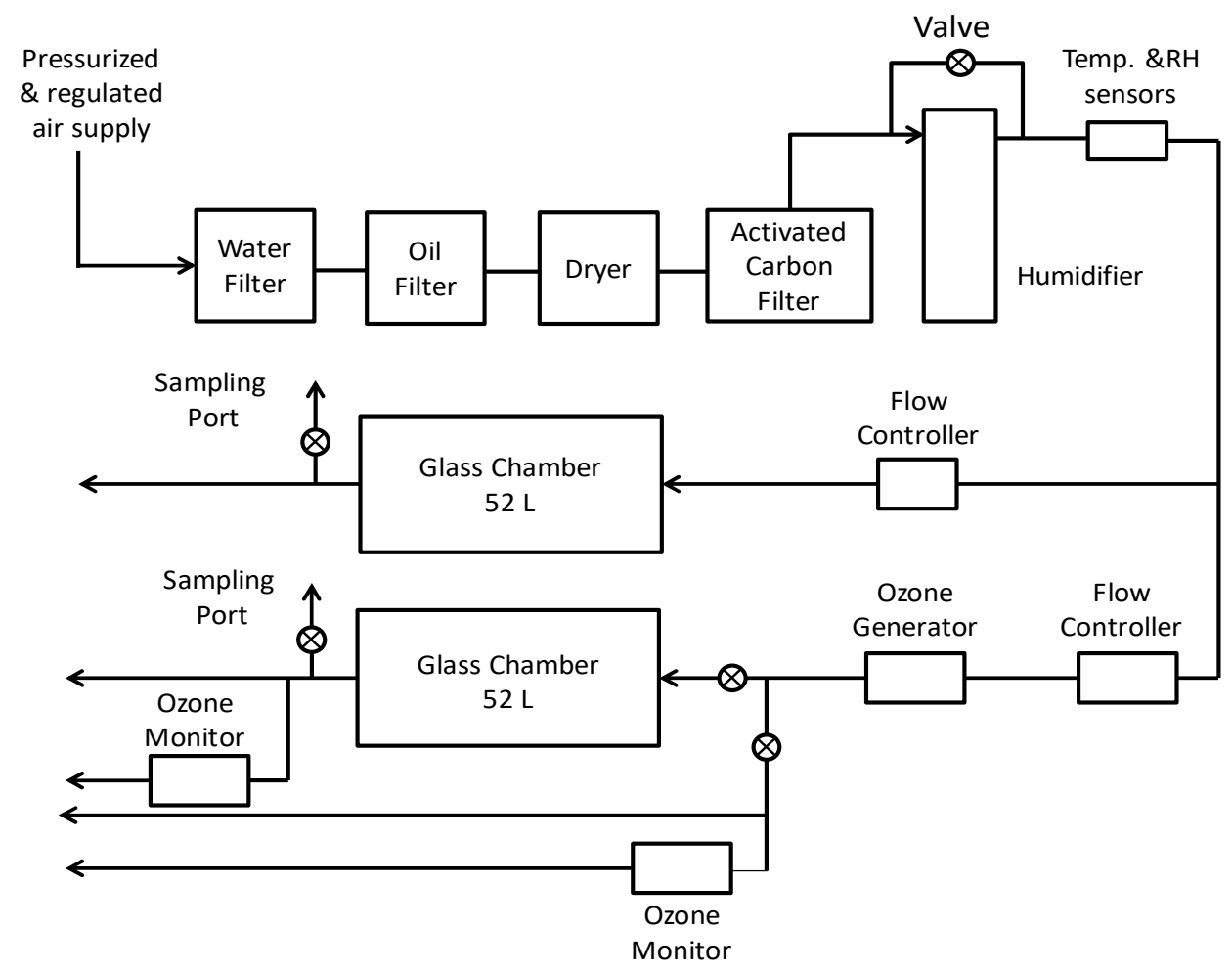

Figure 2.1. Schematic diagram of the experimental apparatus. 
Samples of carpets were prepared from unused carpet stock taken from local carpet stores. These samples were prepared according to the California Department of Public Health specifications for emission tests (CDPH, 2010). The carpets were cut into $20 \mathrm{~cm}$ squares such that each would have a loading factor (test surface area divided by chamber volume) of 0.8 m-1 under the given flow conditions. The backsides of all samples were covered with aluminum foil to prevent exposure to ozone (Rim et al., 2016, CDPH 2010) and reduce the corresponding effects of carpet backing. Chambers were cleaned thoroughly with distilled water and dried with a heat gun prior to every test. Following the approach of Coleman et al. (2008) the test chambers were then quenched with a 350 ppb ozone air stream for 3 hours before testing samples. For each test, the ozonated chamber was supplied with a constant stream of ozone-laden air at $3.0 \pm 0.045$ air exchanges per hour and $120 \pm 2 \mathrm{ppb}$ ozone concentration. The ozone concentration was measured before and after the chamber using two separate ozone analyzers (with recent NIST-traceable calibrations).

\subsubsection{Carbonyl sampling}

To investigate the primary and secondary VOC emissions from carpets, samples of air were taken from both ozonated and non-ozonated chambers to study the effect of ozone-material interactions on the release of specific carbonyls. The carbonyls covered by EPA standard TO-11a (EPA, 1999) were investigated. These compounds include: formaldehyde, acetaldehyde, acrolein, acetone, propionaldehyde, crotonaldehyde, methacrolein, n-buteraldehyde, 2-butanone, benzeldehyde, valeraldehyde, mtolualdehyde, hexaldehyde. This set of carbonyls was supplemented by the analysis of five heavy aldehydes: cyclohexanone, heptanal, octanal, nonanal, and decanal. The air 
samples were collected using glass sampling tubes (SKC, model 226-120) packed with silica gel coated with 2,4-dinitrophenylhydrazine (DNPH). These sampling tubes come with an integrated layer of ozone scrubbing material to avoid interaction of ozone with the active sampling media. A sampling pump from SKC (model 224-PCXR8) was used to collect a constant flow rate of $400 \mathrm{~mL} / \mathrm{min}$ for $60 \mathrm{~min}$. through the sampling tube (similar to Gall et al., 2013). An orifice flowmeter with an OMEGA (PX653-03D5V) pressure transducer was used to measure and ensure constant flow rate through the sampling tube. For ozonated carpet tests, one 1-h air sample was taken from the exit of the chamber starting at 24 hours from the start of the experiment when the concentration of ozone was at steady state values. The 1 - $\mathrm{h}$ air sample from the non-ozonated chamber was taken starting at 25 hours after the start of the test. Solutions were extracted from sampling tubes according to guidelines from the TO-11A standards.

\subsubsection{Carbonyl analysis}

Carbonyl analysis was performed using high performance liquid chromatography with mass spectrometry (HPLC/MS, Thermo Scientific LTQ XL) with auto sampler. Using mass spectrometry for detection instead of conventional UV detection has many benefits, including acquiring greater information about each compound in interest (e.g., retention time and molecular weight) and the ability to detect a wide range of compounds, from formaldehyde-DNPH to decanal-DNPH. The column used was a Poroshell 120 SB-C18 $2.7 \mu \mathrm{m}(3 \mathrm{mmx} 150 \mathrm{~mm})$. The solvent flow rate used was 0.4 $\mathrm{mL} / \mathrm{min}$ with initial concentrations of $60 \%$ acetonitrile and $40 \%$ water. This ratio was kept constant for the first 4 minutes of each HPLC run, increased linearly to $100 \%$ acetonitrile over an 8-minute period, kept constant for 4 minutes, and then changed back 
to $60 \%$ acetonitrile and kept constant for an additional 4 minutes. The total time for every sample test was 20 minutes. The results from each run were analyzed to obtain specific carbonyl mass on the sorbent tube, which was then used to calculate to the gas-phase concentration of the compound during the experiment.

The response of the HLPC/MS to each of the 18 carbonyls was calibrated with a method that used a mix of 18 organic compounds at serial dilutions to obtain a five-point calibration for every compound, with all resulting $\mathrm{R}^{2}$ greater than 0.99 , similar to the procedure used by Cros et al., (2011) and Gall et al. (2013). This mixture was prepared using two types of standard solutions. The first was ERA-013K, a mix of 13 compounds from Sigma Aldrich. The other five compounds, cyclohexanone, heptanal, octanal, nonanal, and decanal were obtained as individual solutions from AccuStandard. Inc. All standard solutions were mixed in specific ratios to form calibration standard solutions.

\subsection{Data analysis}

This section provides a brief summary of methods used to calculate specific air quality parameters for both the ozone and carbonyl aspects of this study.

\subsubsection{Ozone deposition velocities}

The ozone deposition velocity represents a mass transfer coefficient relating the bulk-air ozone concentration to the flux of ozone to the surface (Nazaroff et al., 1993). The steady-state ozone deposition velocity is calculated as described previously (Weschler, 2000; Nicolas et al., 2012) and shown in equation 1: 


$$
k_{s}=A E R \cdot \frac{V}{A_{s}}\left[\frac{C_{\text {inlet }}}{C_{\text {outlet }}}-1\right]-k_{g} \frac{A_{g}}{A_{s}}
$$

Here $\mathrm{C}_{\text {inlet }}$ and $\mathrm{C}_{\text {outlet }}$ represent the ozone concentrations in $\mathrm{ppb}$ in the inlet and outlet air flow of the chamber, respectively; AER is the air exchange rate $\left(\mathrm{h}^{-1}\right) ; \mathrm{A}_{\mathrm{s}}$ and $\mathrm{A}_{\mathrm{g}}$ are the surface areas of the exposed sample and glass chamber, respectively; $\mathrm{V}$ is the volume of chamber; and $\mathrm{k}_{\mathrm{g}}$ and $\mathrm{k}_{\mathrm{s}}$ are the ozone deposition velocities for glass chamber and specimen, respectively. Ozone deposition velocities are calculated for the chamber material first $\left(\mathrm{kg}_{\mathrm{g}}\right)$ by running an empty chamber for a fixed AER until steady-state ozone concentrations are reached (defined here as the concentration changing by less than $2 \mathrm{ppb}$ over a 20-minute period). Inlet and outlet concentrations of ozone averaged over the final 20 minutes of data collection are then used to solve (1) for $\mathrm{kg}_{\mathrm{g}}$. The test is then repeated using different carpet samples, and solving (1) for the unknown values of $\mathrm{k}_{\mathrm{s}}$. An estimate of uncertainty was calculated using a propagation of errors, incorporating uncertainties of the ozone monitors of $2 \%$ of reading and flow controllers of $1.5 \%$, resulting in an average uncertainty of $\pm 0.1 \mathrm{~m} / \mathrm{h}$

\subsubsection{Carbonyl emissions and molar yield calculation}

To quantify carbonyl emissions, the specific emission rate (SER), according to Nicolas et al. (2007) is used:

$$
S E R=C_{\text {exit }} \cdot \frac{A E R}{A_{S} / V}
$$

where $\mathrm{C}_{\text {exit }}$ is the concentration of the specific carbonyl of interest at the exit of the chamber in $\left(\mu \mathrm{g} \mathrm{m}^{-3}\right)$; AER is the air exchange rate $\left(\mathrm{h}^{-1}\right)$; $\mathrm{A}_{\mathrm{s}}$ is the surface area of carpet sample $\left(\mathrm{m}^{2}\right)$; and $\mathrm{V}$ is the volume of test chamber $\left(\mathrm{m}^{3}\right)$. The uncertainty analysis based on error propagation for equation 2 was performed. The uncertainty in SER for each 
compound was found using three repeated measurements for every standard solution compound using HPLC/MS and incorporated in the uncertainty analysis. The percentage RTD of the three readings was less than $20 \%$ for all compounds. The uncertainty for primary emissions (averaged across all observed primary carbonyl emissions) was \pm 2.3 $\mu \mathrm{g} \mathrm{\textrm {m } ^ { - 2 }} \mathrm{h}^{-1}$, and $\pm 1.8 \mu \mathrm{g} \mathrm{m}^{-2} \mathrm{~h}^{-1}$ for specific secondary emissions (averaged across all secondary carbonyl emissions).

To quantify the amount of carbonyl release to ozone consumption, a molar yield, which represents the moles of a compound formed divided by the moles of ozone consumed is calculated from a steady-state mass balance on each carbonyl, as shown in equation 3:

$$
\gamma_{a n}=A E R \cdot \frac{V}{A \cdot k_{s}} \cdot \frac{\text { Cexit }}{C_{\text {ozone }}}
$$

Where $\gamma_{a n}$ represents the molar yield for a specific compound (moles of compound released per moles ozone consumed). $\mathrm{C}_{\text {exit }}$ represents the concentration of a compound in the chamber exit $\left(\mathrm{mol} / \mathrm{m}^{3}\right)$, and $\mathrm{C}_{\text {ozone }}$ represents the ozone concentration in the chamber exit $\left(\mathrm{mol} / \mathrm{m}^{3}\right)$. The other quantities are as mentioned before in equation 2 . The uncertainty analysis using error propagation method was performed and found that the average uncertainty was \pm 0.01 mole $\mathrm{O}_{3} /$ mole carbonyl formed.

\subsection{Results and discussion}

\subsubsection{Exit ozone concentration}

Figure 2.2 shows the change of ozone concentration at the exit of the chamber with time for all six-carpet samples. It can be seen that the concentration increases rapidly during the first hour of each experiment. This exponential increase in ozone 
concentration is consistent with the displacement of the initial volume of "clean" air with ozonated air. Specifically, in the absence of chemical reactions or emissions, and assuming a well-mixed chamber, the concentration of ozone in the chamber at any given time will increase exponentially with a time constant of 1/AER, eventually approaching the concentration of the supply. The concentration in the chamber should reach $99 \%$ of the inlet concentration after about 4 time constants. Thus, the effects of initial test chamber concentrations are largely absent after several hours of testing.

Nevertheless, each experiment was conducted for 16 hours to ensure steady-state conditions (concentration changing by less than 2 ppb over a 20 -minute period). Figure 2.2 reveals that the highest chamber exit ozone concentration was for the polyester carpet sample ( $\sim 75 \mathrm{ppb})$, and the lowest was for wool carpet ( $\sim 45 \mathrm{ppb})$, indicating that polyester was least effective of the carpet samples tested at removing ozone from the air supplied to the chamber. Since ozone in the test chamber continually reacts with gas-phase VOCs emitted from the carpet samples, the concentration curves deviate from a simple exponential profile, with a prominent dip in the ozone concentration from about 300 to 600 minutes into the experiment for the nylon test specimen. 


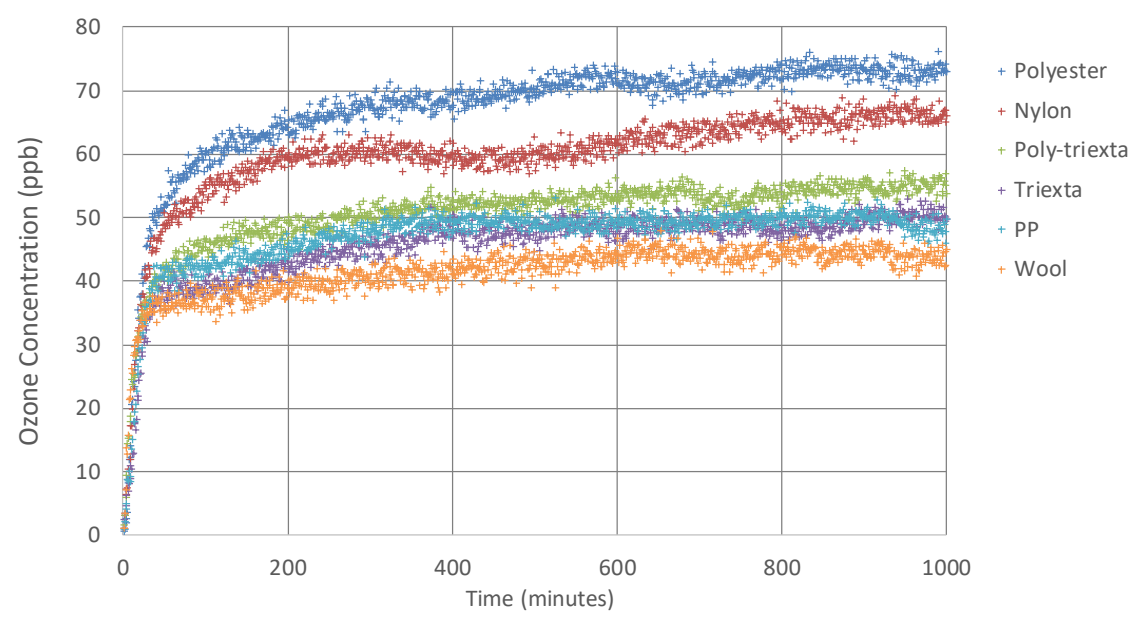

Figure 2.2. The change of exit ozone concentration with time for the six carpet types. The duration of each experiment was $24 \mathrm{~h}$. $\mathrm{PP}=$ polypropylene. Poly-triexta= mix of polyester and triexta fibers.

The percentage of ozone removal from these tests is shown in figure 2.3. As expected, the ozone removal for the empty chamber is the lowest at $11 \%$. This suggests some interaction of ozone with the glass chamber walls and the low-VOC sealant along each of the exterior edges of the chamber. The wool carpet sample was most effective at removing ozone (65\%) while the polyester carpet was least effective (40\%). 


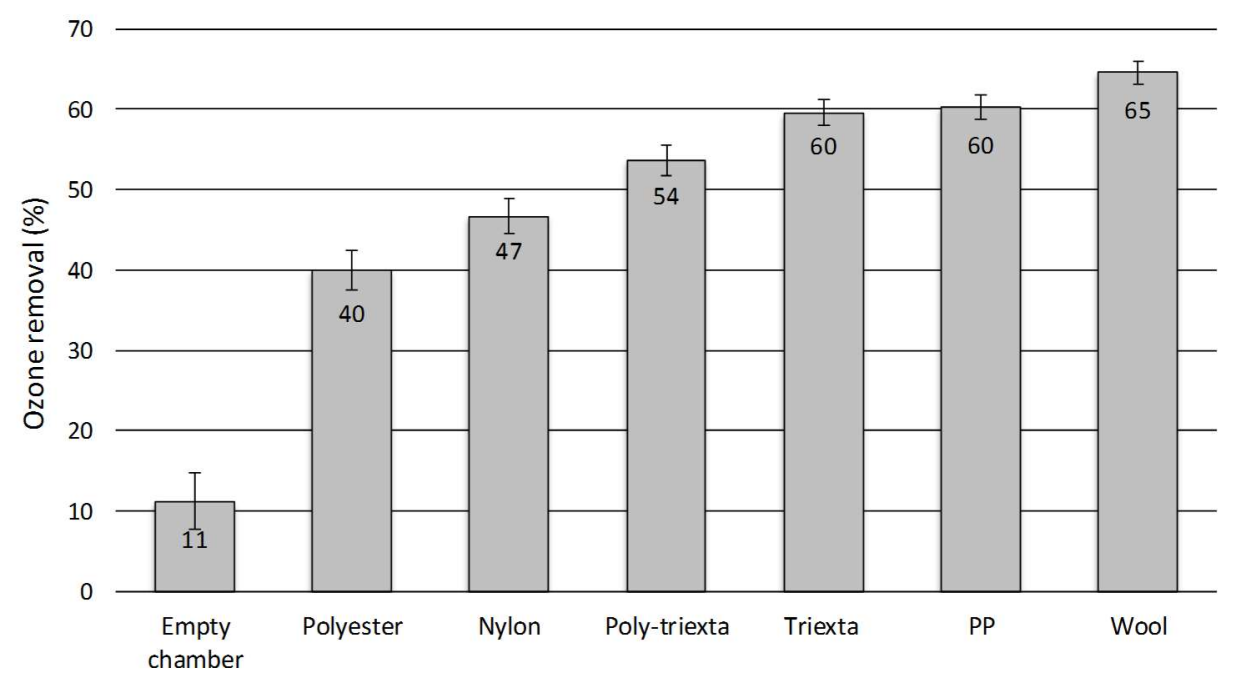

Figure 2.3. Ozone removal percentage at steady-state for carpet samples studied in this investigation. Ozone removal percentages for materials include losses to the chamber surfaces. Numeric value of the removal percentage is reported in the text label on each bar. The error bars represent the instrumental propagation error. $\mathrm{PP}=$ polypropylene. Polytriexta $=$ mix of polyester and triexta fibers.

\subsubsection{Ozone deposition velocity}

Figure 2.4 shows the ozone deposition velocity values for the empty chamber and the six carpet samples. The figure reveals significant differences among materials. The empty glass chamber, had a deposition velocity of $0.02 \mathrm{~m} \mathrm{~h}^{-1}$, which is the same order of magnitude as that reported by Grontoft (2004) for a similar chamber material study. For nylon carpet, which is the most studied fiber material from previous research, reported values of ozone deposition velocities are generally between 2.0 and $7.0 \mathrm{~m} \mathrm{~h}^{-1}$ (Lamble et al., 2011; Cross et al., 2011; and Gall, 2013). The present study found a deposition velocity of $3.0 \mathrm{~m} \mathrm{~h}^{-1}$ for nylon. The wool carpet had the highest deposition velocity at 6.7 $\mathrm{m} \mathrm{h}^{-1}$, while the polyester carpet had the lowest ozone deposition velocity at only $2.1 \mathrm{~m} \mathrm{~h}^{-1}$. For polyester, triexta, polyester-triexta fiber blend, and polypropylene, no previous data were found to compare, although it is important to note the wide range of deposition velocities (by a factor of 3 ) for the samples tested. In general, all carpet 
samples are fabricated with a fiber pile with high surface area. The differences between carpets themselves may be attributed to physical factors, like pile geometry and resulting material porosity, as well as chemical factors like fiber composition, and additional materials used in fabrication, including dyes. For example, wool is mainly composed of an organic protein fiber where carbon forms about 50-52\% of its composition (Crawshaw and Simpson 2002), but others such as polyesters are formed of long chain polymers that are likely less reactive in comparison with other fibers. Morrison and Nazzarof (2002) suggest that variability in uptake of ozone to different carpets is likely due to different surface treatments or backing materials.

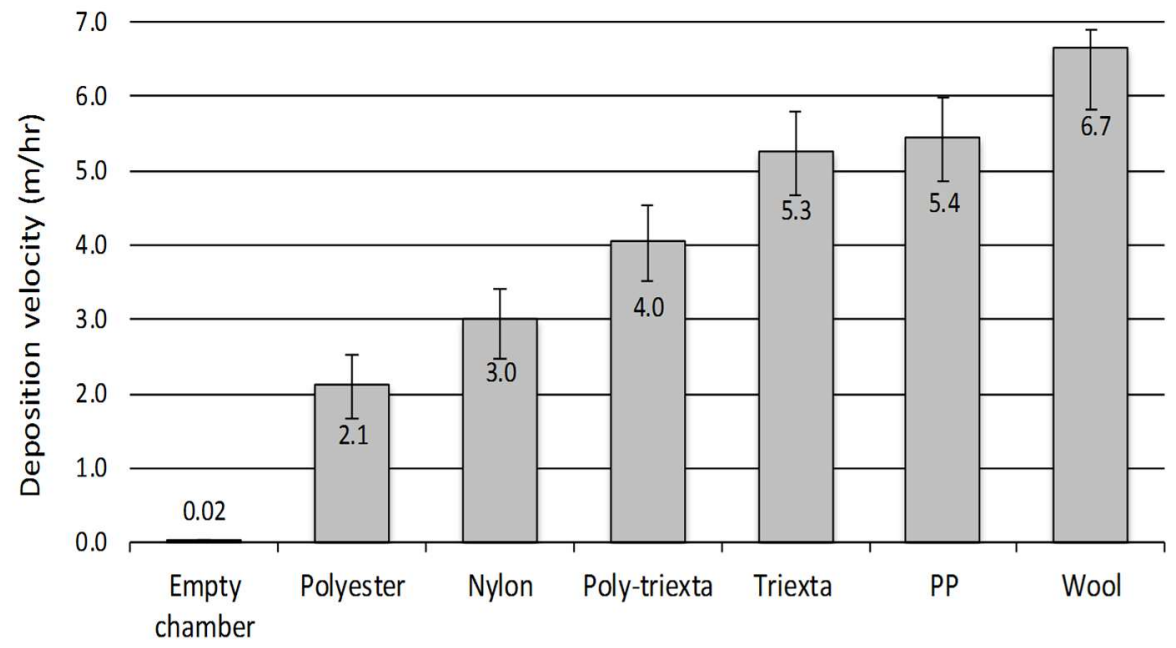

Figure 2.4. Ozone deposition velocities for different carpets used in the study. The error bars represent are the uncertainty as determined from an error propagation using instrument uncertainties. Ozone losses to background surfaces are included in calculated values of ozone deposition velocities to carpet samples. $\mathrm{PP}=$ polypropylene. 


\subsubsection{Carbonyl emissions}

The discussion in this section divides the results into emissions for light carbonyls and heavy aldehydes. Of the 18 compounds targeted, some were either not detected or not distinguishable from other compounds with the same molecular weight (e.g., 2-butanone and n-buteraldehyde). Results for light carbonyls were obtained for formaldehyde (C1), acetaldehyde (C2), and acetone (C3). Heavy aldehyde results were obtained for heptanal (C7), octanal (C8), nonanal (C9), and decanal (C10). Primary emissions refer to emissions in the absence of ozone, and secondary emissions refer to emissions in the presence of ozone; reported values of secondary emission rates do not subtract primary emissions as a background value.

Figure 2.5 shows the primary and secondary emissions of light carbonyls. With one exception, total light carbonyl emissions from the carpet samples increased in the presence of ozone. The notable exception was the polypropylene carpet sample whose secondary emissions were $7 \%$ lower than its primary emissions. A large difference between primary and secondary emissions for any carpet sample is indicative of significant chemical interactions between either the carpet sample fibers and ozone or between the primary emissions and ozone or both.

The carpet samples with the lowest primary emissions of light carbonyls were nylon and triexta, both with $37 \mu \mathrm{g} \mathrm{m}^{-2} \mathrm{~h}^{-1}$. However, while nylon's secondary emissions were only slightly higher than its primary emissions, triexta's secondary emissions of light carbonyls were more than double its primary emissions ( $85 \mathrm{vs} .37 \mu \mathrm{g} \mathrm{m}^{-2} \mathrm{~h}^{-1}$ ). In fact, among all carpet samples, triexta demonstrated the most significant difference between primary and secondary emissions of light carbonyls, with the poly-triexta blend having 
the second most prominent difference between primary and secondary emissions, and the highest overall secondary emissions of light carbonyls at $95 \mu \mathrm{g} \mathrm{m}^{-2} \mathrm{~h}^{-1}$. One important finding evident from this figure is that both primary and secondary emissions vary dramatically (by more than a factor of 2) across the fiber types tested.

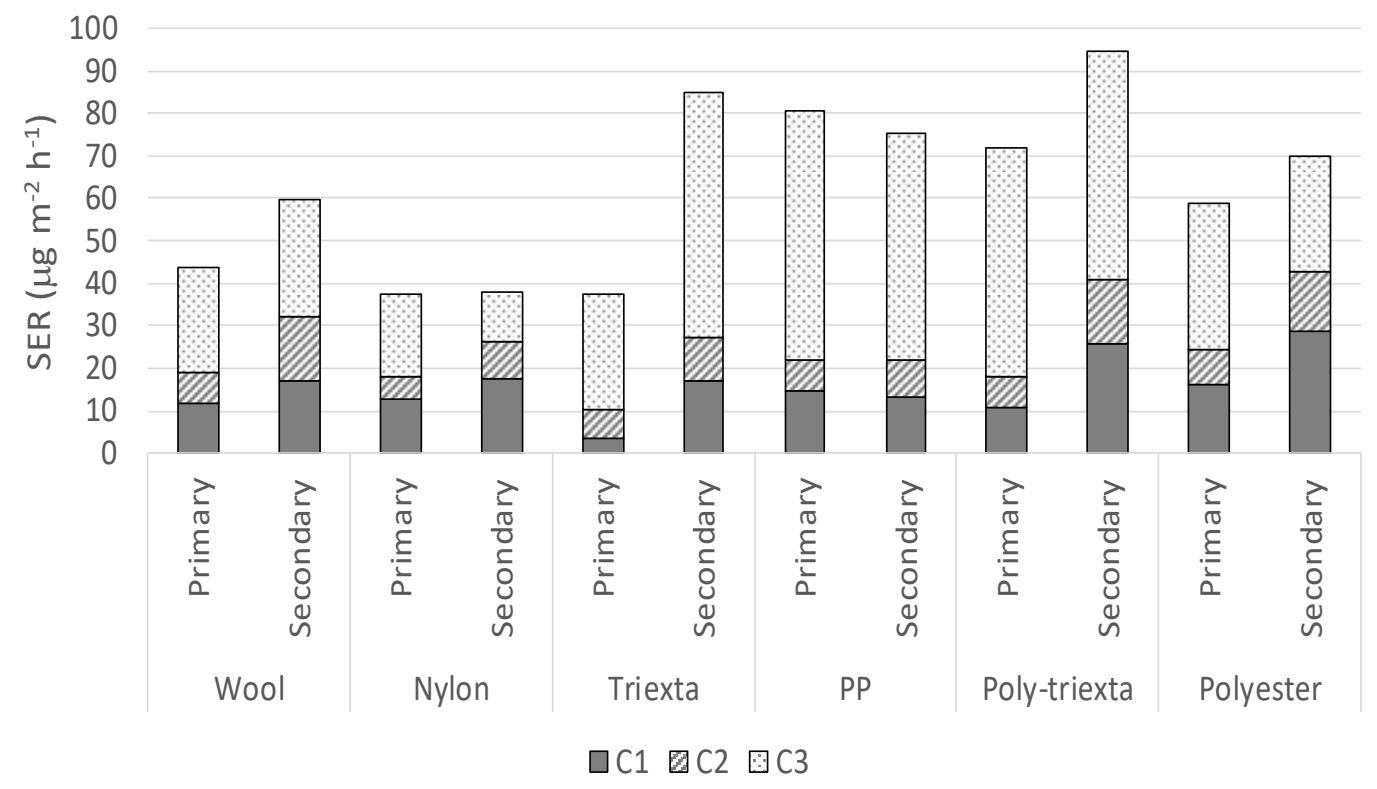

Figure 2.5. Primary and secondary light carbonyl emissions from carpet samples. Secondary emissions are at ozone exposure of $120 \mathrm{ppb}$ for $24 \mathrm{hr}$. PP = polypropylene. C1 is formaldehyde, $\mathrm{C} 2$ is acetaldehyde, $\mathrm{C} 3$ is acetone.

Within the light carbonyls, carpet sample emissions of acetone (C3) were by far the highest and emissions of acetaldehyde (C2) were lowest. While primary emissions of acetone were quite variable, ranging from 19 to $59 \mu \mathrm{g} \mathrm{m}^{-2} \mathrm{~h}^{-1}$ for nylon and polypropylene samples, respectively, primary emissions of acetaldehyde were more uniform, ranging from 6 to $8 \mu \mathrm{g} \mathrm{m}^{-2} \mathrm{~h}^{-1}$. Furthermore, for nylon, polypropylene, and polyester carpets, the secondary emissions of acetone are less than the primary emissions. This behavior agrees with the findings of Cros et al. (2011) and Gall et al. (2013) who 
both reported decreases in acetone secondary emissions that were less than primary emissions for nylon fiber carpet.

Formaldehyde $(\mathrm{C} 1)$ is one of the carbonyls of most interest from a human health perspective due to its classification as a known human carcinogen. Triexta and polyester carpet samples had the lowest and highest primary emissions of formaldehyde at 3 and 16 $\mu \mathrm{g} \mathrm{m}^{-2} \mathrm{~h}^{-1}$, respectively. Secondary emissions of formaldehyde ranged from $13 \mu \mathrm{g} \mathrm{m} \mathrm{m}^{-2} \mathrm{~h}^{-1}$ for polypropylene to $29 \mu \mathrm{g} \mathrm{m}^{-2} \mathrm{~h}^{-1}$ for polyester. Thus, with respect to secondary formaldehyde emissions, the polyester and poly-triexta carpet samples were among the highest emitters. Nylon was the lowest emitter of harmful light carbonyls, and the other carpet samples yielded mixed results.

For formaldehyde (C1) and acetaldehyde (C2), the secondary emissions are generally higher than the primary emissions. This result agrees with the findings of Weschler et al. (1992), who reported an increase in the concentrations of these two compounds for nylon carpets, and Morrison and Nazaroff (2002) who reported an increase in all $\mathrm{C} 1-\mathrm{C} 13$ compounds. However, as noted, the polypropylene carpet sample showed different behavior with the secondary emissions of formaldehyde being slightly lower than the primary emissions. This is possibly due to the lack of double bonds in polypropylene, making it more resistant to ozone attack. 


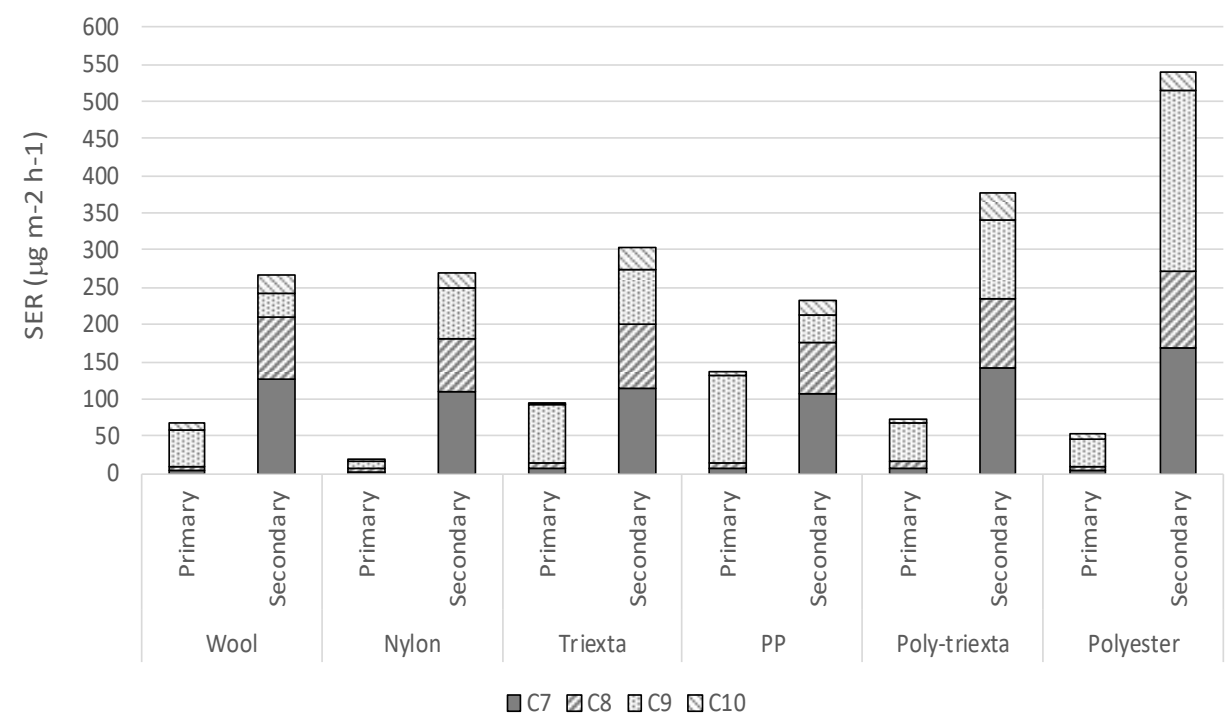

Figure 2.6. Primary and secondary heavy aldehyde emissions from carpet samples. $\mathrm{C} 7$ is heptanal, C8 is octanal, C9 is nonanal, and C10 is decanal.

Figure 2.6 shows the primary and secondary emissions of heavy aldehydes for all six carpet samples tested. The general trend for all heavy aldehyde compounds is that secondary emissions are higher than primary emissions, again, suggesting a high degree of interaction between carpet fibers and ozone, especially for C7-C10 aldehydes (Weschler 2002). Nylon carpet samples had the lowest primary emissions of heavy aldehydes at $19 \mu \mathrm{g} \mathrm{m}^{-2} \mathrm{~h}^{-1}$ while polypropylene had the highest $\left(137 \mu \mathrm{g} \mathrm{m}^{-2} \mathrm{~h}^{-1}\right)$. In sharp contrast, however, polypropylene had the lowest total secondary emissions of heavy aldehydes. The poly-triexta and polyester carpet samples had the highest secondary emissions of heavy aldehydes at 377 and $539 \mu \mathrm{g} \mathrm{m}^{-2} \mathrm{~h}^{-1}$, respectively.

Within the heavy aldehydes, primary emissions of heptanal (C7), octanal (C8), and decanal (C10), for all carpets were less than $10.0 \mu \mathrm{g} \mathrm{m}^{-2} \mathrm{~h}^{-1}$. However, secondary emission rates for these compounds ranged from $19 \mu \mathrm{g} \mathrm{m}^{-2} \mathrm{~h}^{-1}$ of decanal for polypropylene carpet to $169 \mu \mathrm{g} \mathrm{m}^{-2} \mathrm{~h}^{-1}$ of heptanal for the polyester carpet. For most 
carpet samples, secondary emissions of nonanal were substantially higher than primary emissions. This is particularly true for polypropylene, polyester, and nylon, for which the ratio of secondary to primary emissions of nonanal were 6,8 , and 11 , respectively.

So, the nylon carpet sample was among the lowest emitting samples for both light and heavy aldehydes. However, while polypropylene was a high emitter of light carbonyls, it was among the lower emitting carpet samples for heavy aldehydes.

Figure 2.7 shows the molar yields, which is moles of carbonyl produced per moles of ozone consumed. The cumulative values of yields vary from 0.19 for wool fiber carpet to 0.54 for polyester fiber carpet. This suggests that wool carpet is the lowest emitter for the seven compounds relative to ozone removal, especially for acetaldehyde and nonanal.

The polyester carpet is the highest emitter in the group, specifically for formaldehyde, heptanal, and nonanal. By comparing this finding to the ozone removal, where the wool carpet showed the highest percentage ozone removal and highest ozone deposition velocity, it is concluded that the reaction pathway between ozone and wool fiber carpet does not result in formation of the carbonyls targeted here; further investigation is needed to determine the mechanism and nature of byproducts formed. For the yield of a specific compounds, formaldehyde has the maximum yield among all compounds with value of 0.14 for polyester carpet, and the minimum yields is 0.007 for nonanal for the wool carpet. Despite the variation in some carbonyl compounds of this research from others, the comparison of the total yield value for the nylon fiber carpet with value of 0.23 , shows good agreement the cumulative yield for the carpet sample found by Gall et al. 2013 who report a total value of 0.28 , for an analysis of a similar 
class of compounds. However, both values exceed the value of 0.12 reported by Lamble et al. (2011). In general, the total yields give the same indication found in examining the specific emission rates that nylon, as the second least emitter, is a low emitting carpet in comparison to both polyester and poly-triexta carpet which showed higher secondary emissions.

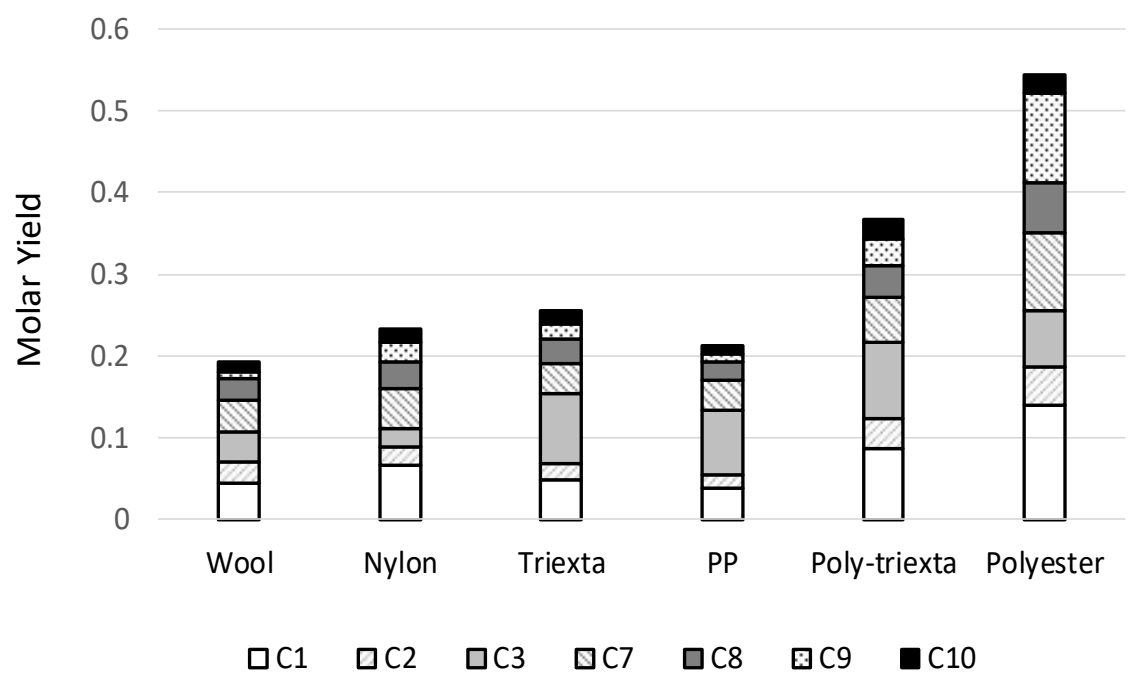

Figure 2.7. Molar yields (moles of product per mole of ozone) for secondary carbonyl emissions from carpet samples after ozone exposure of 120ppb for $24 \mathrm{hr}$. $\mathrm{C} 1=$ Formaldehyde. $\mathrm{C} 2$ Acetaldehyde. $\mathrm{C} 3=$ Acetone $\mathrm{C} 7=$ Heptanal $\mathrm{C} 8=$ Octanal. $\mathrm{C} 9=$ Nonanal. $\mathrm{C} 10=$ Decanal.

\subsection{Conclusions}

The deposition velocities for carpet samples showed values ranging from about 2 to $6 \mathrm{~m} \mathrm{~h}^{-1}$. This indicates that carpets are good sinks for ozone with potential to lower harmful ozone levels indoors. On the other hand, carpets can emit significant levels of volatile organic compounds, and these emissions can be amplified in the presence of ozone. While nylon fiber carpets had among the lowest emissions of carbonyls they were 
also among the least effective at removing ozone from indoor air. Wool and polypropylene carpets were the least effective at removing ozone. Furthermore, while wool generated intermediate levels of carbonyl emissions, polypropylene carpets had the highest primary emissions of carbonyls. While it is difficult to make a strong case for any specific carpet being the best for indoor air quality, several conclusions can be drawn. First, nylon carpets are generally a good choice, particularly for locations that are not exposed to high levels of ambient ozone. Polypropylene fiber carpets, on the other hand, appear to be of limited benefit with respect to indoor air quality concerns, given that the data presented here show they result in only modest removal of ozone but are characterized by high aldehyde emissions.

\section{Acknowledgments}

The authors would like to thank Wentai Luo, and Tom Bennett of Portland State University for providing useful notes in the construction of the test rig, and Dr. Andrea DeBarber of Oregon Health Sciences University for providing training and support in using the High Performance Liquid Chromatography with Mass Spectrometry (HPLC/MS) system in the Chemistry department at Portland State University. Omed Abbass acknowledges support from a scholarship from the Higher Committee of Education Development in Iraq (HCED). This research was supported in part by Assistance Agreement No. 83575401 awarded by the U.S. Environmental Protection Agency. It has not been formally reviewed by EPA. The views expressed in this document are solely those of the authors and do not necessarily reflect those of the 
Agency. EPA does not endorse any products or commercial services mentioned in this publication.

\section{References}

California Department of Resources Recycling and Recovery (CalRecycle), (2016). Carpet Construction and Demolition Recycling. http://www.calrecycle.ca.gov/ConDemo/Carpet/, accessed Sept 4, 2016.

CDPH, (2010). Standard method for the testing and evaluation of volatile organic chemical emissions from indoor sources using environmental chambers. Version 1.1. California department of public health. Feb. 2010.

Coleman BK, Destaillats H, Hodgson AT, Nazaroff WW, (2008). Ozone consumption and volatile byproduct formation from surface reactions with aircraft cabin materials and clothing fabrics. Atmospheric Environment 42, 642-654.

Crawshaw C, Simpson W S, (2002). Wool: Sience and Technology. Woodhead Publishing. 62.

Cros CJ, Morrison GC, Siegel JA, Corsi RL, (2012). Long-term performance of passive materials for removal of ozone from indoor air. Indoor Air 22 (1), 43-53.

Cros CJ, Morrison GC, Siegel J, Corsi R, (2011). Removal of indoor ozone by green building materials, 12th International Conference on Indoor Air Quality and Climate 2011 01/2011; 1 .

EPA, (1999). Compendium Method TO-11A. Determination of Formaldehyde in Ambient Air Using Adsorbent Cartridge Followed by High Performance Liquid Chromatography (HPLC) [Active Sampling Methodology]. Center for Environmental Research Information. Office of Research and Development U.S. Environmental Protection Agency. Cincinnati, OH 45268.

Fick J, Nilsson C, Andersson B, (2004). Formation of oxidation products in a ventilation system. Atmospheric Environment 38, 5895-2599.

Gall ET, Darling E, Siegel J, Morrison G, Corsi R, (2013). Evaluation of three common green building materials for ozone removal, and primary and secondary emissions of aldehydes. Atmospheric Environment 77, 910-918.

Gall ET, Corsi RL, Siegel JA, (2001). Barriers and opportunities for passive removal of indoor ozone. Atmospheric Environment 45 (19), 3338-3341. 
Grøntoft T, Raychaudhuri M, (2004). Compilation of tables of surface deposition velocities for $\mathrm{O}_{3}, \mathrm{NO}_{2}$ and $\mathrm{SO}_{2}$ to a range of indoor surfaces. Atmospheric Environment $38,533-544$.

Hoang C, Kinney KA, Corsi RL, (2009). Ozone removal by green building materials. Building and Environment 44 (8), 1627-1633.

ISO, (2006). International Standard ISO 16000-9. Indoor air- Part 9: Determination of the emission of volatile organic compounds from building products and Furnishing-Emission test chamber method.

Klepeis NE, Nelson WC, Ott WR, Robinson JP, Tsang AM, Switzer P, Behar JV, Hern SC, Engelmann WH, (2001). The National Human Activity Pattern Survey (NHAP): a resource for assessing exposure to environmental pollutants. J. Expo Anal Environ Epidemiol, 11 (3), 231-52.

Lamble SP, Corsi RI, Morrison GC, (2011). Ozone deposition velocities, reaction probabilities and product yields for green building materials. Atmospheric Environment 45, 6965-6972.

Morrison GC, Nazaroff WW, Cano-Ruiz JA, Hodgson AT, Modera MP, (1998). Indoor air quality impacts of ventilation ducts: ozone removal and emissions of volatile organic compounds. Journal of the Air \& Waste Management Association 48 (10), 941-952.

Morrison GC, Nazzarof WW, (2002). Ozone Interaction with Carpet: Secondary Emissions of Aldehydes, Environmental Science and Technology, 36, 2185-2192.

Nicolas M, Ramalho O, Maupetit F, (2007). Reactions between ozone and building products: Impact on primary and secondary emissions, Atmospheric Environment, 41 (15), 3129-3138.

Nazaroff WW, Gadgil, AJ, Weschler CJ, (1993). Critique of the Use of Deposition Velocity in Modeling Indoor Air Quality, ASTM International, 81-103.

Rim D, Gall ET, Maddalena RL, Nazaroff WW, (2016). Ozone reaction with interior building materials: Influence of diurnal ozone variation, temperature and humidity, Atmospheric Environment, 125A, 15-23.

Stephens, B., Gall, ET, Siegel JA, (2012), Measuring the penetration of ambient ozone into residential buildings, Environmental Science and Technology, 46 929-936.

Uhde E, Salthammer T, (2007). Impact of reaction products from building materials and furnishings on indoor air quality - A review of recent advances in indoor chemistry, Atmospheric Environment, 41 (15), 3111-3128.

Walker IS, Sherman, M, Nazaroff W, (2009). Ozone Reductions Using Residential Building Envelopes. Report LBNL-5889E. Ernest Orlando Lawrence Berkeley National Laboratory, Berkeley, CA (US). 
Wang H, Morrison GC, (2010). Ozone-surface reactions in five homes: Surface reaction probabilities, aldehyde yields, and trends. Indoor Air, 224-234.

Wang H, Morrison GC, (2006). Ozone-initiated secondary emission rates of aldehydes from indoor surfaces in four homes. Environmental Science \& Technology 40 (17), 52635268 .

Waring MS, Siegel JA, (2013). Indoor Secondary Organic Aerosol Formation Initiated from Reactions between Ozone and Surface-Sorbed d-Limonene, Environmental Science and Technology, 47 (12), 6341-6348.

Weschler CJ, (2000). Ozone in Indoor Environments: Concentration and Chemistry, Indoor Air, 10, 269-288.

Weschler CJ, (2006). Ozone's Impact on Public Health: Contributions from Indoor Exposures to Ozone and Products of Ozone-Initiated Chemistry. Environ Health Prospect. 114, 1489-1496.

Weschler CJ, (2009). Changes in indoor pollutants since the 1950s. Atmospheric Environment 43 (1), 153-169.

Wechsler C, Hodgson, AT, Wooley, JD, (1992). Indoor chemistry: Ozone, Volatile Organic Compounds, and Carpets. Environmental Science and Technology, 26 23712377.

Wisthaler A, Weschler CJ, (2010). Reactions of ozone with human skin lipids: sources of carbonyls, dicarbonyls, and hydroxycarbonyls in indoor air. Proceedings of the National Academy of Sciences of the United States of America 107 (15), 6568-6575. 


\title{
Chapter 3
}

\section{Paper 2: Effectiveness of indoor plants for passive removal of indoor ozone}

Omed A. Abbass, David J. Sailor, and Elliott T. Gall

Published in Building and Environment 119 (2017) 62-70

\begin{abstract}
Indoor vegetation is often proposed as a passive approach for improving indoor air quality. While studies of outdoor environments indicate that vegetation can be an important sink of outdoor ozone, there is scant data in the literature concerning the dynamics of ozone uptake by indoor plants. This study investigates ozone deposition velocities $\left(v_{d}\right)$ for five common indoor plants (Peace Lily, Ficus, Calathia, Dieffenbachia, Golden Pothos). The transient $v_{d}$ was calculated, using measured leaf areas for each plant, for exposures mimicking three diurnal cycles where ozone concentrations in chamber tests were elevated for $8 \mathrm{~h}$ followed by $16 \mathrm{~h}$ in the absence of ozone. Estimates of $\mathrm{vd}$ at the end of the first exposures ranged from $5.6 \mathrm{~m} \mathrm{~h}^{-1}$ for Golden Pothos to $0.9 \mathrm{~m} \mathrm{~h}^{-1}$ for Peace Lily. Values of vd were approximately $50 \%$ and $66 \%$ lower at the end of a second exposure and third exposure, respectively. Estimates of vd were also made for a range of photosynthetic active radiation (PAR) levels typically observed indoors. An increase in PAR from 0.6 to $41.2 \mu \mathrm{mol} \mathrm{m} \mathrm{m} \mathrm{sec}^{-1}$ resulted in increases in vd ranging from a factor of 1.7 (Diffenbachia) to 4.7 (Peace Lily). For deposition velocities measured in this study, the ozone removal effectiveness ranges from $0.9 \%-9 \%$ for leaf surface area to room volume ratio of $0.06 \mathrm{~m}-1$ (approximately one plant for every $1.8 \mathrm{~m} 2$
\end{abstract}


of floor area) when accounting for values of air exchange and background loss typical of a residential environment.

\subsection{Introduction}

Ozone is a strong oxidant gas with known adverse health effects. The predominant source of indoor ozone is outdoor air, where ozone is formed through photochemistry. The EPA regulates outdoor ozone levels to be no higher than $70 \mathrm{ppb}$ averaged for eighthour period (EPA 2015). Although ozone may be generated indoors by, e.g., photocopiers or air-cleaners using UV light or corona discharge, the transport of outdoor ozone indoors through ventilation and infiltration is the predominant indoor source. Once indoors, ozone can react with different surfaces indoor such as flooring, paints, and even metals (Grøntoft and Raychaudhuri 2004). While these reactions suppress indoor concentrations of ozone, they may also result in the production of byproducts that may be more harmful than ozone itself (Wisthaler and Weschler, 2010).

While indoor levels are typically lower than outdoors due to indoor surface reactions, Weschler (1992) indoor ozone concentrations, in certain circumstances, may exceed $50 \mathrm{ppb}$ and that indoor levels may be as high as $35 \%$ of outdoor levels. For example, in a study of eight schools in France, Blondeau et al. (2005) reported indoor ozone concentrations of up to $60 \mathrm{ppb}$. In addition to outdoor air as a source of indoor ozone, high-tension electrical equipment is another source of indoor ozone. Allen et al. (1978) found that ozone emissions from electrostatic air cleaners and unmaintained photocopiers led to ozone levels up to $202 \mathrm{ppb}$ in small low ventilated spaces. Elevated ozone levels indoors can be expected to have negative health effects on building 
occupants, based on a body of literature investigating health effects in the context of outdoor ozone levels for which more extensive reporting has historically been available. Lippmann (1989) states that studies suggest long-term exposure to outdoor ozone will cause premature aging of lungs. Brauer and Brook (1997) report a reduction in lung function associated with ozone exposure for people working outdoors subjected to ozone levels of around $50 \mathrm{ppb}$. This adverse effect was still noticeable even a day after exposure, indicating that the health effect of ozone exposure, even below its permissible limits, can be serious. This statement is supported by ASHRAE (2011) and Bell et al. (2006) which suggest that ozone levels above $10 \mathrm{ppb}$ are associated with some health risk. Given the predominance of indoor environments in human activity patterns, it is estimated that the average American spends $90 \%$ of their time indoors (Klepeis et al., 2001). Thus, reducing exposure to ozone requires addressing indoor ozone levels.

In the absence of indoor sources of ozone, two general approaches can be employed to achieve reductions in indoor ozone levels. The first is to control the ozone level in air entering the building. The second approach is to reduce the concentration of ozone once present indoors. Previous research suggests that some indoor materials may serve as "passive" (i.e., no direct energy input) air cleaners. For instance, Cros et al. (2012) studied the performance of three building materials (activated carbon mat, painted gypsum board, and ceiling tiles) as passive ozone removing surfaces and found that both activated carbon mat and ceiling tiles are capable of removing ozone from the indoor environment. Gall et all. (2011) performed a Monte Carlo simulation to characterize passive removal materials (PRMs) such as activated carbon cloth and gypsum wallboard, employing statistical distributions for model inputs such as uptake to materials and 
indoor-outdoor air exchange rates. The simulation results show that there are some challenges in achieving a threshold of $50 \%$ removal of indoor ozone. These challenges include the need for using a large area of passive materials, a requirement that the air speed indoors be increased to enhance transport to surfaces, and aesthetic challenges associated with installing such materials.

One indoor air cleaning strategy with limited quantitative research is the use indoor plants. Research about plants, especially outdoor vegetation, shows their ability to remove pollutants including ozone. For instance, Hill (1971) stated that a 16" height of alfalfa canopy in a chamber setting tests showed removal of ozone at concentration of 5 ppm in addition to removing other pollutants as well. Calfapietra et al. (2016) show that nine urban tree species remove ozone, noting that removal increases from 0.5 to 6.5 $\mathrm{nmol} \cdot \mathrm{m}^{-2} \cdot \mathrm{s}^{-1}$ when ozone concentrations increased from 100 to $300 \mathrm{ppb}$.

With regard to indoor plants, much of the existing research on air cleaning effects of focuses on volatile organic compounds (VOCs). For instance, Kim et al. (2010) studied the removal efficiency of formaldehyde at initial concentration of $\left(2.0 \mu \mathrm{L} . \mathrm{L}^{-1}\right)$ due to 68 different species of plants in air tight chamber setting. They report plants based on their formaldehyde removal into groups: excellent $\left(>1.2 \mathrm{mg} \cdot \mathrm{m}^{3}\right.$ per $\mathrm{cm}^{2}$ of leaf area in a $5 \mathrm{~h}$ period of time), intermediate (1.2 to 0.6$)$, and poor $(<0.6)$. Orwell et al. (2004), studied the benzene removal by seven potted plants when initial doses of $25 \mathrm{ppm}$ benzene were injected. Removal rates of 12-27 ppm.day ${ }^{-1}$ were identified during consequent injections. Wolverton et al. (1989) studied the efficiency of 12 indoor plants with activated carbon aerated roots in removing benzene, trichloroethylene, and formaldehyde injected separately into test chambers. The total leaf areas of the plants ranged from 
$\sim 1000 \mathrm{~cm}^{2}$ to $\sim 15,000 \mathrm{~cm}^{2}$. The results showed removal ratios of $5-70 \%$ for the chemicals under investigation, although the authors attributed most of removal effectiveness to the activated carbon root area. Root-associated microbes may also play a role in affecting removal pathways of indoor air pollutants (Russell et al. 2014).

Investigations of ozone uptake by indoor plants, including estimations of deposition velocities, are scarce in the literature. We are aware of one paper that investigated the ozone decay of three indoor plants via decay tests of ozone in a sealed continuously stirred tank reactor (Papinchak et al. 2009). The results show that the time required for the ozone to decay from 200ppb to less than 5 ppb ranged from $38-120$ min per evaluation. The depletion rate of ozone was greater when plants were present in the chamber than for an empty chamber, with variation in the decay rate of ozone noted for different species of indoor plants. Deposition velocities are not reported and it the implications for realistic indoor environments are not discussed. Furthermore, studies have not addressed potentially important indoor environmental factors that may influence pollutant removal by plants, such as indoor lighting levels. This information is crucial to evaluate the effectiveness of indoor plants as passive ozone removal strategies. The current research aims to investigate and calculate the ozone deposition velocity and ozone removal effectiveness of five common indoor plants, and to explore the effect of indoor light level on the ozone deposition velocities. 


\subsection{Methodology}

\subsubsection{Materials}

Five types of indoor plants were chosen based on their popularity and availability. Plants were purchased from a local nursery in Portland, OR, USA in standard 6" (15.24 $\mathrm{cm})$ pots. The top surface area of every leaf of every plant was measured individually using KLONK image measurement software (Image Measurement Corporation), then summed to determine the leaf surface area of each tested plant. The uncertainty associated with consequent measurements of known areas using the software was found to be $3.7 \times 10^{-5} \mathrm{~m}^{2}$. Table 3.1 shows a list of the popular and scientific names of the plants and the measured surface area. The loading factor, the area of sample divided by the volume of chamber, was approximately $1.92 \mathrm{~m}^{2} / \mathrm{m}^{3}$.

To minimize the effect of the interaction of ozone with materials other than plants, such as the pot itself and soil, plants were placed in a $600 \mathrm{~mL}$ glass beaker two days prior to an ozone uptake test. The glass beaker was chosen as an alternative to the standard plastic pot provided by the nursery because glass is an inert material with respect to ozone (Nicolas et al. 2007). During tests with plants, the soil was covered by placing aluminum foil around the plant stem to cover the soil surface and minimize the interaction with ozone. In addition, to characterize the contribution of the soil itself to ozone uptake, one test of a glass beaker was conducted with only soil exposed in the beaker (i.e. no plant present). The exposed soil was found to have a negligible effect on overall ozone removal. 
Table 3.1 List of indoor plants used in tests of ozone removal rate.

\begin{tabular}{lll}
\hline Name & Scientific name & Leaf top surface area $\left(\mathrm{cm}^{2}\right)$ \\
\hline Peace Lily & Spathiphyllum & 998.09 \\
Ficus species & Ficus Decora Burgundy & 1022.31 \\
Calathia & Calathia Species & 1046.93 \\
Dieffenbachia & Dieffenbachia Species & 969.1 \\
Golden Pothos & Epipremnum aureum & 1011.28 \\
\hline
\end{tabular}

\subsubsection{Experimental apparatus}

A diagram for the experimental test system is shown in Figure 1. The apparatus consists of an air supply system, 52 L glass chambers, ozone generation, and ozone monitoring equipment. Compressed air was supplied from the laboratory air supply, which then passed through two stage air filters to remove suspended oil and particulate matter. Air was then dehumidified using a granular drying media (Indicating Drierite, W.A. Hammond Drierite Co. Ltd.) laboratory gas-drying column. The air stream then passed through an activated carbon air filter to purify the air stream of any VOCs in supply air. Air then was humidified using a bypass controlled impinger filled with distilled water to the required relative humidity. The temperature and relative humidity of the air stream were measured and recorded in one-minute interval using a HOBO 12Bit sensor of range of $-40^{\circ} \mathrm{C}$ to $75^{\circ} \mathrm{C}$ with accuracy of $0.2^{\circ} \mathrm{C}$, and $0-100 \%$ relative humidity range with $2.5 \%$ accuracy (Onset, model S-THB-M002) that was connected to an HOBO data logger (Onset, model H21-002). A mass flow controller of range of 0-15LPM with accuracy of $1.5 \%$ (OMEGA, model FMA 5523) was used to stabilize the airflow rate before supplying the air to a stable UV ozone generator (UVP, model SOG-2). The ozonated air stream was then divided into two lines. One was supplied to the glass chamber and the other served as a reference line to measure the inlet ozone concentration. Two UV portable photometric ozone analyzers (2B Technologies, model 106-L) were 
used to record the ozone concentrations in one-minute interval upstream and downstream the chamber in the range of $0-60 \mathrm{ppb}$ with accuracy of $2 \%$ of the reading. All tubing, connections, and valves were PTFE or stainless steel to minimize their reactivity with ozone. The air pressure inside the chamber was maintained at slightly positive pressure above atmospheric pressure to prevent intrusion of air into the chamber.

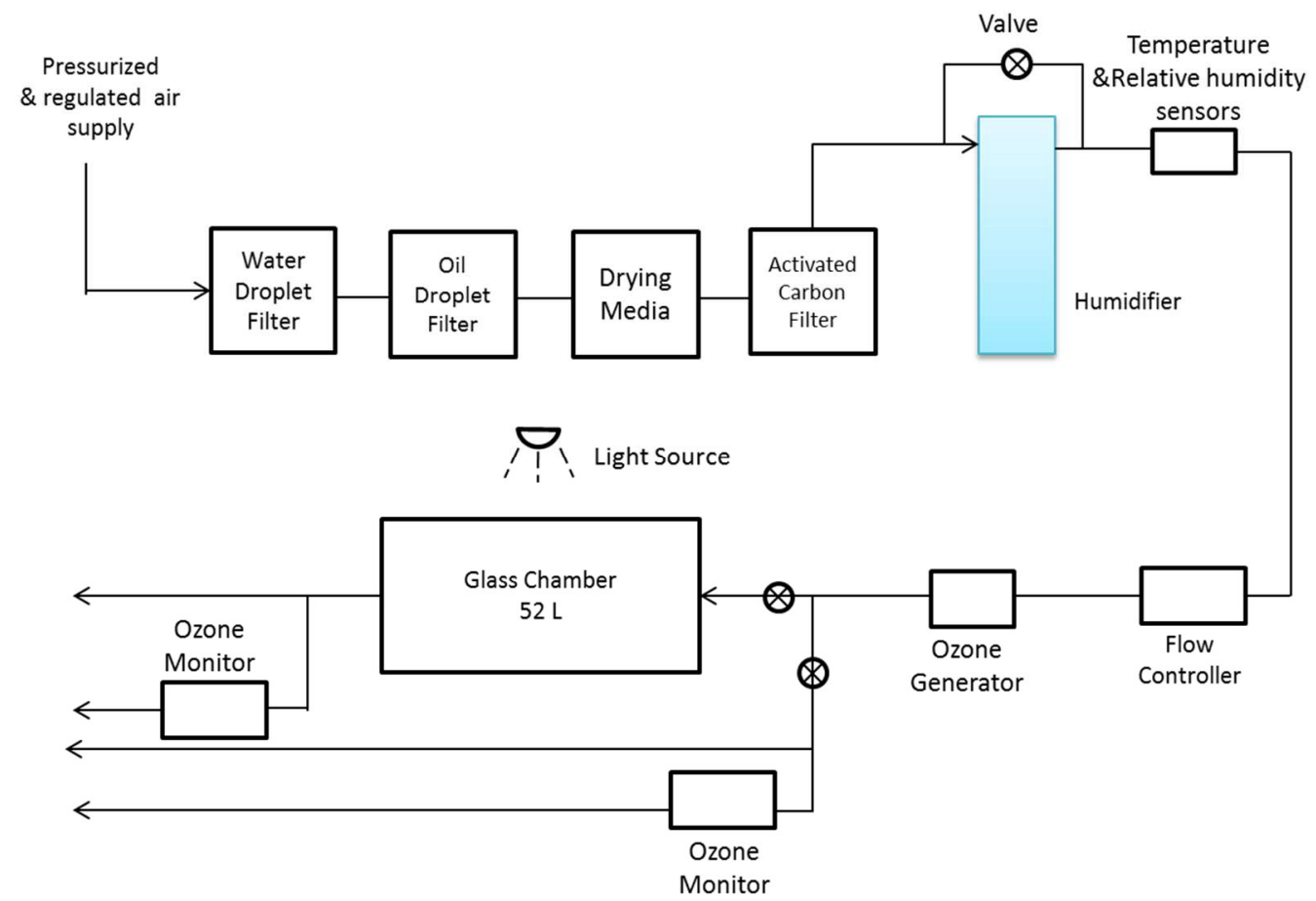

Figure 3.1. Schematic diagram of the experimental apparatus

\subsubsection{Experimental Procedure}

The experimental chamber was supplied with ozonated air with an air exchange rate of $3.0 \pm 0.045 \mathrm{~h}^{-1}$. The monitored values for temperature were in the range of $21 \pm$ $1^{\circ} \mathrm{C}$, and the relative humidity was $50 \pm 2 \%$. The ozone concentration at the inlet to the chamber was $60 \pm 1.2 \mathrm{ppb}$, which was selected to represent an elevated indoor level, but in the range observed in prior field studies (Blondeau et al. 2005). 
Prior to conducting an experiment, the chamber was thoroughly wiped with distilled water, dried with a heat gun, then quenched with a stream of air containing elevated ozone ( $350 \mathrm{ppb}$ ) for three hours (similar to Coleman et al. 2008). To characterize background ozone removal, two separate tests were performed to calculate the ozone consumption by an empty chamber and a chamber with a soil-filled glass beaker covered with aluminum foil. From these tests, ozone deposition velocity for the glass chamber material and background materials were calculated. It was found that the soil-filled glass beaker with aluminum cover had a statistically insignificant effect on ozone deposition velocity values compared to the glass chamber alone.

For plant tests, each plant was exposed to eight hours of ozonated air (at $60 \mathrm{ppb)}$ followed by 16 hours of a non-ozonated air stream. The eight-hour exposure time was chosen based on an EPA report for ozone exposure analysis in urban areas and prior experimental studies (EPA 2015; Rim et al. 2016). This 24-h cycle was repeated two more times to observe the ozone deposition change with three repeated cycles of ozone exposure. Thus, each test lasted for a total of three days.

A separate series of tests was conducted to study the effect of light on ozone removal. This test was conducted by exposing the plants to an ozonated stream of air until the ozone concentration at the test chamber exit reached a steady state condition (defined as changing by no more than $2 \mathrm{ppb}$ in 20 minutes). After reaching steady-state, a light source was sequentially turned on for $2.5 \mathrm{~h}$ and then turned off for $2.5 \mathrm{~h}$ to monitor the change in ozone concentration as a result of plants' photosynthetic activity. A control test was also performed to confirm that the light did not affect ozone removal for an 
empty chamber. Figure 3.2 shows the timeline of the sequence of both ozone re-exposure and light tests.

a)

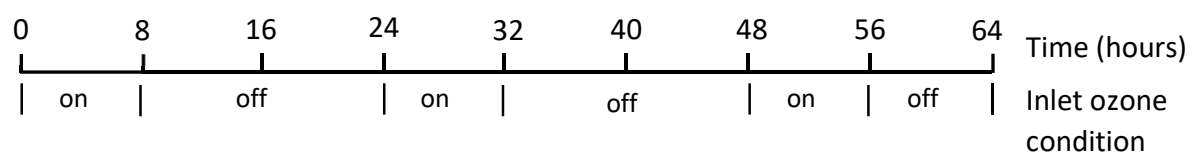

b)

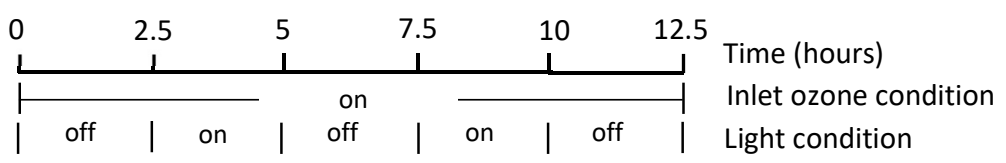

Figure 3.2. Experimental timeline for tests of ozone uptake to each type of plant. a) Ozone re-exposure test. b) Light exposure test.

To quantify the light intensity in the indoor environment in the spectrum that is most relevant for plant activity, a short field study of indoor lighting conditions in a Portland State University building and residential apartment was conducted. A photosynthetically active radiation (PAR) sensor (Onset, model S-LIA-M003), solar radiation sensor (Onset model S-LIB-M003), and combined temperature and relative humidity sensor (Onset, model S-THB-M002) were used to record the PAR, solar intensity, temperature and relative humidity for different indoor conditions. These sensors were connected to portable data logger (Onset, model S-THB-M002). This test was performed to ensure that PAR and solar radiation levels were consistent with levels that may be reasonably anticipated to be present in an indoor environment. The peak PAR and solar intensity values recorded in different indoor locations are shown in Table 3.2. The values recorded in the shade of an indoor south facing hallway under clear sky conditions were chosen to adjust the lighting condition of the tests. This condition was chosen as 
outdoor ozone levels typically reach their peak values in late morning or early afternoon (Beig et al. 2007).

Two fluorescent lamps (Bright Green, model UL\#E170906) with power of $23 \mathrm{~W} / 1600$ lumens each were used to provide a PAR radiation value of $41.2 \mu \mathrm{mol} \mathrm{m} \mathrm{m}^{-2}$ $\mathrm{sec}^{-1}$ for the plants during the test period. Both lamps were mounted on a tripod, adjusting the vertical distance from the plant to achieve the required PAR value. The power was supplied to the lamps using a timer switch to control the periods of on and off as shown in Figure 3.2b.

Table 3.2. Peak photosynthetic active radiation (PAR) and solar radiation intensity values recorded in different indoor locations.

\begin{tabular}{lcc} 
Place* & $\begin{array}{c}\text { PAR } \\
\left(\mu \mathrm{mol} \mathrm{m}^{-2} \mathrm{sec}^{-1}\right)\end{array}$ & $\begin{array}{c}\text { Solar radiation intensity } \\
\left(\mathrm{W} / \mathrm{m}^{2}\right)\end{array}$ \\
\hline Inside laboratory, no windows (ceiling lamps on) & 1.2 & 0.6 \\
In residential apartment at night & 1.2 & 0.6 \\
South facing hallway, cloudy day & 18.7 & 3.1 \\
North facing office, cloudy day (in shade) & 10.5 & 1.9 \\
South facing hallway, sunny day (in shade) & 39.7 & 6.9 \\
Inside lab with lamps projected to plants & 41.2 & 6.9 \\
\hline *All values of PAR and solar radiation intensity are maximum values observed in each location. All values \\
except the residential apartment were collected in the Portland State University Engineering Building. All \\
data collection occurred in September 2016, on days for which outdoor conditions were as noted.
\end{tabular}

\subsection{Data analysis}

\subsubsection{Ozone deposition velocity}

For the plants tested in this research, a transient ozone deposition velocity was calculated, similar to (Poppendieck 2007). An ozone mass balance for the chamber is shown in equation 1, which is solved for the transient ozone deposition velocity shown in equation 2. To calculate the ozone deposition velocity for the empty chamber material, which is glass in our experiments, a test of an empty chamber was conducted. The 
background test ran until the steady-state condition was achieved, i.e., where empty chamber exit concentration change was less than 2ppb over 20 minutes (Coleman 2008), and the loss rate to background chamber surfaces was solved for as described in Abbass et al. (2017). A mass balance on ozone for the test chamber is shown in equation 1 which is solved for the transient ozone deposition velocity shown in equation 2 :

$$
\begin{aligned}
& \frac{d C}{d t}=A E R \cdot C_{\text {inlet }}-A E R \cdot C_{\text {outlet }}-k_{g} \cdot C_{\text {outlet }} \cdot \frac{A g}{V}-k_{S} \cdot C_{\text {outlet }} \cdot \frac{A s}{V} \\
& k_{S}^{t}=\frac{V}{A_{S}} \cdot \frac{1}{C_{\text {outlet }}^{t}}\left[A E R\left(C_{\text {inlet }}^{t}-C_{\text {outlet }}^{t}\right)-k_{g} C_{\text {outlet }}^{t} \cdot \frac{A_{g}}{V}-\frac{C_{\text {outlet }}^{t}-C_{\text {outlet }}^{t+1}}{\Delta t}\right]
\end{aligned}
$$

Where $\mathrm{C}_{\text {inlet }}$ and $\mathrm{C}_{\text {outlet }}$ are the concentration of ozone in the inlet and outlet of the chamber (ppb) respectively, $\frac{d C}{d t}$ represents the change in the outlet ozone concentration (ppb per minute); AER is the air exchange rate $\left(\mathrm{h}^{-1}\right), \mathrm{V}$ is the net volume of chamber minus the volume of soil container $\left(\mathrm{m}^{3}\right) ; \mathrm{Ag}_{\mathrm{g}}, \mathrm{A}_{\mathrm{s}}$ are the internal surface areas of the glass chamber, and the sample area respectively $\left(\mathrm{m}^{2}\right) ; k_{g}$ and $k_{s}$ are ozone deposition velocities for the glass chamber material and the plant $\left(\mathrm{m} . \mathrm{h}^{-1}\right)$, respectively. For every plant test, the ozone deposition velocity of glass is used in equation 2 to calculate the transient deposition velocity of the plant sample, $k_{s}$. The presence of the glass beaker inside the chamber was found to have a negligible effect on ozone deposition velocity for the glass chamber. To facilitate comparison across plants, the steady-state ozone deposition velocity was calculated for each test when the rate of change in exit ozone concentration was less than 2 ppb over 20 minutes, as in Coleman et al. (2008).

The experimental uncertainty was calculated using a propagation of error analysis for the instruments used: an uncertainty of $2 \%$ of readings from ozone monitors, $1.5 \%$ of 
reading for the flow controller, and $0.63 \%$ for the estimated surface area of the plants. The resulting uncertainty in the calculated ozone deposition velocity for the empty chamber was found to be a maximum of $\pm 0.009 \mathrm{~m} / \mathrm{h}$. For deposition velocity in the plant experiments, the uncertainty varied between \pm 0.14 and $\pm 0.27 \mathrm{~m} / \mathrm{h}$ depending on the type of plant and the exposure test.

\subsubsection{Plant ozone removal effectiveness}

To simulate the ozone removal effectiveness of indoor plants in realistic, hypothetical indoor spaces, an analysis similar to that of Kunkel et al. (2010) was performed. The effectiveness metric, $H$, was employed in this analysis and is defined as shown in equation 3:

$$
H=1-\frac{C^{*}}{C^{* *}}
$$

where $\mathrm{C}^{*}$ and $\mathrm{C}^{* *}$ can be obtained by solving equation 1 for the case of a space with and without the presence of the plants, respectively.

The effectiveness metric represents the percent removal of indoor ozone due to the presence of an air cleaning strategy. The effectiveness is 1 if the all ozone is removed and 0 if the strategy had no effect on indoor ozone levels. The effectiveness is calculated as shown in equation 4 , for time-averaged conditions, with $\mathrm{C}^{*}$ and $\mathrm{C}^{* *}$ as shown in equations 4 and 5 :

$$
\begin{aligned}
& C^{* *}=\frac{C_{\text {outlet }}}{C_{\text {inlet }}}=\frac{1}{1+\frac{L_{b}}{A E R}} \\
& C^{*}=\frac{C_{\text {outlet }}}{C_{\text {inlet }}}=\frac{1}{1+\frac{L_{b}}{A E R}+k_{S} \frac{A_{S}}{V * A E R}}
\end{aligned}
$$


where $C_{\text {outlet }}$ is the concentration exiting the hypothetical indoor space, or the indoor level of ozone (ppb), and $C_{\text {inlet }}$ is the concentration entering the hypothetical indoor space, or the outdoor level of ozone ( $\mathrm{ppb})$.

Equations 5 and 6, therefore enable calculation of indoor-outdoor ratios of ozone by defining typical values of air exchange rate (AER, $\mathrm{h}^{-1}$ ), background ozone loss rate $\left(L_{\mathrm{b}}, \mathrm{h}^{-1}\right)$, and plant surface area $\left(A_{s}, \mathrm{~m}^{2}\right)$ to zone volume $\left(V, \mathrm{~m}^{3}\right)$ ratio. Air exchange rate was input as $0.5 \mathrm{~h}^{-1}$ based on the median value of 164 homes in Texas, reported by Yamamoto et al. (2010). Background ozone loss rate was set to a value of $2.8 \mathrm{~h}^{-1}$ based on the mean value from a study of 43 homes in California (Lee et al. 1999). The value of $k_{s}$ are taken from calculations of steady state ozone deposition velocity for plants determined in this investigation. In this analysis, the value of the ratio of plant surface area to the space volume will be changed in the range of $(0.01$ to 0.1$) \mathrm{m}^{-1}$ to calculate the ozone removal effectiveness $\mathrm{H}$. This approach enables a better understanding of the potential for ozone removal by indoor plants in realistic indoor environments.

\subsection{Results and discussion}

\subsubsection{Exit ozone concentration}

Figure 3.3 shows the chamber exit ozone concentration of the multiple exposure tests for the Peace Lily plant as an example. The results for the other four plants are shown in Figure 3.8 of the Supporting Information (SI). Figure 3.3 shows that the exit ozone concentration for the $1^{\text {st }}$ exposure increases, nearly linearly, from approximately $t=20$ minutes until the end of the test. In contrast, for the second and third exposures, the exit ozone concentration reaches a steady state value after approximately 200 
minutes. Also, the maximum value at the end of test for the first exposure is reduced by about $7 \mathrm{ppb}$ than in the subsequent exposures. Similar behavior, but with different ozone exit values (7-17) ppb, was noticed for the other four plants. This suggests that the plants were more effective at removing ozone in the first exposure. For the subsequent exposures, ozone removal is still present but to a lesser extent than for the first exposure. This behavior could be explained as a result of unexposed plant leaves having higher reactivity with the ozone when exposed for the first time. This exposure will subsequently lead to a change in the composition or structure of the leaf surface that will lead to a reduction in ozone removal activity. This explanation is in-line with the results of Szinyei (2014) and Kozlowski (1980), both of whom showed images of damage to plant leaves as a result of ozone exposure. Lambers et al. (2008) also states that ozone will enter the leaf through stomata causing direct damage to photosynthetic cells.

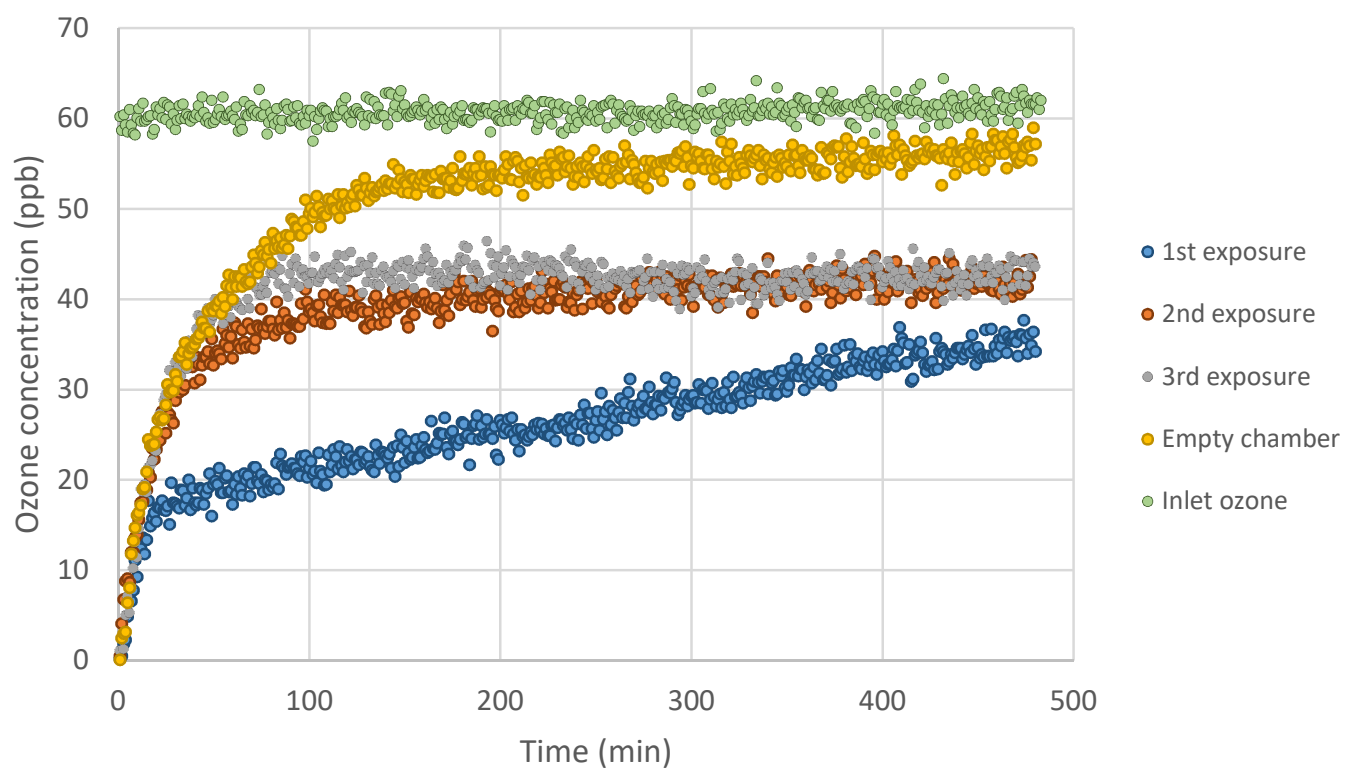

Figure 3.3. Empty chamber, inlet, and outlet ozone concentration for Peace Lily plant. The ozone was on for 8 hours and off for 16 hours. This pattern of ozone exposure was repeated three times and reported as first, second, and third exposures. 


\subsubsection{Ozone deposition velocity}

The background ozone deposition velocity for the empty chamber is calculated first by passing an ozonized air stream through an empty, thoroughly cleaned chamber. By applying steady state values of inlet and outlet ozone concentrations, and air exchange rate to equation 1 , the background ozone deposition velocity was found to be $0.019 \mathrm{~m} \mathrm{~h}^{-1}$. This value is of similar order of magnitude to values reported by Grøntoft and Raychaudhuri (2004) for cleaned glass. For the plants, Figure 3.4 shows the transient ozone deposition velocity for the five plant species tested. The figure shows that for all plants, the values of deposition velocity are generally high at the first hour of the test, consistent with the findings of Kersiens and Lendzian (1989) who conducted experiments of ozone uptake to outdoor plants. In the case of second and third exposures, the deposition velocity then converges to steady state values for nearly all cases. Elevated initial ozone deposition velocities may partly be attributed to low initial ozone concentrations at the beginning of each tests as the chamber ozone concentrations increase from $\sim 0 \mathrm{ppb}$ to steady-state values as a constant level of ozone is injected into the well-mixed flow reactor. It is plausible that during initial periods of ozone exposure (when well-mixed chamber ozone levels are low), replenishment of reactive sites on plant surfaces more effectively compete with ozone uptake, leading to higher values of ozone deposition velocity. As time elapses, the ozone concentration increases inside the chamber until approaching a steady-state value (see the example in Figure 3.3 for Peace Lily). Then, deposition velocity curves appear to flatten, reaching an asymptotic value after about two hours. These differences in ozone deposition velocity may be attributed to 
the leaf composition and structure including leaf surface roughness that varies from one plant to another.
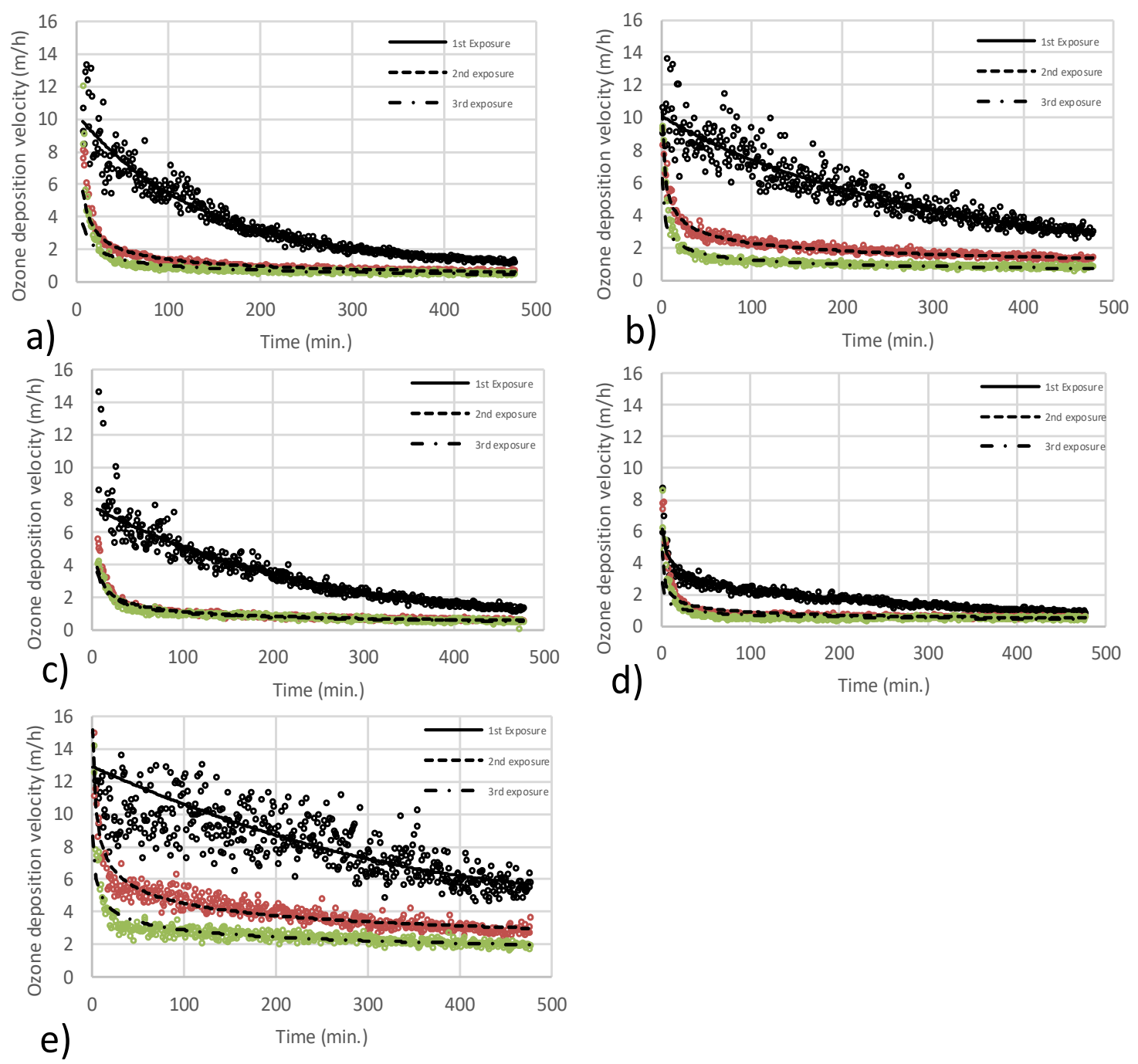

Figure 3.4. Change of transient ozone deposition velocity for all plants with number of exposures for a) Ficus species, b) Dieffenbachia, c) Calathia, d) Peace Lily, e) Golden Pothos. Lines of best fit are the best polynomial fit.

The near steady-state values of deposition velocity for all plants for the three exposures were calculated by averaging the last 20 minutes of each 8-hour test; results of these calculations are reported in Figure 3.5. The figure shows that the Golden Pothos is 
the plant with the highest ozone deposition values across all plants for all three exposures. Conversely, the Peace Lily consistently had the lowest values. Also, the ozone deposition velocities for the first exposure for all plants are the highest in value, while for the second exposures are about half the value of the first exposure, and the third exposure values are about one third of those from the first exposure. From Figure 3.5, it can also be concluded that the Golden Pothos has high ozone deposition values to a degree that it is in-line with other indoor surfaces including, for example, carpets as reported by Abbass et al. (2017). To compare the average value of the Golden Pothos with other researchers' findings, the equivalent ozone deposition velocity was calculated from the decay curve for Golden Pothos provided by Papinchak et al. (2009), assuming a first order decay after subtracting the background losses. The calculated equivalent ozone deposition velocity was $\sim 3.5 \mathrm{~m} \mathrm{~h}^{-1}$. This value matches the average value of ozone deposition velocity across the three exposures in this research, which is found to be $3.5 \mathrm{~m} \mathrm{~h}^{-1}$ as well.

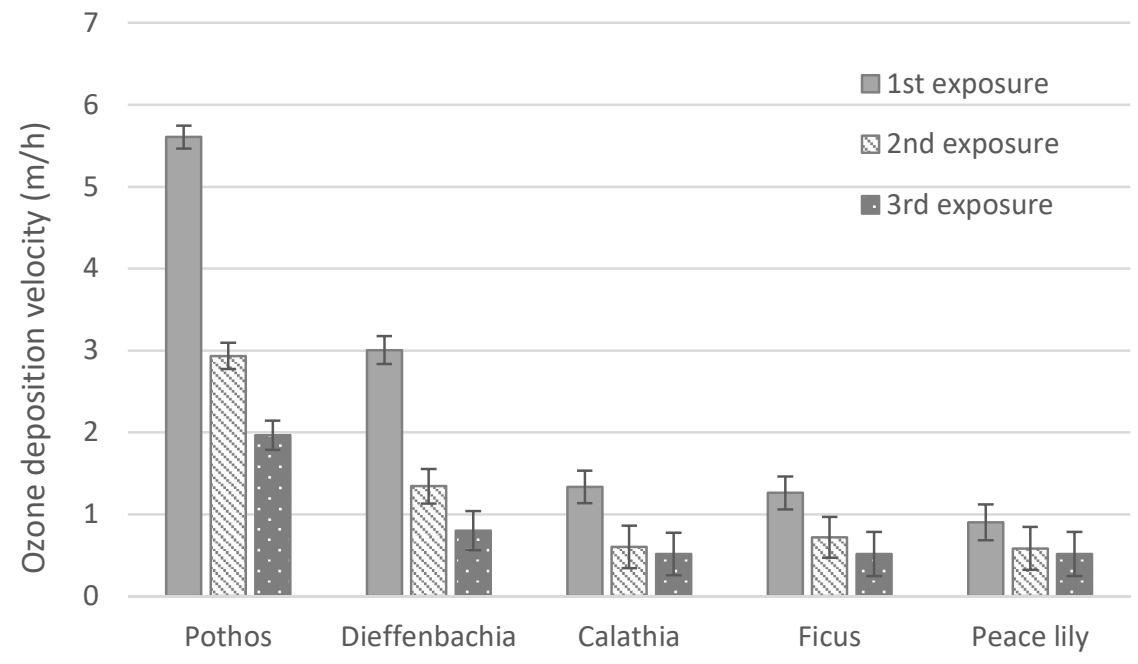

Figure 3.5. Comparison of change of steady state ozone deposition velocity for the plants with number of exposure. The steady state value represents the average of last 20 values in transient data. Error bars are calculated based on error propagation. The PAR light intensity was $1.2 \mu \mathrm{mol} \mathrm{m} \mathrm{mec}^{-1}$ as only typical overhead laboratory lights were on. 
Figure 3.6 shows the results of experiments testing the effect of light on ozone deposition velocities to the five plants. The PAR lighting levels for the experiments in Figure 6 were $1.2 \mu \mathrm{mol} \mathrm{m}^{-2} \mathrm{sec}^{-1}$ for the first $180 \mathrm{~min}$. when the chamber lights were off and laboratory lighting was on. It is worth noting that results presented in Figures 3.3-3.5 were conducted at this level $\left(1.2 \mu \mathrm{mol} \mathrm{m} \mathrm{m}^{-2} \mathrm{sec}^{-1}\right)$ of PAR. This value increased to 41.7 $\mu \mathrm{mol} \mathrm{m} \mathrm{sec}^{-1}$ when the chamber overhead lamps were on. For every plant, the light test was performed eight hours subsequent to the three exposure tests except for the Ficus plant where the test was performed a week later. The data reported in Figure 3.6 shows that all plants have reached steady state values at about one hour after the initial ozone exposure, and the steady state ozone deposition values for all plants are very similar across all exposures except for the Ficus plant which is substantially higher for the first exposure than the third exposure. This effect for the Ficus plant could be explained by the fact that this plant was left unexposed to ozone for seven days, providing additional time for biological mechanisms to repair damage to the plant, with the likely outcome of regenerating ozone reaction sizes and increasing the plant's ability to remove ozone.

The graph also shows that when the lights were on, the ozone deposition velocity for all plants increased meaningfully. The increment varies between a factor of 1.7 for Dieffenbachia (or an absolute increase of $0.45 \mathrm{~m} \mathrm{~h}^{-1}$ ) to a factor 4.7 (an increase of $2.7 \mathrm{~m}$ $\mathrm{h}^{-1}$ ) for Peace lily. One plausible explanation for the observed dependence of ozone removal on light level is that higher light levels will result in stomatal openings on the leaves. This permits greater flux of chamber air to penetrate to the leaf. As a result, ozone can either be consumed by the photosynthetic process or react with interior leaf components (Fares et al. 2010), resulting in an increase in ozone flux to the surface of 
leaf. This proposed mechanism, however, will vary from one plant to the next. Another observation of the plants' behavior is the speed with which they respond to changes in levels of lighting. To evaluate this effect, the rate of change of ozone deposition velocity was calculated for the 20 minutes after discrete changes in light levels. The slope values show that the Ficus Species had the fastest response, with a slope value of $0.079 \mathrm{~m} \mathrm{~h}^{-1}$ $\min ^{-1}$, and Dieffenbachia was the slowest with a slope value of $0.01 \mathrm{~m} \mathrm{~h}^{-1} \mathrm{~min}^{-1}$.

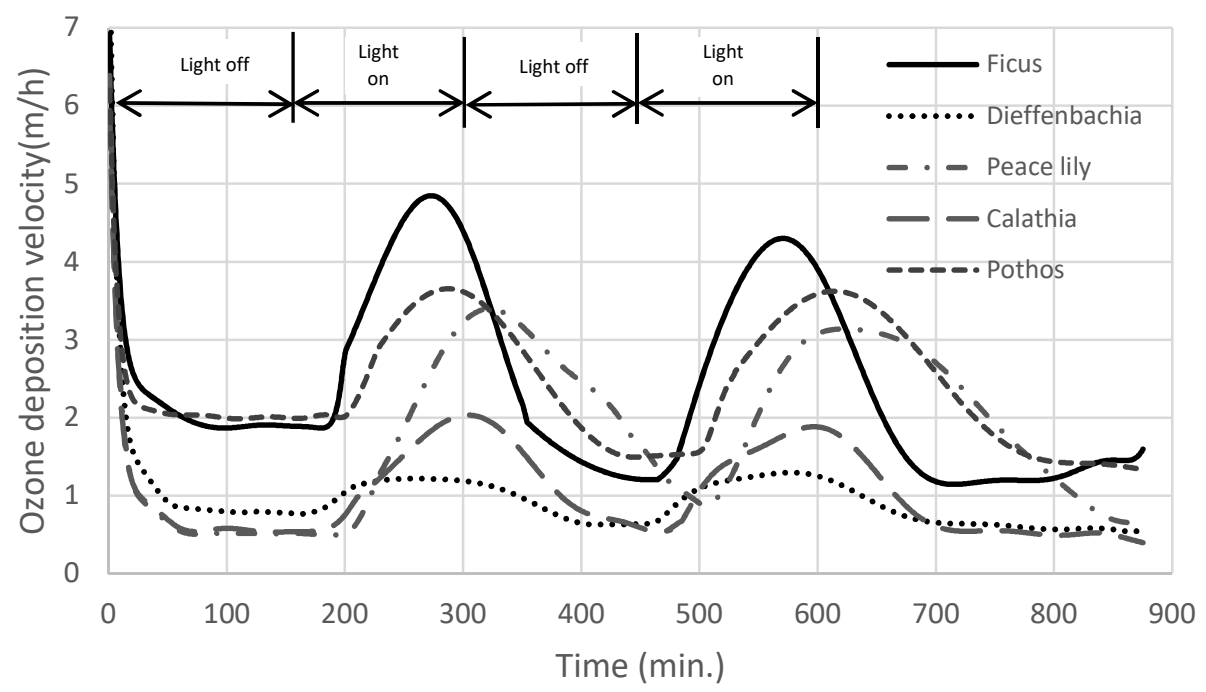

Figure 3.6 Ozone deposition velocity change of the five plants with exposure to light. Inlet ozone concentration was $60 \mathrm{ppb}$. A light with PAR value of $41.2 \mu \mathrm{mol} \mathrm{m}^{-2} \mathrm{sec}^{-1}$ was used to replicate indoor lighting conditions of a southern facing indoor environment shaded from direct insolation on a sunny day. The light was off at minute 600 and later.

\subsubsection{Ozone removal effectiveness}

The ozone removal effectiveness of indoor plants is shown in Figure 3.7, calculated as a function of the ratio of plant leaf area to volume of a hypothetical indoor environment as described in Section 3.2. Values of calculated effectiveness are determined for the range of the highest and lowest determined values of steady state 
ozone deposition velocities; the highest value being for Golden Pothos for the first exposure to ozone $\left(5.61 \mathrm{~m} \mathrm{~h}^{-1}\right)$ and the lowest value being for Ficus Species for the third exposure $\left(0.51 \mathrm{~m} \mathrm{~h}^{-1}\right)$. The values of effectiveness of other plants will be within the zone between the two lines. Note that the selection of this range of values was chosen to be illustrative; several plants exhibited higher $v_{d}$ than $5.6 \mathrm{~m} \mathrm{~h}^{-1}$ during early portions of their first exposure to elevated ozone which would result in higher values of effectiveness for those time periods. However, experiments summarized by Figures 3.4 and 3.5 show uniformly lower $v_{d}$ during second and third exposures to elevated ozone across all tested plants. Therefore, since $5.6 \mathrm{~m} \mathrm{~h}^{-1}$ represented the highest near steady-state $v_{d}$ across the five studied plants, it was deemed a reasonable upper-limit for this effectiveness screening analysis. Calculated values of effectiveness are shown in Figure 3.7 for ranges of plant leaf area to room volume ratio of $0.01-0.1 \mathrm{~m}^{-1}$; a similar calculation across a larger (less realistic) range of leaf area to volume ratios is provided in Figure 3.9 of the Supporting Information. Figure 3.7 also shows that ozone removal effectiveness will be in the range of $0.1-2 \%$ across the plants studied here for a $0.01 \mathrm{~m}^{-1}$ leaf surface area to volume ratio, and between $2-15 \%$ for a $0.1 \mathrm{~m}^{-1}$ leaf surface area to volume ratio. 


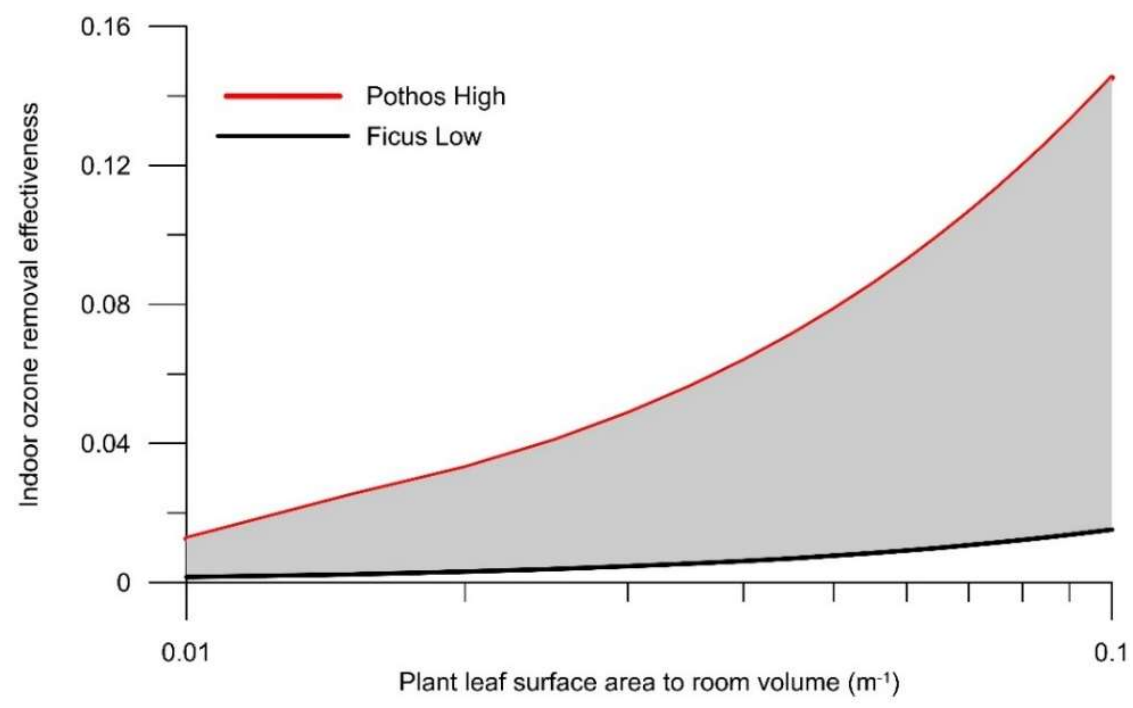

Figure 3.7 Effectiveness of ozone removal versus the ratio of plant leaf area to space volume. The upper line shows the calculated value based on maximum steady state ozone deposition velocity of Golden Pothos with value of $5.61 \mathrm{~m} \mathrm{~h}^{-1}$, and the lower line is calculated based on the lower value of ozone deposition velocity of Peace lily with value of $0.52 \mathrm{~m} \mathrm{~h}^{-1}$.

The number of plants necessary to provide a given leaf surface area is dependent on the size of the plant; Papinchak et al. (2009) report that five Golden Pothos plants provided $\sim 13,000 \mathrm{~cm}^{2}$ of leaf surface area, or $2,600 \mathrm{~cm}^{2} /$ plant. Using this leaf area per plant to provide an illustrative example, the range reported here $\left(0.01 \mathrm{~m}^{-1}-0.1 \mathrm{~m}^{-1}\right.$ in a $60 \mathrm{~m}^{3}$ room) would be achieved by placing from 2 to 23 plants in the room. It is worth noting that different plants will have varying leaf surface areas provided per plant. The data presented in Figure 3.7 can also be interpreted based on the floor area density necessary to achieve a given effectiveness. For example, achieving a leaf surface area to volume ratio of $0.06 \mathrm{~m}^{-1}$ would require, assuming a ceiling height of $2.5 \mathrm{~m}$ and the previously determined leaf area of $2,600 \mathrm{~cm}^{2} /$ plant, one plant per $1.8 \mathrm{~m}^{2}$ of floor area. This leaf surface area would result in ozone removal effectiveness from $0.9-9 \%$ across the range of low to high values of near steady-state $v_{d}$. 
The range of ozone removal effectiveness values associated with plant leaf area in the range of $0.01-0.1 \mathrm{~m}^{-1}$ are modest in the context of indoor air cleaning applications, generally because the feasible amount of plant surface area is small in comparison with the total volume of an indoor space. However, it is possible that, if no harmful byproducts are formed as a result of ozone removal by plants, such modest contributions to indoor ozone removal may complement other indoor ozone control strategies.

\subsection{Conclusions}

In this research, five different popular indoor plants have been tested for their ability to passively remove indoor ozone. Also, the effect of indoor lighting on ozone removal of plants was investigated. The indoor plants tested had moderate ozone deposition velocity values ranging from about $0.5-5.5 \mathrm{~m} / \mathrm{h}$ depending on period of time exposed to ozone, and number of exposures to ozone. Also, the results show that the ozone deposition velocity may increase substantially, between a factor of 1.7 for Dieffenbachia (or an absolute increase of $0.45 \mathrm{~m} \mathrm{~h}^{-1}$ ) to a factor 4.7 (an increase of $2.7 \mathrm{~m} \mathrm{~h}^{-1}$ ) for Peace lily, by exposing plants to light levels representative of levels typically encountered in indoor environments. However, calculations of effectiveness in a hypothetical indoor environment show, at best, modest contributions of about $0.9-9 \%$ to indoor ozone removal for typical indoor loading factors of plant leaf surface area. Further research is necessary to quantify the combined effect of plant volatile organic compound emissions, ozone removal, and secondary byproducts that may result from ozone interactions with plant surfaces and/or emitted volatile organic compounds to provide further insight into the implications of indoor plants for indoor air quality. 


\section{Acknowledgments}

The authors would like to thank Wentai Luo, and Tom Bennett of Portland State University for providing useful notes in the construction of the test rig. Omed Abbass acknowledges the support of a scholarship from the Higher Committee of Education Development in Iraq (HCED). This research was supported in part by Assistance Agreement No. 83575401 awarded by the U.S. Environmental Protection Agency. It has not been formally reviewed by EPA. The views expressed in this document are solely those of the authors and do not necessarily reflect those of the Agency. EPA does not endorse any products or commercial services mentioned in this publication.

\section{References}

Abbass, O. A., Sailor, D. J., \& Gall, E. T. (2017). Effect of fiber material on ozone removal and carbonyl production from carpets. Atmospheric Environment, 148, 42-48. http://dx.doi.org/10.1016/j.atmosenv.2016.10.034

Allen, R. J., Wadden, R. A., \& Ross, E. D. (1978). Characterization of potential indoor sources of ozone. The American Industrial Hygiene Association Journal, 39(6), 466-471.

ASHRAE 2011, Ozone and Indoor Chemistry. Environmental Health Committee (EHC) Emerging Issue Report. Retrieved online on Jan. (2017) from:

https://www.ashrae.org/File\%20Library/docLib/Committees/EHC/EmergingIssues/EHC_ Emerging_Issue-OzoneandIndoorAirChemistry.pdf

Bell, M. L., Peng, R.D., Cominici, F. (2006). The exposure-response curve for ozone and risk of mortality and the adequacy of current ozone regulations. Environmental Health Perspectives 114(4): 532-536.

Beig, G., Gunthe, S., \& Jadhav, D. B. (2007). Simultaneous measurements of ozone and its precursors on a diurnal scale at a semi urban site in India. Journal of Atmospheric Chemistry, 57(3), 239-253. doi: 10.1007/s10874-007-9068-8

Blondeau, P., Iordache, V., Poupard, O., Genin, D. and Allard, F. (2005), Relationship between outdoor and indoor air quality in eight French schools. Indoor Air, 15: 2-12. doi:10.1111/j.1600-0668.2004. 00263.x 
Brauer, M., \& Brook, J. R. (1997). Ozone personal exposures and health effects for selected groups residing in the Fraser Valley. Atmospheric Environment, 31(14), 21132121. http://dx.doi.org/10.1016/S1352-2310(96)00129-X

Calfapietra, C., Morani, A., Sgrigna, G., Di Giovanni, S., Muzzini, V., Pallozzi, E., ... \& Fares, S. (2016). Removal of ozone by urban and peri-urban forests: Evidence from laboratory, field, and modeling approaches. Journal of environmental quality, 45(1), 224233. doi:10.2134/jeq2015.01.0061

Coleman BK, Destaillats H, Hodgson AT, Nazaroff WW, (2008). Ozone consumption and volatile byproduct formation from surface reactions with aircraft cabin materials and clothing fabrics. Atmospheric Environment 42, 642-654.

http://dx.doi.org/10.1016/j.atmosenv.2007.10.001

Cros CJ, Morrison GC, Siegel JA, Corsi RL, (2012). Long-term performance of passive materials for removal of ozone from indoor air. Indoor Air 22 (1), 43-53. doi: 10.1111/j.1600-0668.2011. 00734.x

EPA, 2015. NAAQS Table. An online content from U.S. Environmental Protection Agency website. Retrieved online on Dec. (2016) from: https://www.epa.gov/criteria-airpollutants/naaqs-table

Fares, S., Goldstein, A., \& Loreto, F. (2010). Determinants of ozone fluxes and metrics for ozone risk assessment in plants. Journal of Experimental Botany, 61(3), 629-633.

Gall ET, Corsi RL, Siegel JA, (2011). Barriers and opportunities for passive removal of indoor ozone. Atmospheric Environment 45 (19), 3338-3341. http://dx.doi.org/10.1016/j.atmosenv.2011.03.032

Grøntoft T, Raychaudhuri M, (2004). Compilation of tables of surface deposition velocities for $\mathrm{O}_{3}, \mathrm{NO} 2$ and $\mathrm{SO} 2$ to a range of indoor surfaces. Atmospheric Environment $38,533-544$.

Hill, A. C. (1971). Vegetation: a sink for atmospheric pollutants. Journal of the Air Pollution Control Association, 21(6), 341-346.

Kim, K.J., Jeong, M.I., Lee, D.W., Song, J.S., Kim, H.D., Yoo, E.H., Jeong, S.J., Han, S.W., Kays, S.J., Lim, Y.-W., Kim, H.-H., (2010). Variation in formaldehyde removal efficiency among indoor plant species. Hort Science 45, 1489- 1495.

Klepeis, N. E., Nelson, W. C., Ott, W. R., Robinson, J. P., Tsang, A. M., Switzer, P., ... \& Engelmann, W. H. (2001). The National Human Activity Pattern Survey (NHAPS): a resource for assessing exposure to environmental pollutants. Journal of Exposure Science and Environmental Epidemiology, 11(3), 231.

Kozlowski, T. T. (1980). Responses of shade trees to pollution. Journal of Arboriculture, 6(2) 29-40. 
Kerstiens, G., \& Lendzian, K. J. (1989). Interactions between ozone and plant cuticles. New Phytologist, 112(1), 21-27.

Kunkel, D. A., Gall, E. T., Siegel, J. A., Novoselac, A., Morrison, G. C., \& Corsi, R. L. (2010). Passive reduction of human exposure to indoor ozone. Building and Environment, 45(2), 445-452.

Lippmann, M. (1989). Health effects of ozone a critical review. Journal of the Air Pollution Control Association, 39(5), 672-695.

Lambers, H., Chapin III, F. S., \& Pons, T. L. (2008). Photosynthesis. In Plant physiological ecology (pp. 11-99). Springer New York.

Lee, K., Vallarino, J., Dumyahn, T., Ozkaynak, H., Spengler, J.D., (1999). Ozone decay rates in residences. Journal of the Air and Waste Management Association 49 (10), 12381244.

Nicolas M, Ramalho O, Maupetit F, (2007). Reactions between ozone and building products: Impact on primary and secondary emissions, Atmospheric Environment, 41 (15), 3129-3138.

Orwell, R.L., Wood, R.L., Tarran, J., Torpy, F., Burchett, M.D., (2004). Removal of benzene by the indoor plant/substrate microcosm and implications for air quality. Water. Air. Soil Pollut. 157, 193-207. doi:10.1023/B: WATE.0000038896.55713.5b

Papinchak, H. L., Holcomb, E. J., Best, T. O., \& Decoteau, D. R. (2009). Effectiveness of houseplants in reducing the indoor air pollutant ozone. HortTechnology, 19(2), 286-290.

Poppendieck D, Hubbard H, Ward M, Weschler C, Corsi RL, (2007). Ozone reactions with indoor materials during building disinfection. Atmospheric Environment 41 (15), 3166-3176. http://dx.doi.org/10.1016/j.atmosenv.2006.06.060

Rim, D., Gall, E. T., Maddalena, R. L., \& Nazaroff, W. W. (2016). Ozone reaction with interior building materials: Influence of diurnal ozone variation, temperature and humidity. Atmospheric Environment, 125, 15-23.

Russell, J.A., Hu, Y., Chau, L., Pauliushchyk, M., Anastopoulos, I., Anandan, S., Waring, M.S. (2014). Indoor-biofilter growth and exposure to airborne chemicals drive similar changes in plant root bacterial communities. Applied Environmental Microbiology, 80(16): 4805-4813.

Szinyei, D. (2014). Modelling and evaluation of ozone dry deposition (Doctoral dissertation, Freie Universität Berlin).

Weschler C, Hodgson, AT, Wooley, JD, (1992). Indoor chemistry: Ozone, Volatile Organic Compounds, and Carpets. Environmental Science and Technology, 26 23712377. doi:10.1021/es00036a006 
Wisthaler A, Weschler CJ, (2010). Reactions of ozone with human skin lipids: sources of carbonyls, dicarbonyls, and hydroxycarbonyls in indoor air. Proceedings of the National Academy of Sciences of the United States of America 107 (15), 6568-6575. doi: 10.1073/pnas.0904498106

Wolverton, B. Johnson, A. Bounds, K. (1989). “Interior Landscape Plants for Indoor Air Pollution Abatement". Final report. National Aeronautics and Space Administration. Report number: NASA -TM-101768.

Wood R.A., Burchett M.D., Alquezar R., Orwell R.L., Tarran J., Torpy F. (2006). The potted-plant microcosm substantially reduces indoor air VOC pollution: I. Office fieldstudy. Water Air Soil Pollution 175:163-180. doi: 10.1007/s11270-006-9124-Z

Yamamoto, N., Shendell, D. G., Winer, A. M., \& Zhang, J. (2010). Residential air exchange rates in three major US metropolitan areas: results from the Relationship Among Indoor, Outdoor, and Personal Air Study 1999-2001. Indoor Air, 20(1), 85-90. doi: 10.1111/j.1600-0668.2009.00622.x 


\section{Supporting Information for Chapter 3:}

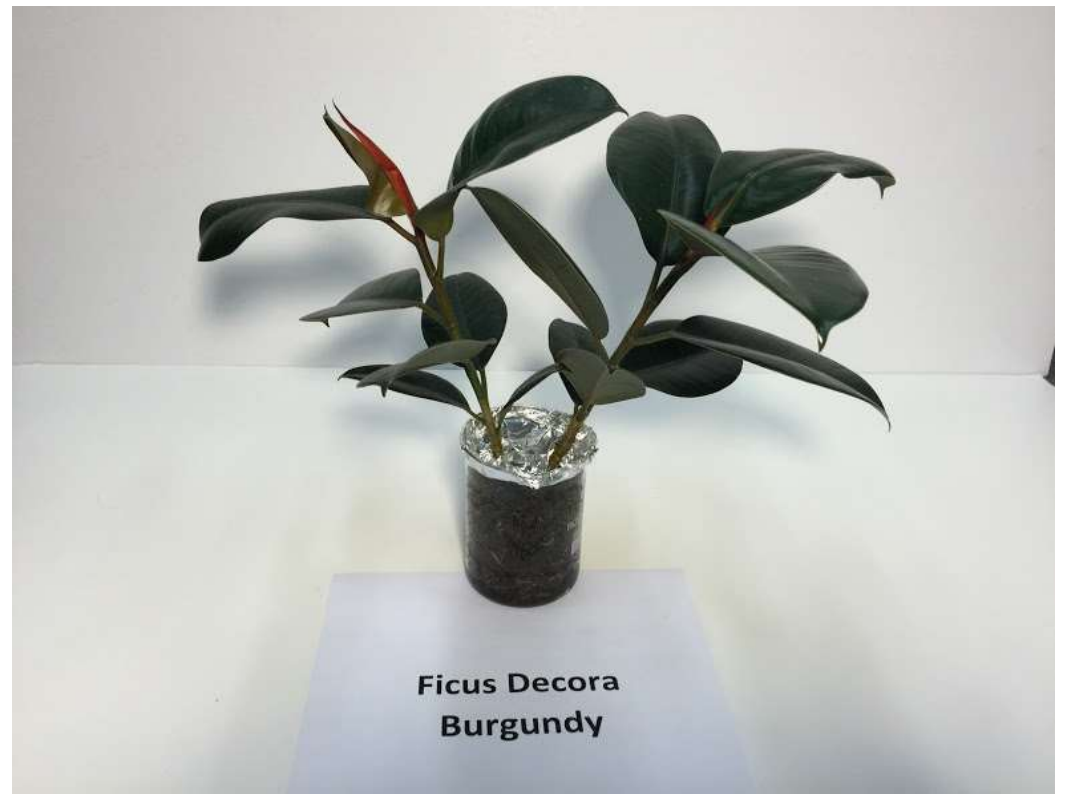

Figure 3.8. A photo shows a sample of the plants used in tests, and the glass beaker used as ozone resistant container.

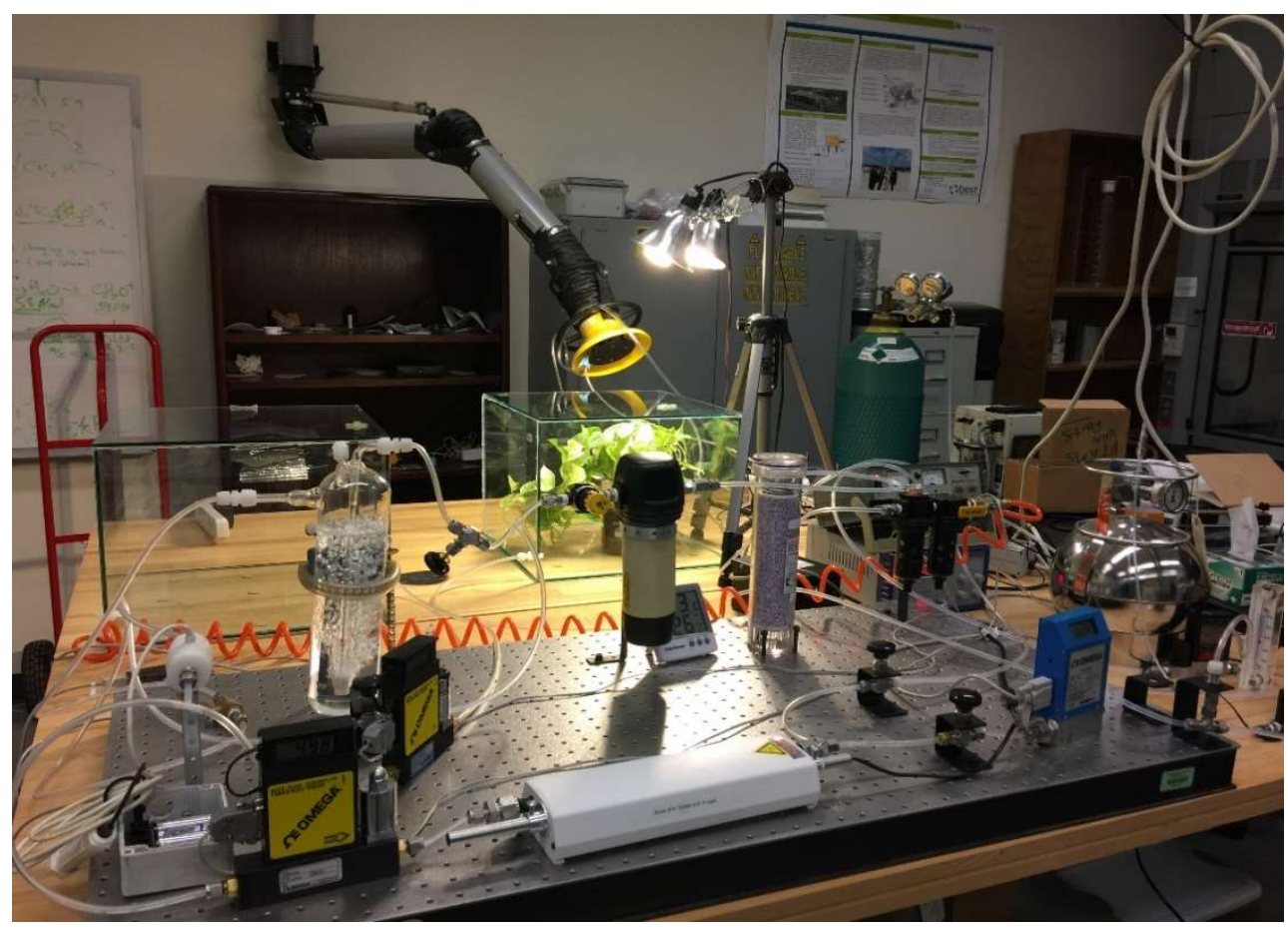

Figure 3.9. A photo shows the experimental apparatus for ozone removal tests 


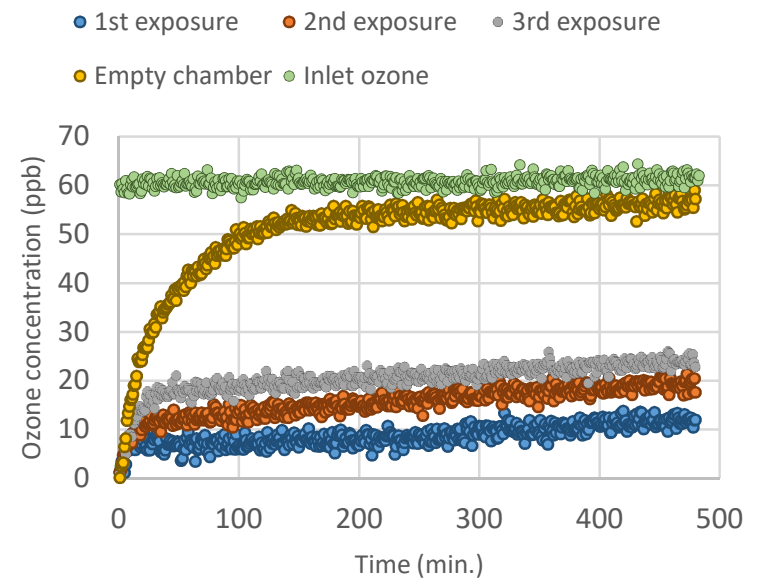

a- Golden Pothos

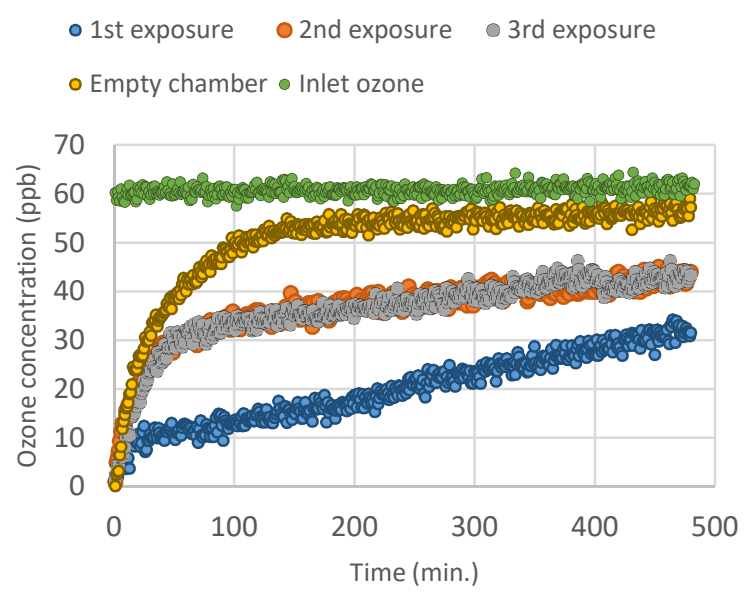

c- Calathia

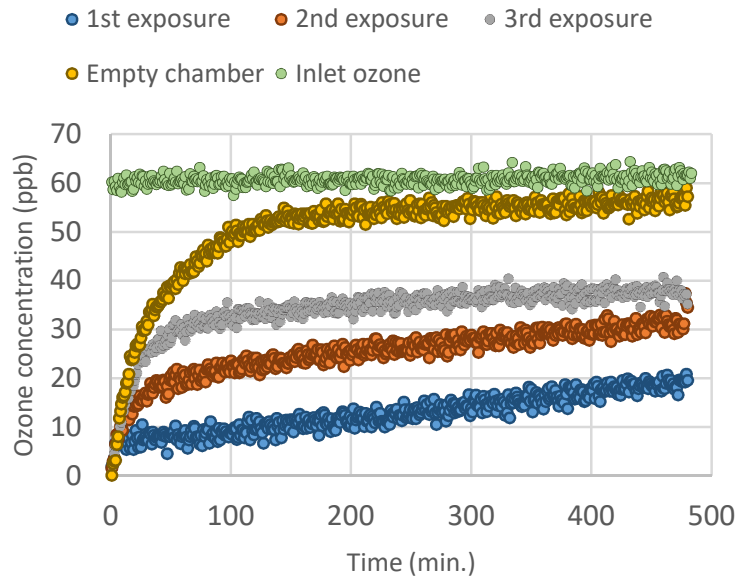

b- Dieffenbachia

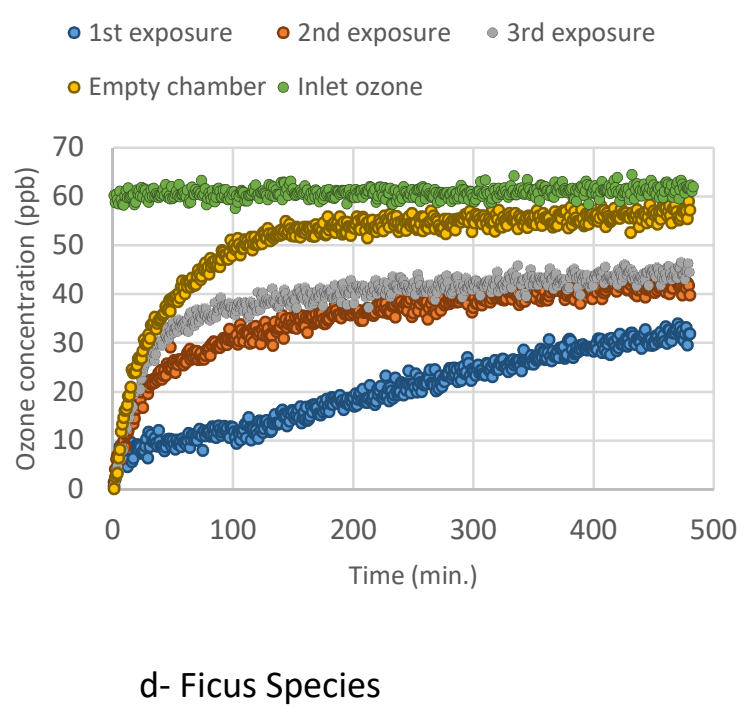

Figure 3.10. Change of ozone concentration with time. The figures show the exit ozone concentrations of inlet, empty chamber, and three exposures of the plants used in this study. 


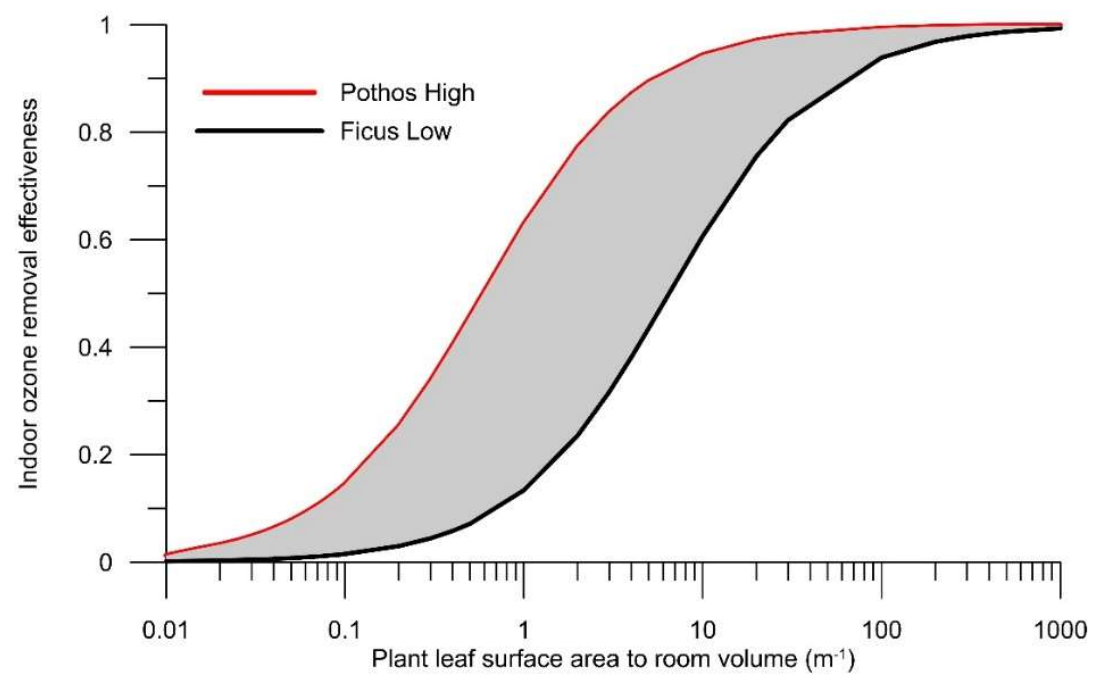

Figure 3.11. Effectiveness of ozone removal versus the ratio of plant leaf area to space volume. The upper line shows the calculated value based on maximum steady state ozone deposition velocity of Pothos with value of $5.61 \mathrm{mh}^{-1}$, and the lower line is calculated based on the lower value of ozone deposition velocity of Ficus with value of $0.51 \mathrm{mh}^{-1}$. 


\section{Chapter 4}

\section{Paper 3: Ozone removal efficiency and surface analysis of green and white roof HVAC filters}

Omed A. Abbass, David J. Sailor, and Elliott T. Gall

In preparation for submission to Building and Environment

\section{Abstract}

In this study, ozone removal efficiency was experimentally calculated from three commercial building heating, ventilation, and air-conditioning (HVAC) system filters. Filters were taken from rooftop HVAC systems installed for two months on a white membrane and vegetated green roof of a commercial building. One new, unused filter sample was tested as a reference. Samples from these filters were installed in a PTFE holder and exposed to ozonated air streams at 40 and $120 \mathrm{ppb}$ and relative humidity levels of $30 \%$ and $70 \%$ for each ozone concentration, with a face velocity of $1.1 \mathrm{~cm} \mathrm{~s}^{-1}$. Filter surface were analyzed with a scanning electron microscope (SEM) to observe the structure and composition of the materials loaded on each filter surfaces before and after exposing to ozone. The results show that for all samples tested, the ozone removal efficiency decreases from peak values at the starting of tests to reach steady state values at the end of tests of about $5-15 \%$ for white roof and unused filters, and about $10-25 \%$ for green roof filters. In addition, the green roof filter showed more ozone removal than white and unused filter samples. Unexpectedly, the unused filter samples had slightly higher ozone removal than the white roof filter, we hypothesize due to apparent reductions in surface roughness of fibers in the white roof filter that can be observed in SEM images. The data also show that the ozone removal percentage is higher at the 40 ppb ozone concentration than at $120 \mathrm{ppb}$. With respect to humidity, better ozone removal 
was recorded for the air supply with the higher level of humidity. SEM images show lumps of vegetation deposits on green roof filter samples appear to result in greater ozone removal efficiency of green roof filters than either white roof or unused filters.

\subsection{Introduction}

The heating, ventilation, and air-conditioning (HVAC) system is central to ensuring the comfort and health of occupants of built environments. In commercial buildings, an HVAC system modulates the temperature, relative humidity, and levels of air pollutants in the indoor space via a combination of recirculation, filtration, and mixing of indoor and outdoor ventilation air. Historically, the role of HVAC filters in a ventilation system is to trap particulate matter in the air supply system, for the protection of both occupants and downstream HVAC infrastructure. However, some research suggests that HVAC filters contribute to the removal of other air pollutants, including ozone (Zhao et. al. 2007). Ground level ozone is a contaminant that forms outdoors as a result of a photochemical reaction between nitrogen oxides (NOx), volatile organic compounds (VOCs) in the presence of sunlight (Pudasainee 2006). Ozone is an oxidant gas that has adverse effects on human health, including contributing to acute mortality (Gryparis et al. 2004) and lung function disorders (Lippmann 1989). The US EPA National Ambient Air Quality Standard for ozone is $70 \mathrm{ppb}$ averaged for eight hours. (EPA 2015). However, much higher levels, in exceedance of 100ppb, especially in summer, are observed in many cities (Davis and Speckman 1999, Taha and Sailor 2010, Shao et. al 2009).

Outdoor ozone is transported indoors through the ventilation system and via infiltration across the building envelope. A fraction of ozone transferring across the 
building envelope (Stephens et al. 2011) and through the HVAC system components like ducts and filters (Morrison et al. 1998) will be consumed via reactive deposition. HVAC filters are generally made of fibers with carbon-containing compounds, which may include surface reaction sites such as carbon-carbon double bonds on which ozone chemistry can occur. However, the removal efficiency of unused filters, is generally low for filters not designed to specifically target ozone. For instance, Zhao et. al. (2007) compared ozone removal of filters made from synthetic fiberglass materials that were either unused or used in residential or commercial buildings. The tests were conducted in a stainless steel chamber with inlet ozone concentration of approximately $80 \mathrm{ppb}$ and relative humidity between 45 and $60 \%$. The results of tests show low ozone removal values of about 0 to $9 \%$ for unused filters, and values ranging between 10 and $41 \%$ for used filters. Lee and Davidson (1999) tested the ozone removal efficiency of ten commercial filters that include granular activated carbon in their composition. Tests were conducted at inlet ozone levels of $120 \mathrm{ppb}$, a $2.54 \mathrm{~m} \mathrm{~s}^{-1}$ face velocity and $50 \% \mathrm{RH}$. The test results show that effectiveness of activated carbon filters varied over a broad range, from $4.6 \%$ to $98 \%$ based on filter type. Other studies of ozone removal by activated carbon-containing filters confirm ozone removal efficiencies in this range may persist for 5-7 years (Shields et al. 1999; Weschler et. al. 1994).

While ozone removal is generally considered positive, reaction products formed as a result of ozone chemistry on filters should also be considered. For instance, Lin and Chen (2014) have studied ozone removal and carbonyl generation from HVAC filters taken from different buildings. Samples were set up in stainless steel holder and exposed to ozonated air at $60 \mathrm{ppb}$ and $60 \%$ Relative humidity at $1.64 \mathrm{~cm} \mathrm{~s}^{-1}$ face velocity. The 
results of this study show low ozone removal percentage (less than 10\%) for nonactivated carbon containing filters. For used filters, the ozone removal ranged between $10-92 \%$. Carbonyl concentrations resulting from ozone reactions with filters or material deposited on filters ranged between $2-20 \mu \mathrm{g} \mathrm{m}^{-3}$ except for the tested activated carbon filter, which was $\sim 90 \mu \mathrm{g} \mathrm{m}^{-3}$. Hyttinen et. al. (2006) conducted a study about ozone removal and VOC emissions from dusty, clean, and sooty filters taken from different buildings with different periods of time in operation. The effect of dust load, diesel soot, relative humidity and time of exposure were studied. Samples were tested in small laboratory scale with inlet ozone concentration ranged from $22-77 \mathrm{ppb}$. The results show differences in ozone removal among filter types where no ozone removal was observed from unused polyester filters, and higher ozone removal (25-30\%) with higher TVOC emissions from in soot loaded filters. From these studies, it is clear that the loading of HVAC filters impacts both ozone removal and byproduct formation, with consequences for indoor air quality.

Many commercial HVAC units are installed on rooftops of buildings. At the same time, two increasingly popular sustainable building practices relate to the nature of the rooftop surface: the construction of green roofs, and white membrane roofs. Green roofs, which also known as ecoroofs or vegetated roofs, are roofs which contain a soil layer that serves as plants growing media (Sailor 2008). It has been suggested that green roofs increase building energy-efficiency, improve storm water management, and reduce the urban heat island effect (Berardi et. al. 2014), although outcomes vary as a function of specific design criteria like extent of vegetative cover (Sailor et al. 2012). White membrane roofs are roofs covered with thin white membrane layer to increase albedo that 
contributes in reducing roof surface temperature and then increase building thermal efficiency and mitigate urban heat island (Oleson et. al. 2010). It is plausible that filters in HVAC infrastructure installed on green roofs will treat ventilation air with different levels of air pollution compared to filters installed in HVAC infrastructure installed on white membrane roofs.

The objective of this research is to investigate the ozone removal efficiency of HVAC filters installed in air handling units installed on green roof and white roofs of a commercial building and to compare that to a new, unused filter. Furthermore, we apply scanning electron microscopy (SEM) imaging and chemical analysis to understand the surface deposit composition of new and used filters. This investigation will elucidate the nature of fouling of HVAC filters and consequent implications for ozone removal and byproduct formation as it relates to rooftop type. The results will be important to understand the role of green and white roofs in accumulation of deposits on HVAC filter surfaces, and their effect on ozone removal.

\subsection{Methodology}

\subsubsection{Materials:}

In this research, three identical HVAC filters (Purolator, CLARCOR Air Filtration Products, Inc.) with dimensions of 24"x24”x2" (609mmx609mmx50mm) with high capacity MERV 8 rating were used in tests. Filters were made of a mixture of polyester and polyolefin fabric as confirmed by the manufacturer. Two filters were taken from air handling units situated in green roof and white roof sections of a commercial building in Portland Oregon USA. Each filter had been installed and in service in its 
respective HVAC infrastructure on the rooftop for a period of two months (SeptemberOctober, 2015). The test field site is further described in Section 2.2. A new, unused filter was also tested to both evaluate ozone removal to unused filters and to provide a reference for comparison of SEM images and ozone removal to used filters. All filters were sampled from the field, wrapped with aluminum foil and stored in the original packaging in a controlled laboratory environment until they were tested for ozone removal, SEM imaging, and chemical composition.

\subsubsection{Field site}

Figures 4.11, and 4.12 in supporting document show images, and plan view for the site depicting both green and white membrane roofs. The roof of the building includes three extensive green roof sections with total area of $3600 \mathrm{~m}^{2}$ adjacent to a white membrane roof with area of $5486 \mathrm{~m}^{2}$. The green roof surface was covered with a vegetation layer composed of a mixture of succulents including several species in the Sedum genus. The other section of the roof is covered with a conventional, waterproof white membrane.One air-handling unit is located on each roof from which air filters were sampled. The green roof AHU is located at the center of green roof. The white membrane roof is located to lower center of white membrane roof as shown in figure 4.11 in supporting information section.

\subsubsection{Experimental Apparatus}

A diagram for the experimental test system is depicted in Figure 1. The system includes an air supply system that purifies and conditions air to a desired humidity level. Purifying filters and drying media (Indicating Drierite, W.A. Hammond Drierite Co. Ltd.) were used before an activated carbon filter to ensure air purity and to remove VOCs 
present in supply air. A glass impinger filled with distilled water and by-pass valve was used to control the relative humidity of the supply air. A 12-bit combined sensor (Onset HOBO, S-THB-M008) was used to monitor and record temperature and relative humidity of the supplied air using a data logger (Onset HOBO, H21-002). A mass flow controller (OMEGA, model FMA 5523) was used to regulate the flow rate of air entering a stable UV ozone generator (UVP, model SOG-2). The ozonated air then was fed to a customfabricated two-piece filter holder made of PTFE (see Figure 4.13 of the Supporting Information). Two UV portable photometric ozone analyzers (2B Technologies, model 106-L) were used to record the ozone concentrations in one-minute interval upstream and downstream the chamber with a stated accuracy of $2 \%$ of the reading. All tubing, connections, and valves were PTFE or stainless steel to minimize their reactivity with ozone.

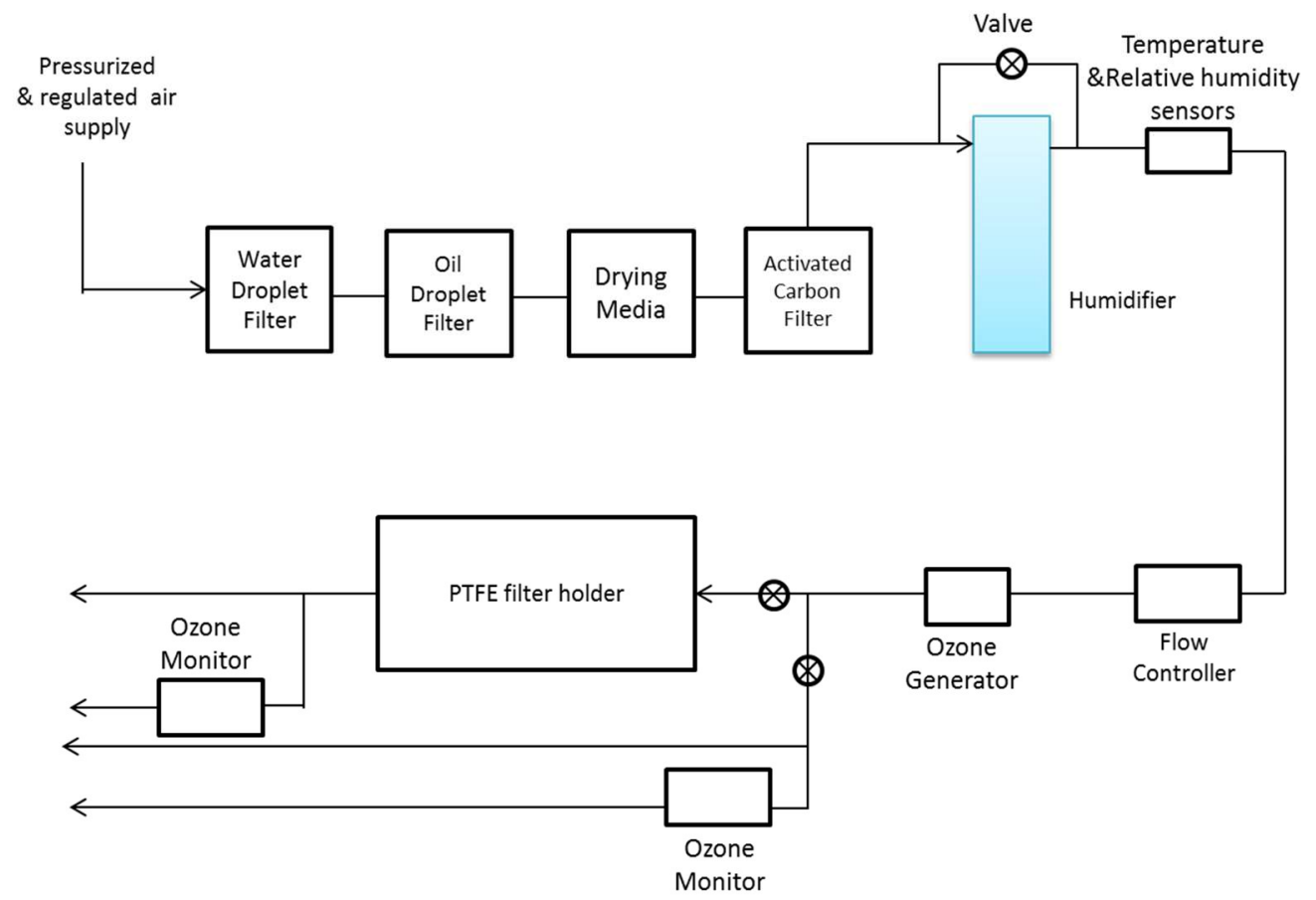

Figure 4.1. Schematic diagram of the experimental apparatus 


\subsubsection{Tests of ozone removal efficiency}

Samples of HVAC filters were taken from unused filters, and filter located in HVAC infrastructure located at top of green roofs and white membrane roofs were tested for ozone removal. Flat, circular samples of HVAC filters with diameter of $100 \mathrm{~mm}$ were cut to fit in the filter holder. To create an air-tight seal, a portion of the filter was compressed between the mating surfaces of the filter holder; the effective filter area exposed to ozone during experiments was that of a circle with dimeter $76 \mathrm{~mm}$. The filter sample was securely mounted in the filter holder using flexible Teflon gaskets.

Prior to conducting each ozone removal efficiency test, the filter holder was washed thoroughly with distilled water, dried with a heat gun, and then quenched under a $380 \mathrm{ppb}$ ozone stream for two hours. A test of ozone removal to the empty filter holder showed very small, of about $1 \%$ ozone consumption since PTFE is highly inert to ozone reactions (De Smedt et. al. 1999). Samples of air filters were tested for ozone removal efficiency under different inlet ozone and relative humidity conditions, summarized in Table 4.1. The ozone removal efficiency tests were performed by providing ozonated air at a flowrate of $3.0 \pm 0.075 \mathrm{LPM}$. This flow rate resulted in a filter face velocity of 1.1 $\mathrm{cm} \mathrm{s}^{-1}$. This value is similar to the face velocity value of $1.3 \mathrm{~cm} \mathrm{~s}^{-1}$ reported by Destaillats et. al. (2011). Two inlet ozone values, 40 and $120 \mathrm{ppb}$, with accuracy of $\pm 2 \%$ each, and two relative humidity values 30 , and $70 \%$, with accuracy of $\pm 2 \%$, were chosen as supply air conditions to cover wide range of ozone and relative humidity levels observed in other studies of ozone removal to surfaces (Lee and Davidson, 1999; Morrison et. al., 1998). The monitored values for laboratory temperature were in the range of $21 \pm 1^{\circ} \mathrm{C}$. 
Ozone removal efficiency through a filter sample is defined according to equation 4, as described by Zhao et al. (2007):

$$
E=\left(1-\frac{C_{e}}{C_{i}}\right) * 100
$$

where $\mathrm{C}_{\mathrm{e}}$ and $\mathrm{C}_{\mathrm{i}}$ are ozone concentrations (ppb) at the exit and inlet of filter, respectively. Uncertainty analysis using propagation of error was performed with inlet and outlet ozone concentrations measured with $2 \%$ accuracy each. Removal efficiencies are calculated for each test from upstream and downstream ozone concentrations recorded for a period of five hours. 
Table 4.1. Summary of experiments for testing of ozone removal to and surface composition of filter samples

\begin{tabular}{|c|c|c|c|c|c|c|}
\hline Experiment ID* & $\begin{array}{c}\text { Filter } \\
\text { sample } \\
\text { from: }\end{array}$ & $\begin{array}{c}\text { Face } \\
\text { velocity } \\
(\mathrm{cm} / \mathrm{s})\end{array}$ & $\begin{array}{c}\text { Test } \\
\text { chamber } \\
\text { temp. } \\
\left({ }^{\circ} \mathrm{C}\right)\end{array}$ & $\begin{array}{c}\text { Ozone } \\
\text { level } \\
\text { (ppb) }\end{array}$ & $\begin{array}{c}\text { Relative } \\
\text { humidity } \\
(\%)\end{array}$ & $\begin{array}{c}\text { SEM }^{\%} \\
\text { analysis }\end{array}$ \\
\hline GR_LowO3_LowRH & \multirow{5}{*}{$\begin{array}{c}\text { Green roof } \\
\text { HVAC } \\
\text { system }\end{array}$} & \multirow{4}{*}{1.1} & \multirow{4}{*}{21} & \multirow{2}{*}{40} & 30 & \\
\hline GR_LowO3_HighRH & & & & & 70 & \\
\hline GR_HighO3_LowRH & & & & \multirow{2}{*}{120} & 30 & \\
\hline GR_HighO3_HighRH & & & & & 70 & yes \\
\hline GR_NoO3 & & N/A & N/A & N/A & N/A & yes \\
\hline WM_LowO3_LowRH & \multirow{5}{*}{$\begin{array}{l}\text { White } \\
\text { membrane } \\
\text { roof HVAC } \\
\text { system }\end{array}$} & \multirow{4}{*}{1.1} & \multirow{4}{*}{21} & \multirow{2}{*}{40} & 30 & \\
\hline WM_LowO3_HighRH & & & & & 70 & \\
\hline WM_HighO3_LowRH & & & & \multirow{2}{*}{120} & 30 & \\
\hline WM_HighO3_HighRH & & & & & 70 & yes \\
\hline WM_NoO3 & & N/A & N/A & N/A & N/A & yes \\
\hline New_LowO3_LowRH & \multirow{5}{*}{$\begin{array}{l}\text { Unused } \\
\text { filter }\end{array}$} & \multirow{4}{*}{1.1} & \multirow{4}{*}{21} & \multirow{2}{*}{40} & 30 & \\
\hline New_LowO3_HighRH & & & & & 70 & \\
\hline New_HighO3_LowRH & & & & \multirow{2}{*}{120} & 30 & \\
\hline New_HighO3_HighRH & & & & & 70 & yes \\
\hline New_NoO3 & & $\mathrm{N} / \mathrm{A}$ & N/A & N/A & N/A & yes \\
\hline
\end{tabular}

*Experiment ID is the combination of the origin of the HVAC filter (ecoroof or green roof, white membrane roof, or unused filter) with low $(40 \mathrm{ppb})$ or high $(120 \mathrm{ppb})$ ozone conditions and low $(30 \%)$ or high $(70 \%) \mathrm{RH}$ condition.

\# A sample was cut from the HVAC filter of the indicated origin. A different sample was cut for each test. $\%$ SEM $=$ scanning electron microscopy. Different samples were prepared for every SEM analysis.

\subsubsection{Physical and Chemical analysis of filters}

Six filter samples were prepared for SEM analysis, as noted in Table 4.1. Three were non-ozonated filter samples, and three were samples exposed to ozone. One sample was from an unused filter, while the other two were taken from HVAC filters of roof top units (RTUs) on the green roof and the white membrane roof. Square pieces (20 $\mathrm{mm}$ by $20 \mathrm{~mm}$ ) of filter samples were cut for testing in the SEM chamber. The non-ozonated samples were also cut from collected HVAC filters, and the same process of ozone exposure described in sections 2.3 and 2.4 was repeated in preparing the ozonated samples at $120 \mathrm{ppb}$ and $70 \% \mathrm{RH}$ for subsequent SEM analysis. 
To characterize the surface composition and analysis of filter samples used in this study, simultaneous high magnification imaging and elemental analysis were performed in the Center for Electron Microscopy and Nanofabrication at Portland State University. In these analyses a variable pressure scanning electron microscope (SEM) (Zeiss, Ligma VP) with nitrogen gas chamber at $50 \mathrm{~Pa}$ was used to obtain surface images for each filter sample at $100,500,1000$, and $5000 \times$ magnifications. These images provide information about the construction and physical structure of filter fibers and deposited material on the surfaces of different filters. To characterize the elemental analysis of certain locations of filters, including filter fibers as manufactured (i.e., unused filters) as well as deposits accumulated on filter fiber surfaces, energy dispersive spectroscopy (EDS) was performed using an analyzer (Oxford Instruments, Xmax 50mm) attached to the SEM. EDS minimum detection limit is $0.1 \%$ by weight with accuracy within $\pm 2 \%$ by weight. The analysis of data was performed using Aztec V 3.1 software. This technology enables qualitative and quantitative characterization of the elements composing the materials of filter fibers and deposits. The elemental analysis was performed at two locations for each of the filter fiber and deposited materials, determined by visual analysis of the magnified samples, for every filter examined. A total of 34 unique locations were specified and analyzed for all ozonated and non-ozonated filters.

\subsection{Results and discussion}

\subsubsection{Exit ozone concentrations:}

Figure 4.2 shows inlet and outlet ozone concentrations for green roof, white membrane roof and unused filter samples at inlet ozone concentrations of 40 and $120 \mathrm{ppb}$ at $70 \%$ relative humidity. Both subfigures show that exit ozone concentrations for green 
roof filters are noticeably lower, especially at the beginning of the tests, than other filter types. Also, exit ozone concentration for unused filter sample is slightly lower than the white membrane roof filter. In addition, both unused and white membrane roof filters exit ozone concentration reach steady state value in much shorter time than the green roof samples in both 40 and $120 \mathrm{ppb}$ tests. However, for $120 \mathrm{ppb}$ test, all exit values for all filters seem to reach a tangent value of about $100 \mathrm{ppb}$ after about $150 \mathrm{~min}$. but for inlet ozone tests of $40 \mathrm{ppb}$, the difference in exit ozone concentration is still noticeable between the three filter types. Lower exit ozone values refer to more ozone reaction with both filter fiber material and deposits on filters (Bekö et. al. 2007). This reaction will consume some ozone which leads to lower concentration downstream of filters. One other possible ozone consumption mechanism is through homogeneous ozone reaction with VOC emissions from filter and deposits that may lead to have lower ozone concentration values after the filters. This reaction will depend on the amount of VOCs released that could be connected to the amount of deposits on the surface of filter. 


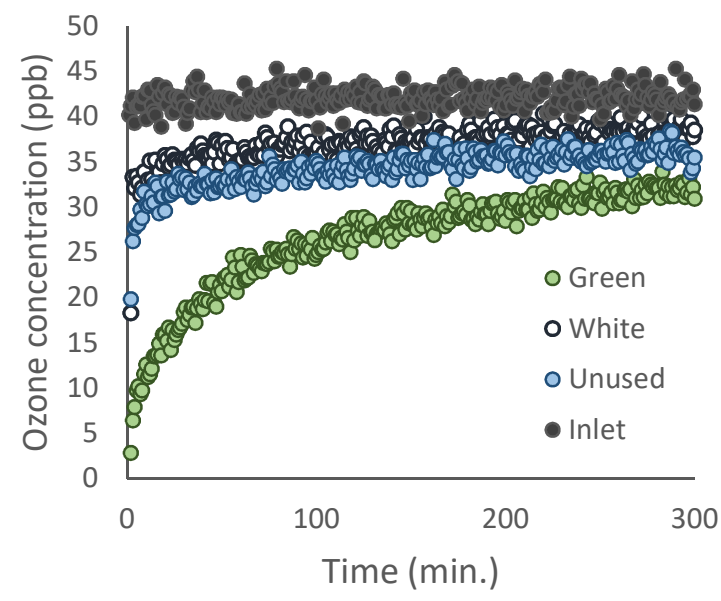

a)

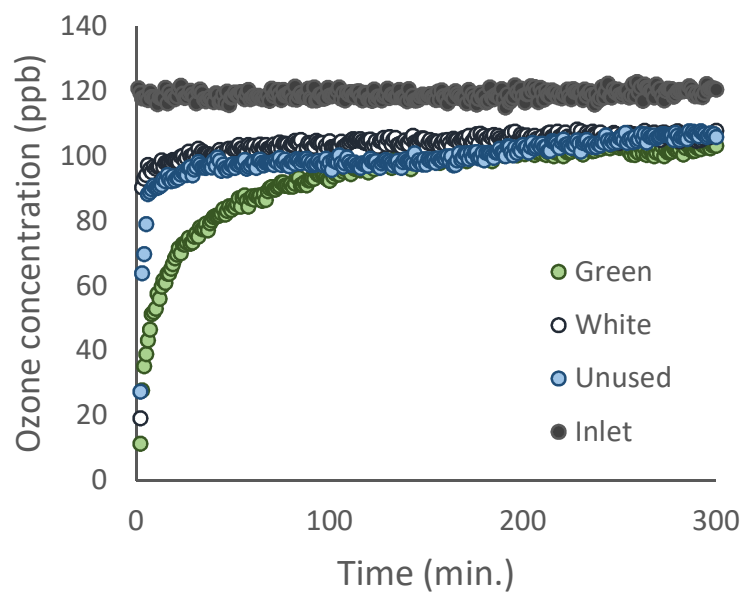

b)

Figure 4.2. Inlet and exit ozone concentrations for green, white membrane roof, and unused filter samples. a) at $40 \mathrm{ppb}$ ozone inlet. b) at $120 \mathrm{ppb}$ ozone inlet. All tests performed at $70 \% \mathrm{RH}$ inlet.

\subsubsection{Ozone removal effectiveness}

Figure 4.3 shows the ozone removal effectiveness for tests conducted at two inlet ozone values, 40 and 120ppb, and two relative humidity levels, 30 and $70 \%$. It can be seen that ozone removal effectiveness is high at beginning of tests, decaying to a steady state value of around $10 \%$ for both unused and white membrane roof filters. For green roof filter tests, ozone removal effectiveness have higher values than white membrane roof and unused filters for the first 150mins, then the curve decays as well approaching to around the same tangent value of $10 \%$ at the end of test. This decay behavior is also reported by Zhao (2007) and Hyttinen (2006) for both clean and deposit loaded filters.

Figures $4.3 \mathrm{c}$ and $4.3 \mathrm{~d}$ show ozone removal effectiveness for $40 \mathrm{ppb}$ ozone inlet tests. The figures show similar trend of higher ozone removal at the start of tests. However, higher steady state values are noticeable in comparison to $120 \mathrm{ppb}$ tests. To facilitate the 
comparison of steady state ozone removal effectiveness values, the average of last 20 min. of ozone removal efficiency of all tests were graphed together and shown in figure 4.4. The figure shows that for all cases, ozone removal efficiency at 40ppb inlet ozone is higher than the tests with $120 \mathrm{ppb}$, especially for green roof filters where difference reach up to $16 \%$. This behavior is a result of higher inlet ozone concentrations leading to more oxidation on the filter fiber. More oxidization will result a reduction in the capacity and reactivity of filter fiber and deposits to continue reaction and consume ozone, but when inlet ozone level is lower, $40 \mathrm{ppb}$, the reactivity will be higher than $120 \mathrm{ppb}$ tests since fewer reaction sites will be consumed on deposited particles and fiber filters in comparison with the $120 \mathrm{ppb}$ tests. Figure 4.5 illustrates the relative humidity effect on ozone removal effectiveness for both 40 and $120 \mathrm{ppb}$ ozone inlet and for both 30 and $70 \%$ tests. The subfigures show that the change in relative humidity has minor effect on ozone removal at $40 \mathrm{ppb}$ ozone inlet tests. However, a slight increase in ozone removal effectiveness is noticeable at $120 \mathrm{ppb}$ ozone inlet for the white membrane and unused filter tests, and much less enhancement for the green roof filter tests. Numerical values for change in steady state ozone removal effectiveness with change in relative humidity can be seen in figure 4.4. There is no statistically significant difference is seen at $40 \mathrm{ppb}$ ozone inlet as relative humidity changes, however, about $5 \%$ ozone removal increment is seen at 120ppb ozone inlet especially for white membrane roof and unused filters. 


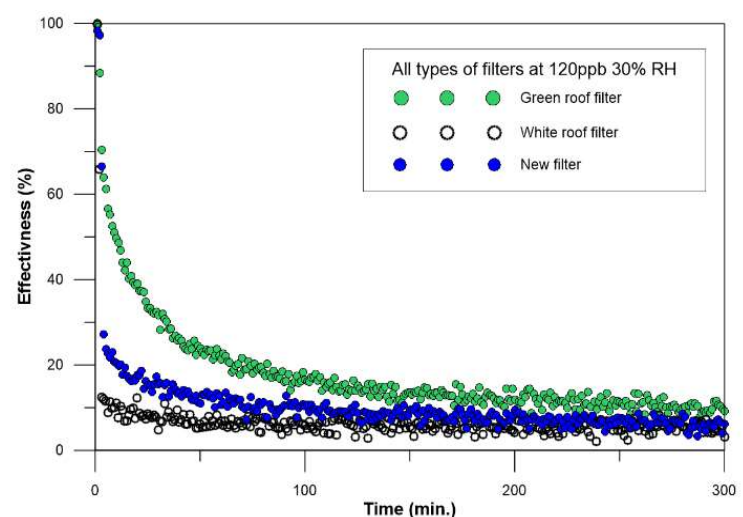

a)

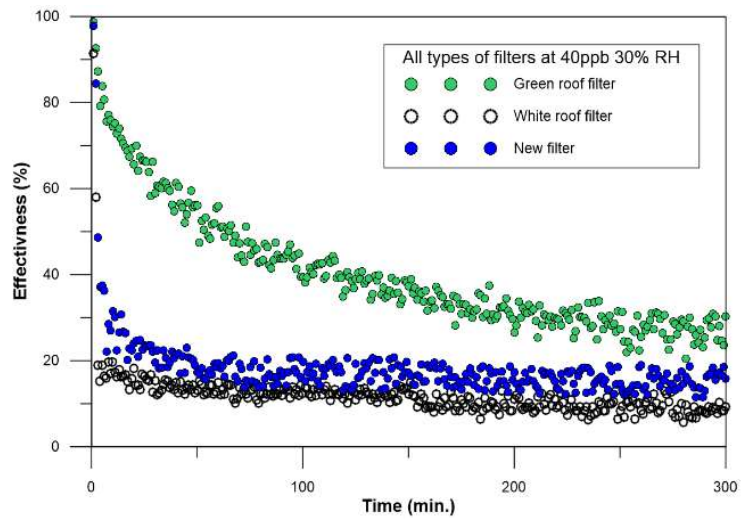

c)

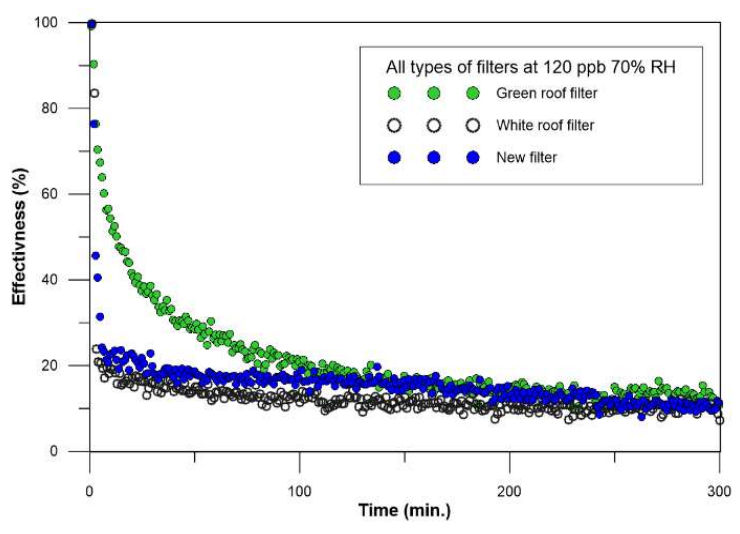

b)

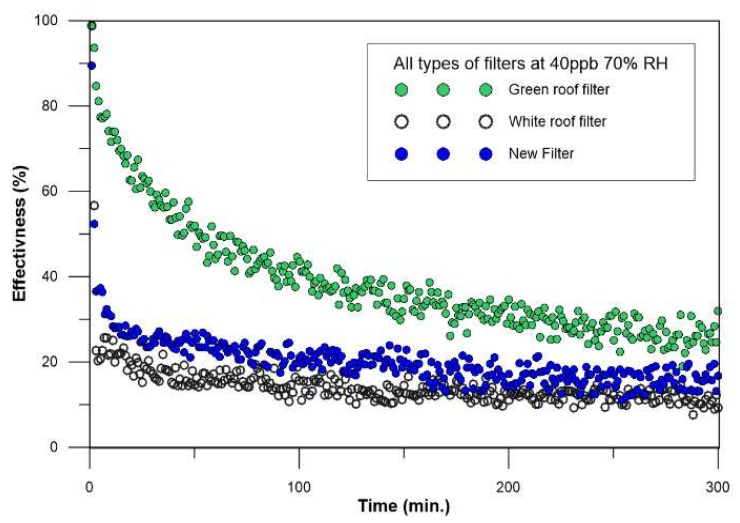

d)

Figure 4.3. Ozone removal effectiveness for green, white membrane, and unused (new) filter samples at 40,120ppb, and 30,70\% relative humidity. 


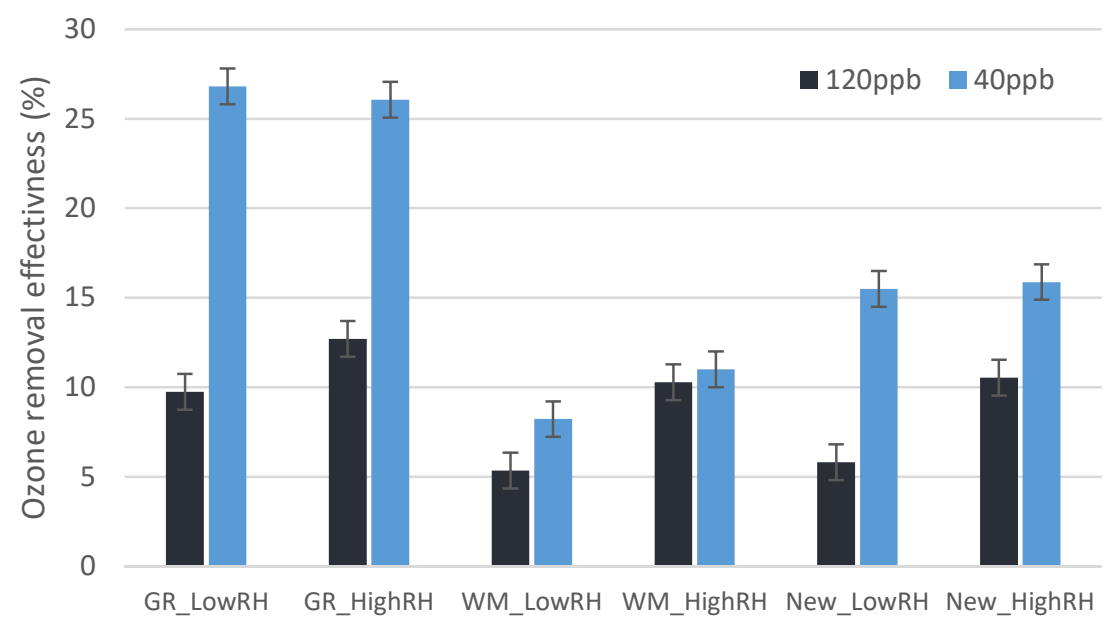

Figure 4.4. Steady state ozone removal effectiveness for green (GR), white membrane (WM) roofs, and new (unused) filters at 40, 120ppb inlet ozone. Low_RH $=30 \% \mathrm{RH}$, HighRH $=70 \%$ RH. The values are the average of last $20 \mathrm{~min}$. of each test. Error bars represent the uncertainty as determined from an error propagation using instrument uncertainties. 


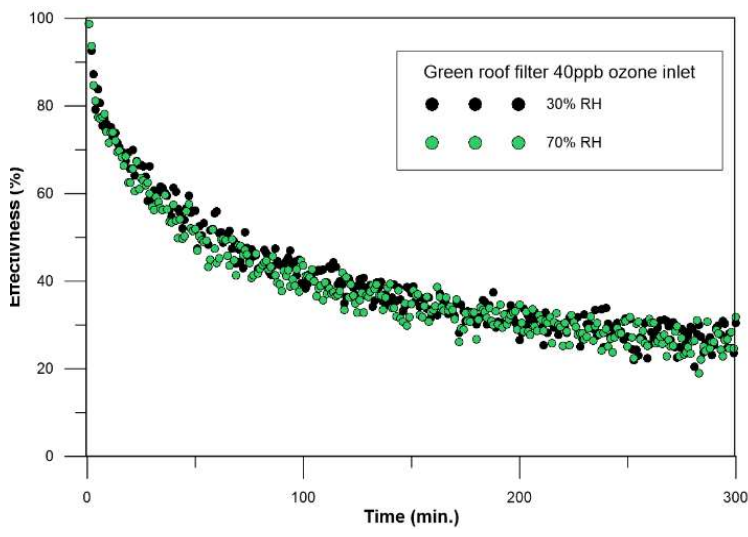

a)

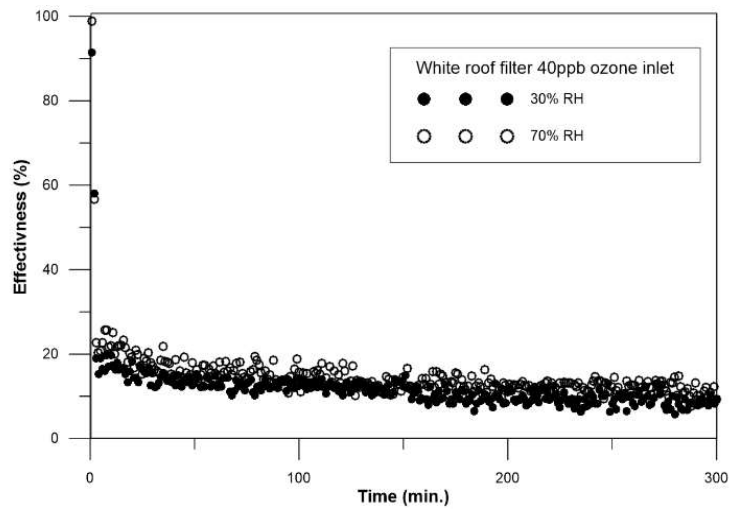

c)

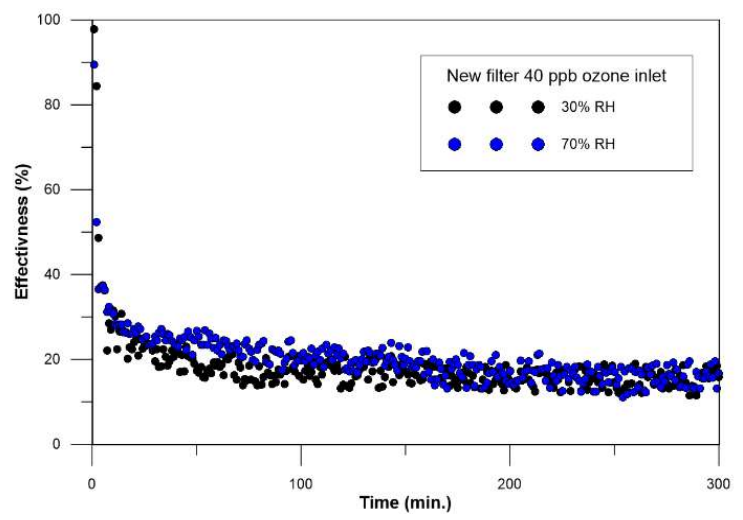

e)

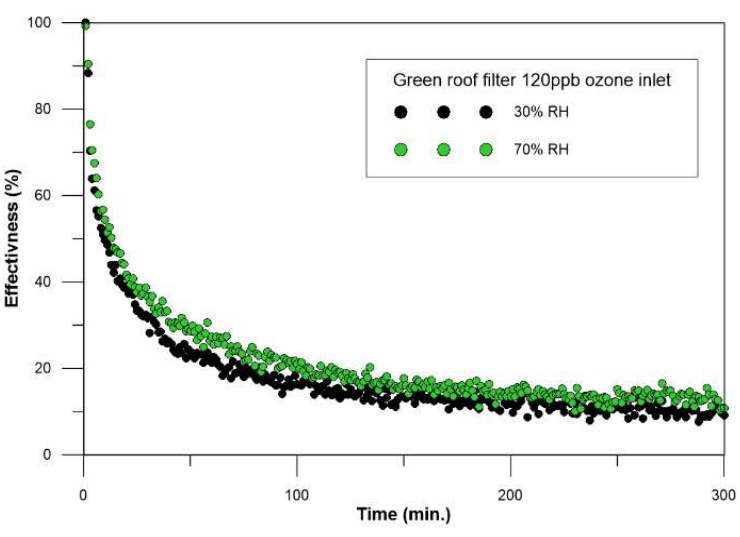

b)

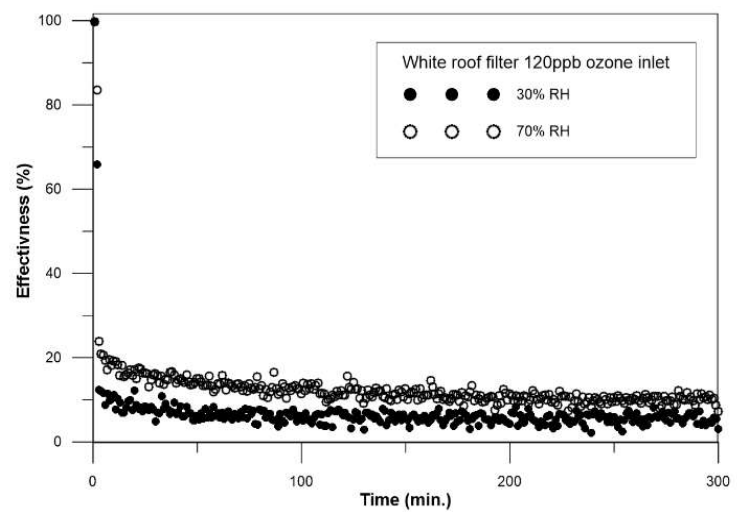

d)

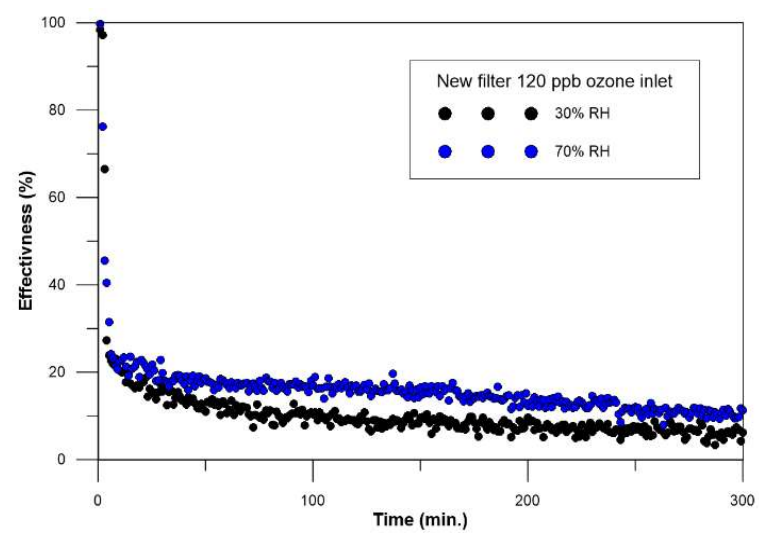

f)

Figure 4.5. Relative humidity effect on ozone removal effectiveness for green, white membrane roof, and unused filters samples at 40, 120ppb ozone inlet, and 30,70\% relative humidity. 


\subsubsection{SEM Images and surface elemental analysis}

Figure 4.6 shows SEM images for the green roof non-ozonated filter at low and high magnification. The Figure show high accumulation of deposits on filter fibers. A higher magnification at 5000x in figure $4.6 \mathrm{~b}$ show pollen within other probable lumped vegetation origin materials. This confirms that most of deposits on the green roof filter are from the vegetation layer planted on the green roof. These deposits may be the major material that ozone will react with causing high ozone removal effectiveness for green roof filters. Images of white membrane roof filter are shown in figure 4.7. It is obvious that there are much less deposits on the white membrane roof filter. However, there are still some deposits on the higher magnification image on figure $4.7 \mathrm{~b}$. Fewer deposits on this filter explains the lower ozone removal effectiveness values compared to green roof filter as ozone removal will depend mostly of the amount of particles accumulated and captured by filter fiber (Lin and Chen 2014). Figure 4.8 shows SEM images for unused filters. Figure 4.8a shows no deposits on the surface of fibers except in couple spots that could exist because of possible contamination during transportation, or sample preparation. Figure $4.8 \mathrm{~b}$ shows furry fiber surface that is not seen in white membrane roof fiber shown in figure $4.7 \mathrm{~b}$ which shows a smoother fiber surface. We hypothesize that the "furry" surface of the unused fibers have much larger real surface area than fibers collected from filters servicing the white membrane roof; this difference in surface morphology may explain the reason behind higher ozone removal effectiveness of unused filter samples in comparison with white membrane roof samples. The smoother surface observed in the fibers in filters taken from the white membrane roof could be attributed to 
extensive exposure to air movement and moisture in air stream passing through filters in air handling units as white membrane roof filter were in service for two months.

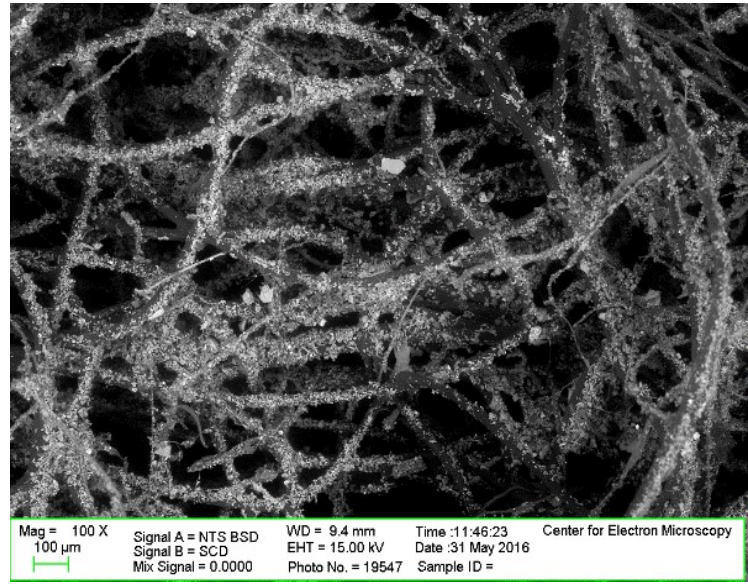

a)

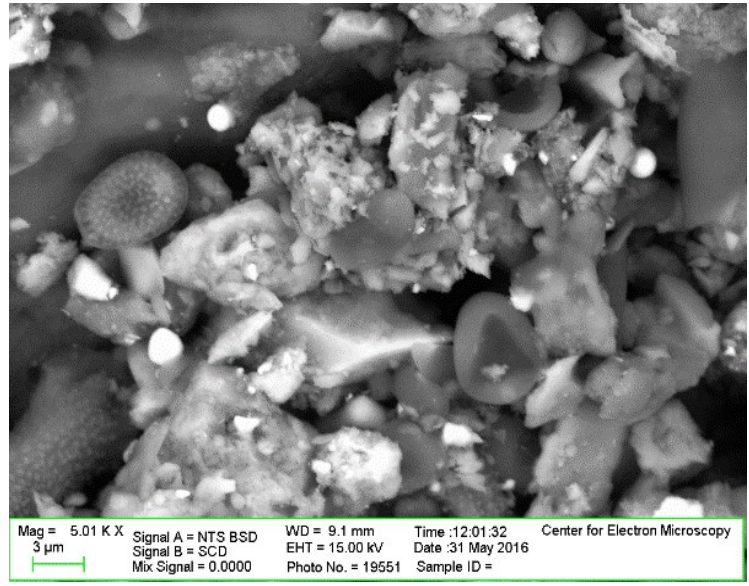

b)

Figure 4.6. SEM images for green roof filter samples non-ozonated at different magnification. a)100x. b) 5000x.

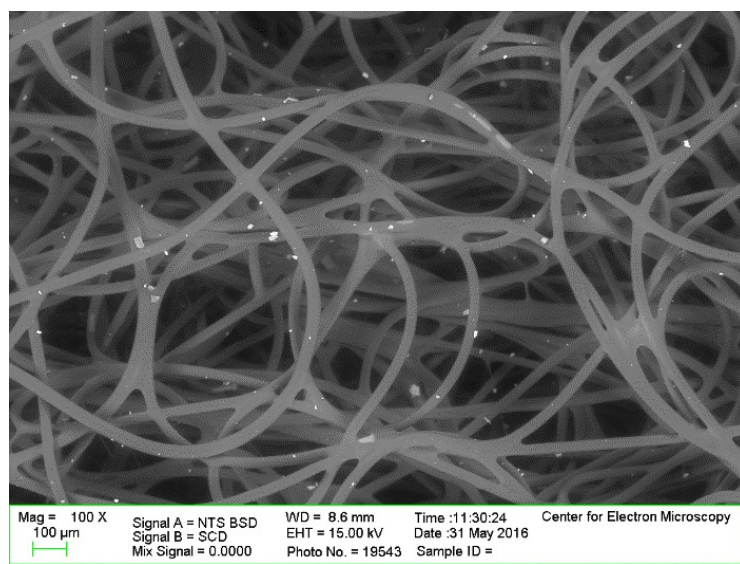

a)

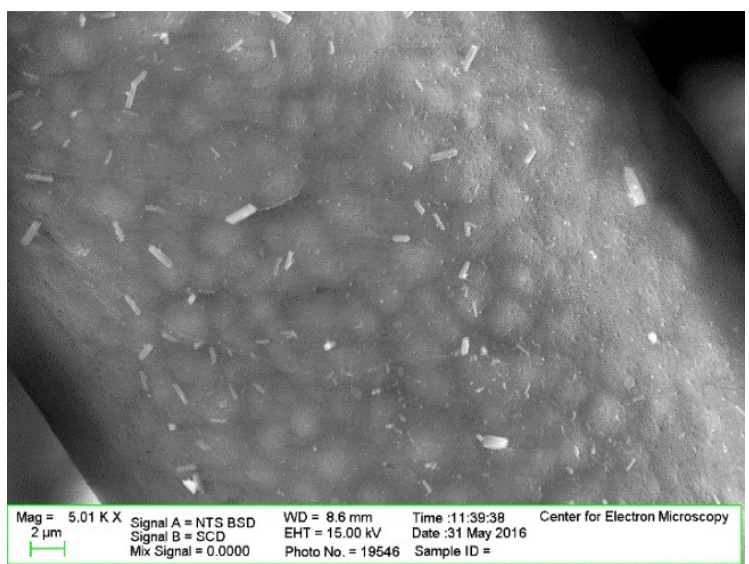

b)

Figure 4.7. SEM images for white membrane roof filter samples non-ozonated at different magnification. a)100x. b)5000x 


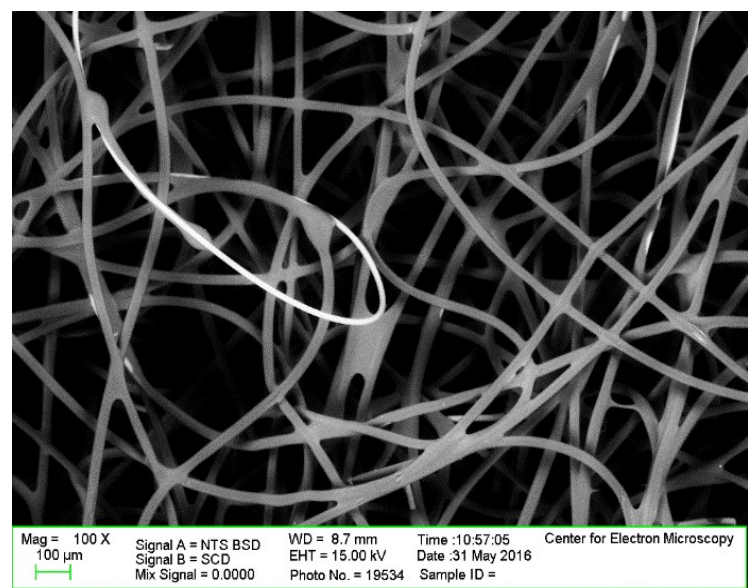

a)

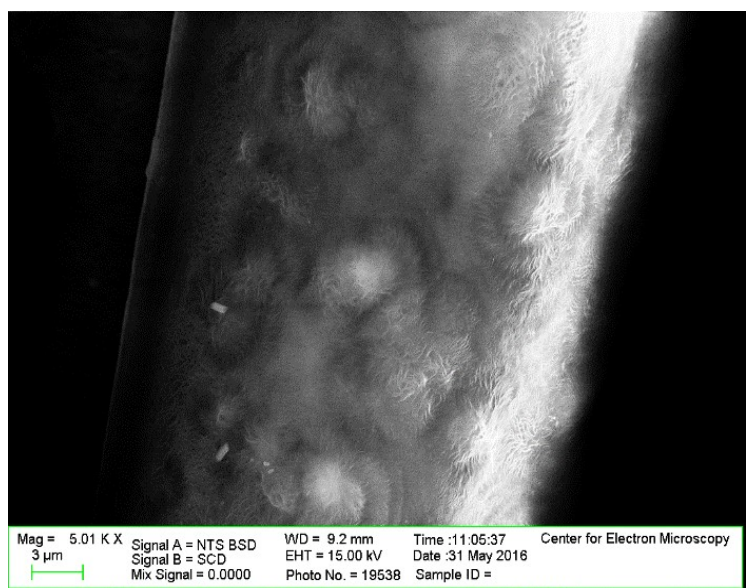

b)

Figure 4.8. SEM images for unused filter samples non-ozonated at different magnification. a)100x. b)5000x

To estimate and compare the composition of filter fibers and the deposits on fibers, an EDS elemental analysis was performed for locations on filter fibers and deposits shown in figure 4.9. The figure shows that duplicate positions, then measurements, are performed for every filter type. Figure 4.10 show samples of EDS elemental analysis graphs for one location from each filter type. The average of numerical data of results for locations of interest in every filter are listed in table 4.2. 


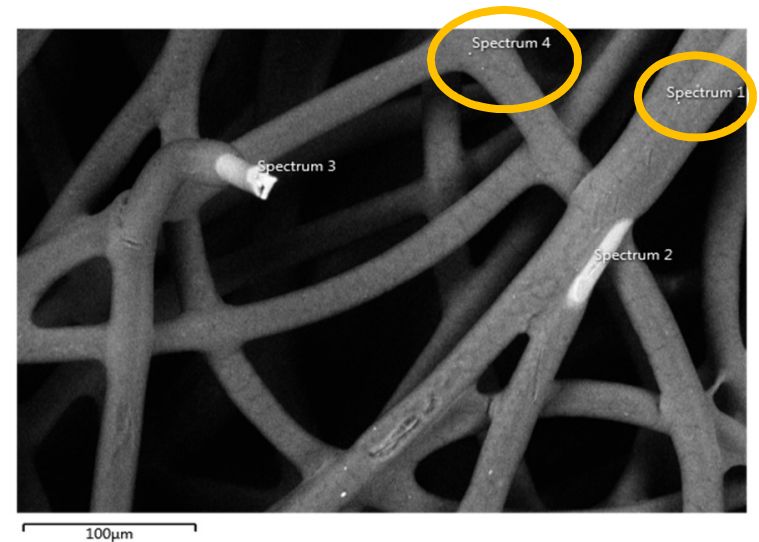

a)

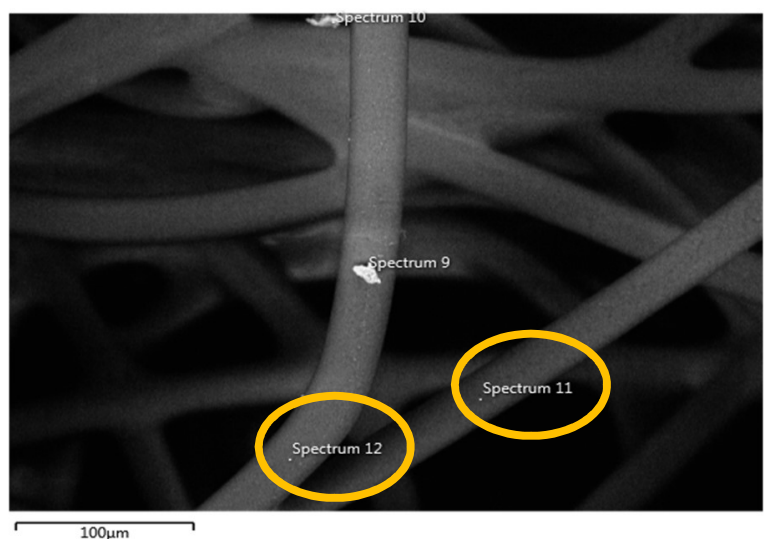

c)

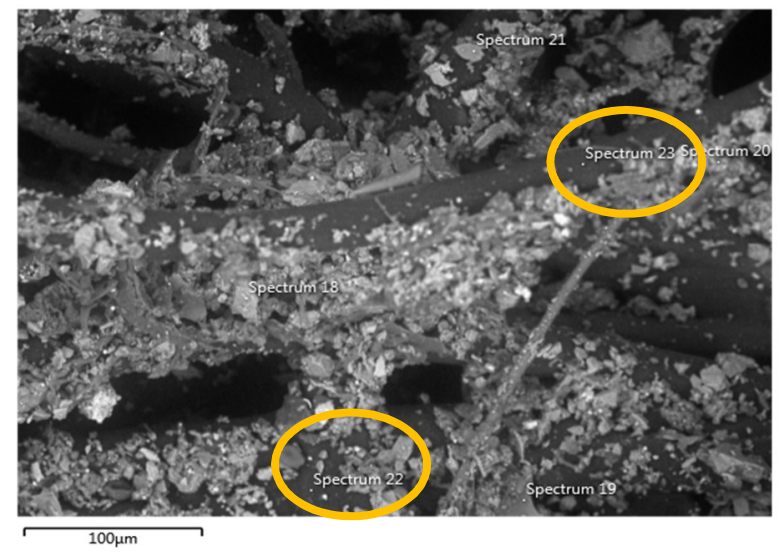

e)

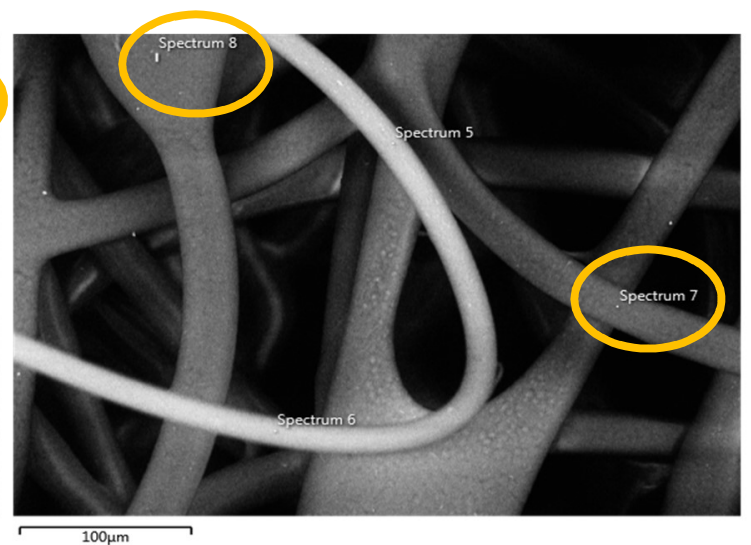

b)

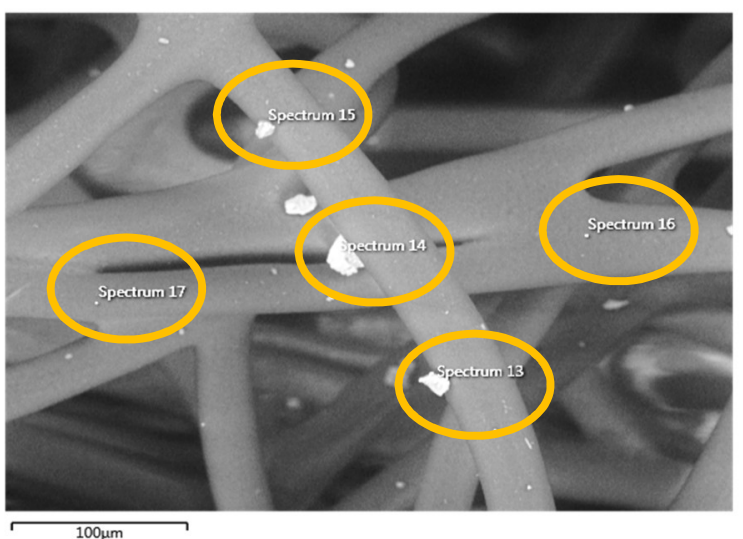

d)

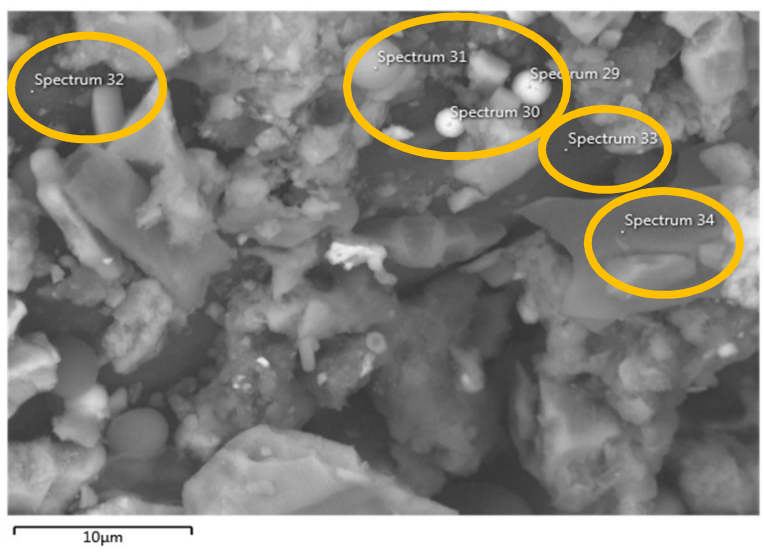

f)

Figure 4.9. SEM images show locations where elemental analysis was performed. a) Nonozonated unused filter fiber. b) Ozonated unused filter fiber. c) Non-Ozonated white membrane roof filter fiber. d) Ozonated white membrane roof filter fiber and deposits. e) Non-ozonated green roof fiber. f) Ozonated green roof fiber and deposits. 
Figure 4.10a shows the analysis of a non-ozonated unused filter fiber. It shows that carbon and oxygen are the only compounds detected in unused filter fiber. The average of duplicate measurements in table 4.2 show that carbon forms about $96 \%$, and oxygen forms the remaining $4 \%$. This result is expected as the fiber material is made of organic material comprising these two elements according to EDS method. For ozonated unused filter fiber, the data in table 4.2 show that there is still no change in composition. However, there is a slight increase in oxygen percentage by about $1 \%$. This increase could be attributed to oxidization of filter fiber material resulting from exposure to ozone. The same conclusion is also reported by Lee and Davidson (1999), who performed chemical analysis for additives to filters using X-ray photoelectron spectroscopy (XPS). They concluded that exposure to ozone will change the oxidation state of the carbon. Figure $4.10 \mathrm{~b}$ show elemental analysis of white membrane roof filter fiber. The figure and data in table 4.2 show similar composition to unused filter fiber as the elements detected are carbon and oxygen only. For ozonated white membrane roof filter fiber, no significant difference on composition is seen from the data in table 4.2. Figure 4.10c show the analysis of a fiber of non-ozonated green roof filter. The figure and data in table 4.2 show other elements present in the analysis in addition to carbon and oxygen like: silicon, iron, calcium, aluminum and other elements. These compounds are not detected on the fiber surfaces of unused and white membrane roof filters. The existence of these compounds may be attributed to heavy contamination of green filter fiber with vegetation and other origin deposits as shown in figures $4.6 \mathrm{~b}$ and $4.9 \mathrm{f}$. These data support the evidence that green roof filter fibers, in addition to deposits on the fiber, plays a major role for high ozone reactivity of green roof filter. For ozonated green roof filter fiber, data 
in table 4.2 show similar elemental composition. However, an observation that is similar to unused filter fiber is seen that there is small increase, about $1.5 \%$, in oxygen than nonozonated green roof fiber. This can be a sign of fiber oxidization because of exposure to ozone. To get information about the elemental composition of deposits on filter fibers, the average data for deposits on both ozonated white membrane and ozonated green roofs shown in figures $4.9 \mathrm{~d}$ and $4.9 \mathrm{f}$ are shown in table 4.2. The data show that in addition to carbon and oxygen, silicon and iron form the highest percentage of elements, in addition to less values of other elements, in white membrane roof deposits. Existence of these elements may help to conclude that these deposits are inorganic compounds (Hyttinen et. al. 2006) that could be originated from soil derived particles. For green roof filter deposits, the data show extensively higher oxygen, silicon and iron than deposits on white membrane roof. These differences may confirm the difference of origin of deposits on both filters. 


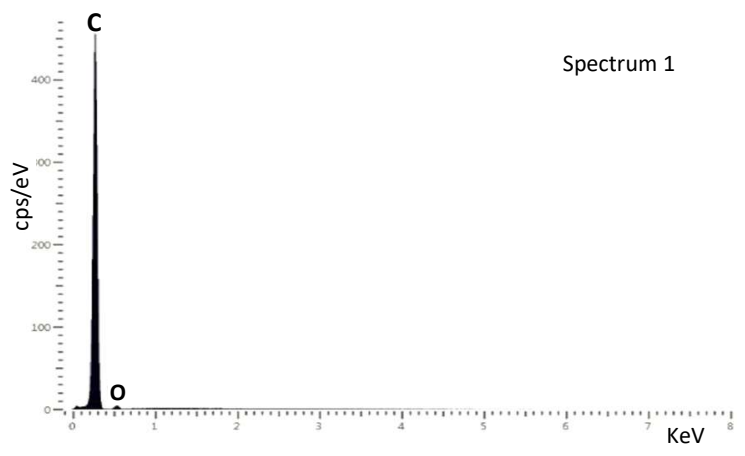

a)

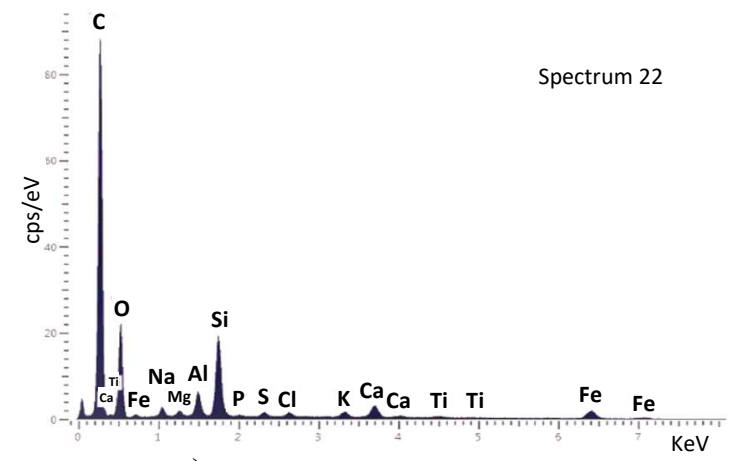

c)

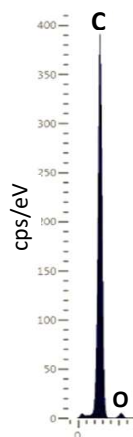

b)
Spectrum 11

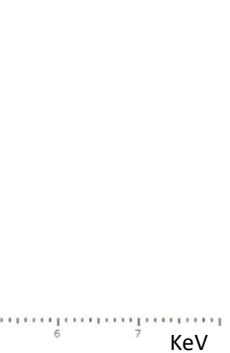

Figure 4.10. EDS elemental analysis graphs of filter fibers and deposits. a) Nonozonated unused filter fiber. b) Non-ozonated white membrane filter fiber. c) Nonozonated green roof filter fiber. Axes represent as following: $\mathrm{Cps} / \mathrm{Ev}$ : counts per second per electron-volt, keV: kilo-electron-volt. 
Table 4.2. Elemental analysis data in normalized weight percent for different filter fibers and deposits gained using EDS analyzer. The values in table are the average of two locations of interest except where stated otherwise.

\begin{tabular}{lcccccccccccccc} 
Specimen type & $\mathrm{C}$ & $\mathrm{O}$ & $\mathrm{Na}$ & $\mathrm{Mg}$ & $\mathrm{Al}$ & $\mathrm{Si}$ & $\mathrm{P}$ & $\mathrm{S}$ & $\mathrm{Cl}$ & $\mathrm{K}$ & $\mathrm{Ca}$ & $\mathrm{Ti}$ & $\mathrm{Fe}$ & Total \\
\hline \hline $\begin{array}{l}\text { Non-ozonated new } \\
\text { filter fiber }\end{array}$ & 97.86 & 2.13 & 0 & 0 & 0 & 0 & 0 & 0 & 0 & 0 & 0 & 0 & 0 & 100 \\
$\begin{array}{l}\text { Ozonated new filter } \\
\text { fiber }\end{array}$ & 96.81 & 3.15 & 0 & 0 & 0.04 & 0 & 0 & 0 & 0 & 0 & 0 & 0 & 0 & 100 \\
$\begin{array}{l}\text { Non-ozonated WM } \\
\text { roof fiber }\end{array}$ & 98.27 & 1.72 & 0 & 0 & 0 & 0 & 0 & 0 & 0 & 0 & 0 & 0 & 0 & 100 \\
$\begin{array}{l}\text { Ozonated WM roof } \\
\text { fiber }\end{array}$ & 98.39 & 1.58 & 0 & 0 & 0 & 0 & 0 & 0 & 0 & 0 & 0 & 0 & 0 & 100 \\
$\begin{array}{l}\text { Non-ozonated GR filter } \\
\text { fiber }\end{array}$ & 74.12 & 14.06 & 0.47 & 0.24 & 1.06 & 3.73 & 0.08 & 0.26 & 0.31 & 0.51 & 1.39 & 0.24 & 3.57 & 100 \\
$\begin{array}{l}\text { Ozonated GR filter } \\
\text { fiber }\end{array}$ & 69.77 & 15.66 & 0.65 & 0.32 & 1.45 & 4.77 & 0.09 & 0.29 & 0.38 & 0.61 & 1.8 & 0.23 & 3.96 & 100 \\
$\begin{array}{l}\text { Ozonated deposits on } \\
\text { WM filter\& }\end{array}$ & 88.08 & 7.16 & 0.29 & 0.06 & 0.88 & 1.98 & 0.03 & 0.01 & 0 & 0.06 & 0.25 & 0.04 & 1.16 & 100 \\
$\begin{array}{l}\text { Ozonated deposits on } \\
\text { GR filter\% }\end{array}$ & 55.30 & 19.59 & 0.73 & 0.31 & 1.99 & 7.88 & 0.12 & 0.26 & 0.35 & 0.93 & 1.64 & 0.26 & 10.47 & 100 \\
\hline
\end{tabular}

$\&$ Data represents the average of three location

$\%$ Data represents the average of four location

\subsection{Conclusions:}

In this study, ozone removal effectiveness for HVAC filters were tested in a laboratory setting. Inlet ozone concentrations of 40 and $120 \mathrm{ppb}$ with relative humidity of 30 and $70 \%$ for each ozone test were tested with a face velocity of $1.1 \mathrm{~cm} \mathrm{~s}^{-1}$. Used filters from RTUs on a vegetated green roof and a white membrane roof were tested alongside an unused control filter. The results of tests show that the green roof filter showed more ozone removal efficiency than other filters especially at the beginning of tests. Steady state ozone removal at the end of 5 hours showed ozone removal efficiency (for the 40 ppb test case) of about $26 \%$ for the green roof filter, 10 , and $15 \%$ for the white membrane and unused filters respectively. Lower ozone removal efficiencies in the range of 5 to $15 \%$ were found for the $120 \mathrm{ppb}$ inlet ozone case. Test cases with higher relative humidity 
resulted in only a modest effect on ozone removal of the green roof filter, but about a 5\% improvement for the white membrane roof and unused filters. Scanning Electron Microscope (SEM) images show large deposits on the green roof filter that led to the highest ozone reactivity. The images also show that unused filter fibers have fuzzier surfaces than white membrane filter fibers, leading mostly to more actual surface area than white roof used filter. This resulted greater ozone removal for the unused filter than for the white membrane roof filter. Elemental analysis show that the unused, and white membrane roof filter fibers are mostly composed of carbon and oxygen, whereas the green roof filter surface contains other elements not present in the unused filter. Based on the results of research, green filter roof filter shows better capacity to remove more ozone than other filter samples. However, to better understand the role of green roof filters, additional measurements should be conducted, including measurement of VOC emissions.

\section{References}

Bekö, G., Clausen, G., \& Weschler, C. J. (2007). Further studies of oxidation processes on filter surfaces: Evidence for oxidation products and the influence of time in service. Atmospheric Environment, 41(25), 5202-5212.

Berardi, U., GhaffarianHoseini, A., \& GhaffarianHoseini, A. (2014). State-of-the-art analysis of the environmental benefits of green roofs. Applied Energy, 115, 411-428.

Davis, J. M., \& Speckman, P. (1999). A model for predicting maximum and $8 \mathrm{~h}$ average ozone in Houston. Atmospheric Environment, 33(16), 2487-2500.

De Smedt, F., De Gendt, S., Heyns, M. M., \& Vinckier, C. (2001). Materials compatibility and organic build-up during ozone-based cleaning of semiconductor devices. In DIFFUSION AND DEFECT DATA PART B SOLID STATE PHENOMENA (pp. 63-66). Scitec Publications; 1999.

Destaillats, H., Chen, W., Apte, M. G., Li, N., Spears, M., Almosni, J., ... \& Fisk, W. J. (2011). Secondary pollutants from ozone reactions with ventilation filters and degradation of filter media additives. Atmospheric environment, 45(21), 3561-3568. 
EPA, (2015). NAAQS Table. An online content from U.S. Environmental Protection Agency website. https://www.epa.gov/criteria-air-pollutants/naaqs-table. Reached on Dec. 2016.

Gryparis, A., Forsberg, B., Katsouyanni, K., Analitis, A., Touloumi, G., Schwartz, J., ... \& Wichmann, H. E. (2004). Acute effects of ozone on mortality from the "air pollution and health: A European approach" project. American journal of respiratory and critical care medicine, 170(10), 1080-1087.

Hyttinen, M., Pasanen, P., \& Kalliokoski, P. (2006). Removal of ozone on clean, dusty and sooty supply air filters. Atmospheric Environment, 40(2), 315-325.

Lee, P., \& Davidson, J. (1999). Evaluation of activated carbon filters for removal of ozone at the ppb level. American Industrial Hygiene Association Journal, 60(5), 589-600.

Lin, C. C., \& Chen, H. Y. (2014). Impact of HVAC filter on indoor air quality in terms of ozone removal and carbonyls generation. Atmospheric Environment, 89, 29-34

Lippmann, M. (1989). Health effects of ozone a critical review. Japca, 39(5), 672-695. http://dx.doi.org/10.1080/08940630.1989.10466554

Morrison, G. C., Nazaroff, W. W., Cano-Ruiz, J. A., Hodgson, A. T., \& Modera, M. P. (1998). Indoor air quality impacts of ventilation ducts: ozone removal and emissions of volatile organic compounds. Journal of the Air \& Waste Management Association, 48(10), 941-952.

Oleson, K. W., Bonan, G. B., \& Feddema, J. (2010). Effects of white roofs on urban temperature in a global climate model. Geophysical Research Letters, 37(3).

Pudasainee, D., Sapkota, B., Shrestha, M. L., Kaga, A., Kondo, A., \& Inoue, Y. (2006). Ground level ozone concentrations and its association with NOx and meteorological parameters in Kathmandu valley, Nepal. Atmospheric environment, 40(40), 8081-8087.

Sailor, D. J. (2008). A green roof model for building energy simulation programs. Energy and buildings, 40(8), 1466-1478.

Sailor, D. J., Elley, T. B., \& Gibson, M. (2012). Exploring the building energy impacts of green roof design decisions-a modeling study of buildings in four distinct climates. Journal of Building Physics, 35(4), 372-391.

Shao, M., Lu, S., Liu, Y., Xie, X., Chang, C., Huang, S., \& Chen, Z. (2009). Volatile organic compounds measured in summer in Beijing and their role in ground-level ozone formation. Journal of Geophysical Research: Atmospheres, 114(D2).

Shields, H. C., Weschler, C. J., \& Naik, D. V. (1999). Ozone removal by charcoal filters after continuous extensive use (5 to 8 years). Indoor Air, 99, 49-54. 
Stephens, B., Gall, E. T., \& Siegel, J. A. (2011). Measuring the penetration of ambient ozone into residential buildings. Environmental science \& technology, 46(2), 929-936.

Taha, H., \& Sailor, D. (2010). Evaluating the Effects of Radiative Forcing Feedback in Modelling Urban Ozone Air Quality in Portland, Oregon: Two-Way Coupled MM5-

CMAQ Numerical Model Simulations. Boundary-layer meteorology, 137(2), 291-305. Doi: 10.1007/s10546-010-9533-9

Weschler, C. J., Shields, H. C., \& Naik, D. V. (1994). Ozone-removal efficiencies of activated carbon filters after more than three years of continuous service. ASHRAE transactions, 100(2), 1121-1129.

Zhao, P., Siegel, J. A., \& Corsi, R. L. (2007). Ozone removal by HVAC filters. Atmospheric Environment, 41(15), 3151-3160. 


\section{Supporting Information for Chapter 4:}

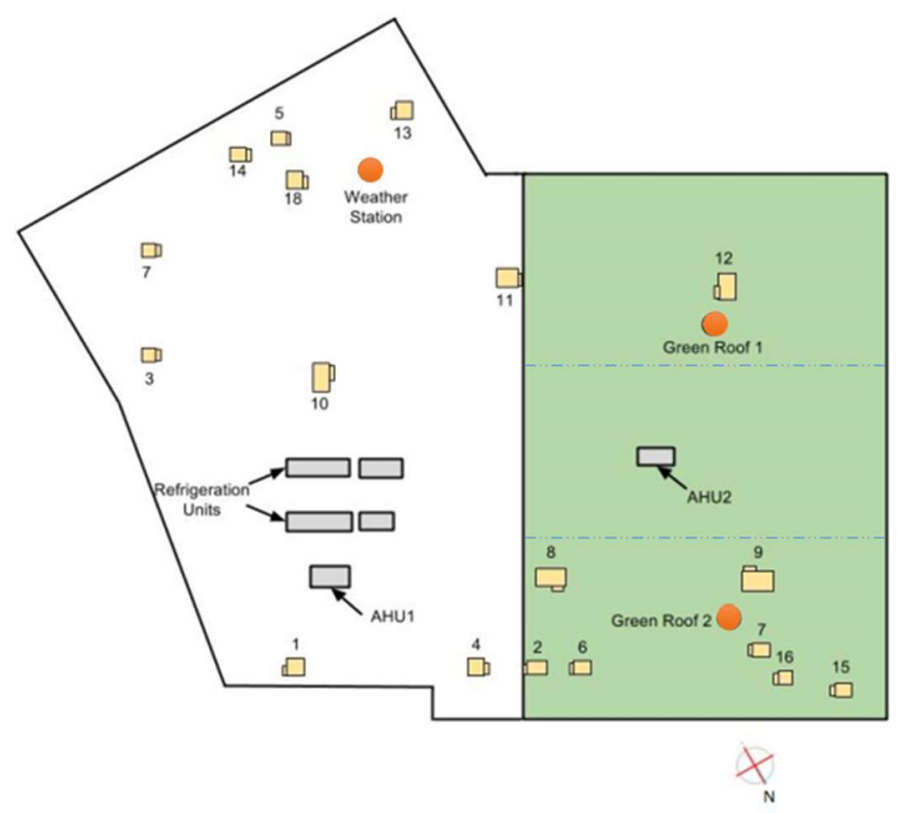

Figure 4.11. Plan view for the roof of the commercial building. The green section shows the green roof, and the white section shows the white membrane roof. AHU1 and AHU2 refers to locations where filters are sampled from.

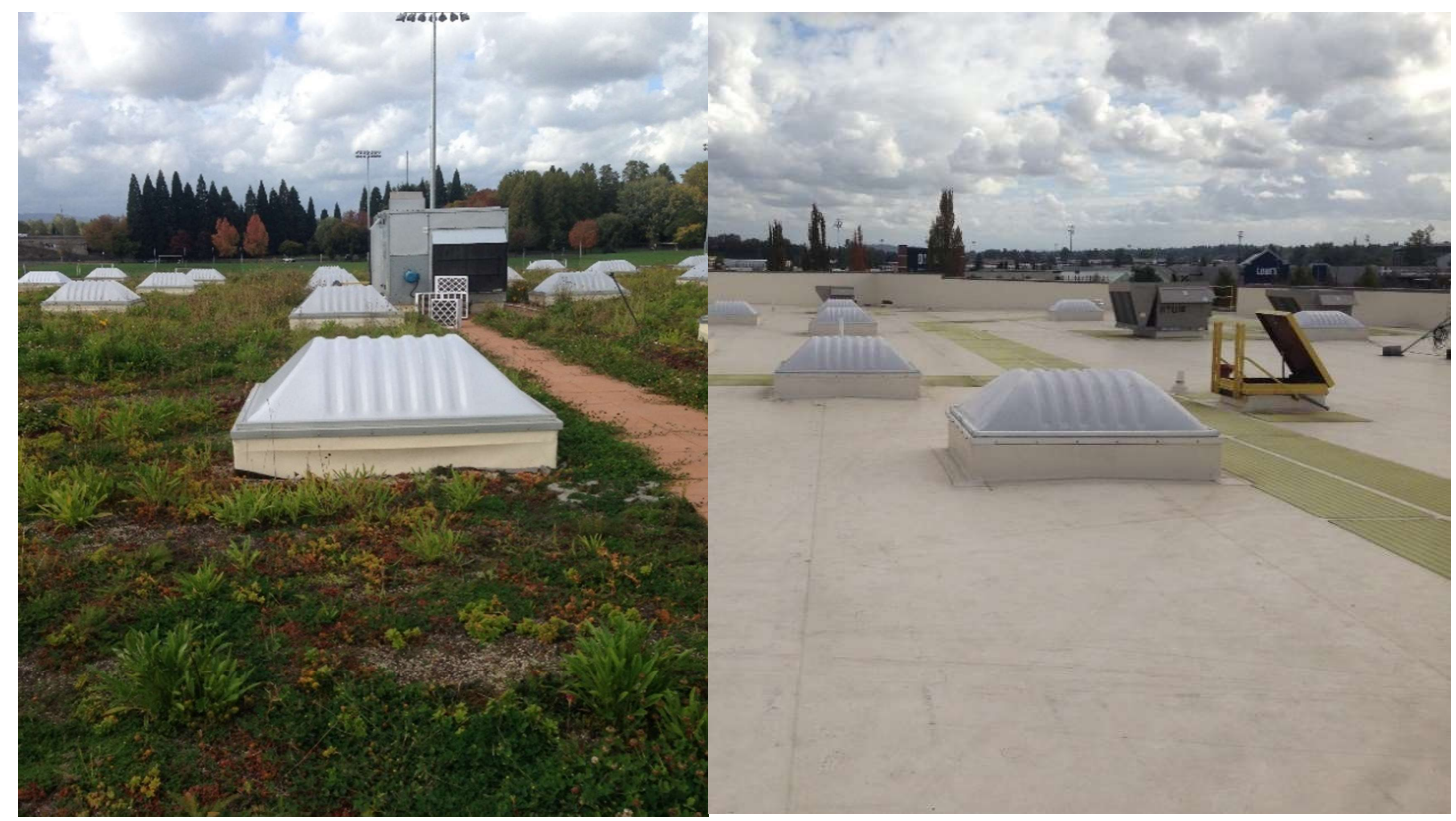

Figure 4.12. A photo shows the green roof (left) and white membrane roof (right). The air handling unit is shown on the left photo with filters in the process of replacement. 


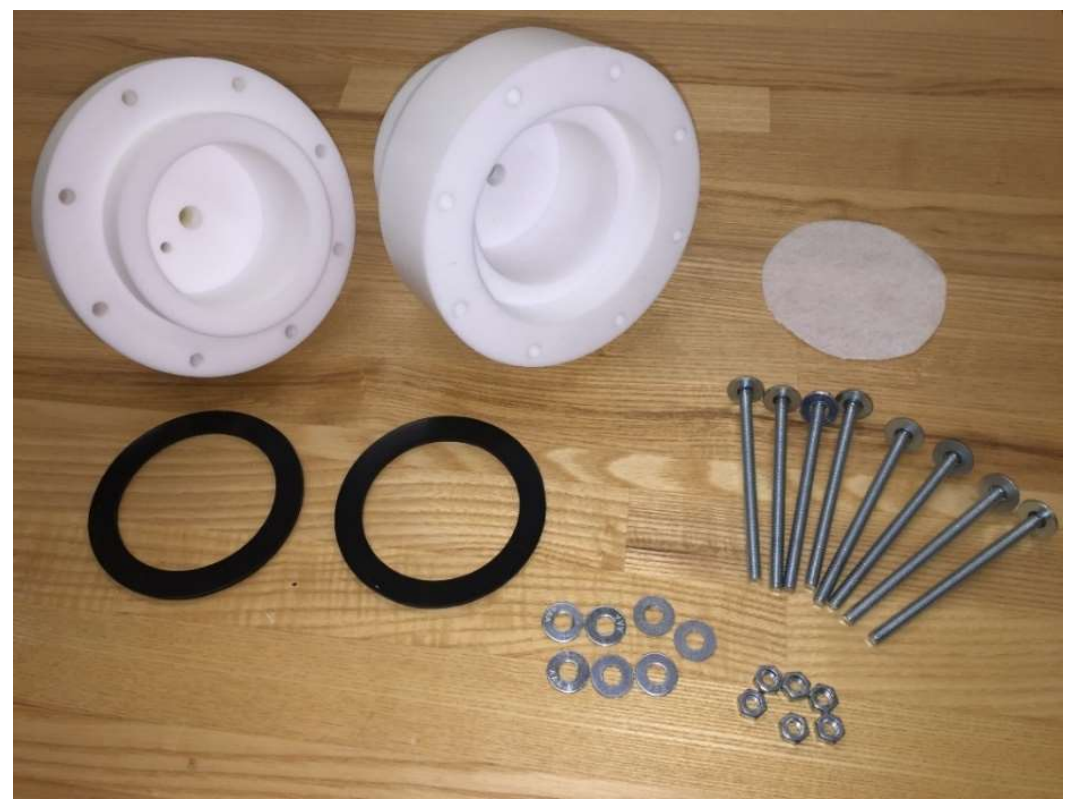

Figure 4.13. A photo shows the Teflon filter holder with gaskets, connection bolts and sample of filter used in ozone removal tests. 


\title{
Chapter 5
}

\section{Paper4: Ozone deposition velocity, TVOC, and carbonyl emissions from freshly indoor latex painted surfaces}

\author{
Omed A. Abbass, David J. Sailor, and Elliott T. Gall \\ In preparation for submission to Building and Environment
}

\begin{abstract}
Inside buildings, paint is the most popular covering and finishing material.

Therefore, it is crucial to understand their role on indoor air quality. In this study, three indoor latex paints identified as normal, low, and zero VOC were investigated for ozone removal and carbonyl emissions. Three sets of tests were conducted to evaluate ozone deposition velocity, TVOC, and specific carbonyl emissions before and after exposure to elevated ozone at $120 \mathrm{ppb}$ in $52 \mathrm{~L}$ chamber setting at $3 \mathrm{~h}^{-1}$ air exchange rate. Ozone removal tests show that zero VOC paint had the highest steady state ozone deposition velocity among other paint types with value of $2.7 \mathrm{~m} \mathrm{~h}^{-1}$. Also, normal VOC paint had the lowest value of $0.8 \mathrm{~m} \mathrm{hr}^{-1}$. TVOC measurements using PID TVOC sensor showed that normal VOC paint was the highest emitter and zero VOC paint was the lowest. TVOC concentrations increased to peak values during the first $3 \mathrm{hrs}$ of starting the test then decay exponentially. Peak primary concentration was about $13000 \mathrm{ppb}$ for normal VOC paint and lowest peak was 900 ppb for zero VOC paint. In presence of ozone, much lower peak concentrations are receded in the range of 100-400 ppb for low VOC and zero VOC paints respectively. Carbonyl emission tests showed existence of compounds ranging from $\mathrm{C} 3$ to $\mathrm{C} 9$. Higher $\mathrm{C} 9$ values are reported for normal VOC paint, ranging from $20-45 \mu \mathrm{g} \mathrm{m}^{-2} \mathrm{~h}^{-1}$, and much less values, 20-35 $\mu \mathrm{g} \mathrm{m}^{-2} \mathrm{~h}^{-1}$ are detected for zero VOC paint. In presence of ozone, the detected carbonyls showed increase in value, especially
\end{abstract}


C9 which increased about 10x for normal VOC paint to 20x for zero VOC paint. The results of this research show that freshly painted surfaces can be a good sink for ozone however they are at the same time a strong source for VOC emissions as well.

\subsection{Introduction}

Buildings are the place where human's activity are mostly taken place. Studies show that people living in urban cities, especially elderly, spend about $90 \%$ of their time indoors in homes, offices, schools or others (Segalin et. al. 2017). Paint forms the most popular finishing coating inside buildings. In the United States only, about 519 million gallons of interior paint was used in 2005, and about $90 \%$ of the last portion is an interior water based paint or latex paint (Corsi and Lin. 2009, US Department of Commerce 2006). Indoor surfaces painted with latex paint forms relatively a large surface area of indoor surfaces (Sparks et. al.1999). Therefore, these surfaces are source for volatile organic compounds (VOCs) that adversely affects the indoor environment (Sparks et. al. 1999). Research show higher concentration of specific VOCs are still existing in buildings even after many months of painting (Cros et. al. 2012). These compounds will result many health risks like skin irritation, headache and asthma (Hansen et.al. 1987). In addition, VOCs sourced from paint during manufacturing and application are one of the sources of compounds that lead to photochemical reaction producing ozone in form of smog (Ling and Guo 2014). Ozone levels outdoors may reach to levels much higher than the limits specified by environmental protection agency (EPA), sometimes greater than 100ppb especially during summer days (Davis and Speckman 1999, Taha and Sailor 2010). Ozone will eventually transfer to indoor environment through ventilation and infiltration then interacting with different surfaces forming by-products, or known as 
secondary emissions, that could be more harmful than the ozone itself (Wisthaler and Weschler, 2010). Moreover, existence of both ozone and VOCs in occupied zone will mostly increase of potential indoor air quality issues that needs closer investigation.

Some of previous research have investigated VOCs released from painted surfaces in absence of ozone. For instance, Chang et. al. (1997), and Sparks et. al. (1999) in a separate study, both investigated the substrate effect on emissions of normal VOC paint in 53L stainless steel chamber setting. The paint was applied on stainless steel plate and new gypsum board in the first study and previously painted board in the second study. The two studies measured similar VOCs over two weeks. The compounds were: Ethylene glycol, texanol, BEE, propylene glycol, and diethylene glycol. Both researches show that VOC concentrations increase rapidly to peak values within few hours of the start of tests then decay gradually. The data from the first study show significant higher VOC concentrations, about 10:1, emitted from stainless steel plate in comparison with gypsum board. The latter study shows almost identical emission curves when applying paint as a second coat on old painted gypsum board. Chang et. al. (1999), studied the emissions and coating performance from four commercial low VOC, and one regular VOC latex paint applied on glass sheet in chamber setting. Formaldehyde, acetaldehyde, benzaldehyde and propanal were measured using gas chromatography/mass spectrometry (GC/MS) over $50 \mathrm{hr}$ test period. The results show that in spite of all paints identified as low VOC content, one paint sample showed peak TVOC concentration of $10 \mathrm{mg} \mathrm{m}^{-3}$. Also, that low VOC paints can still be hazardous indoor air pollutant.

Other researches have studied VOC emissions in presence of ozone from different painted surfaces. For instance, Reiss et.al.(1995) studied the emissions of carbonyls and 
VOCs from four latex paints exposed to $60-110 \mathrm{ppb}$ ozone in glass reactor. Air samples were collected and analyzed to detect formaldehyde, acetaldehyde and acetone. The data from this study show that latex paint exposure to ozone will help to form the above three compounds in a measurable range. Cros et. al. (2012) studied ozone removal and carbonyl emissions before and after exposing to ozone for green indoor surfaces including 3-month old painted gypsum boards. The results show that average ozone deposition velocity for painted gypsum board ranged between $0.5-1.4 \mathrm{~m} \mathrm{hr}^{-1}$. Also there is an increase in carbonyl emissions, especially nonanal by a factor of about $6 \mathrm{x}$, when exposed to $89 \mathrm{ppb}$ ozone. Gall et. all (2013) conducted a series of tests for three green building materials including 3 months old low VOC painted drywalls exposed to 140ppb ozone concentration in large scale room setting. The results show ozone deposition velocity values between $0.25-0.9 \mathrm{~m} \mathrm{hr}^{-1}$ based on change of relative humidity and air mixing condition. Also an increase in secondary emissions rate, after exposing to ozone, ranging between 0-35 $\mu \mathrm{g} \mathrm{m}^{-2} \mathrm{~h}^{-1}$ and average value for all tests of about $8.5 \mu \mathrm{g} \mathrm{m}^{-2} \mathrm{~h}^{-1}$.

It is obvious from the previous research that paint has a noticeable impact on VOC levels indoors. Moreover, existence of both ozone and VOC in occupied zone will mostly increase of potential of indoor air quality issues that needs more investigation. Most previous research have tested painted surfaces that are few weeks to months old. There is limited data on research that studies emissions from different VOC content paints when they are newly applied to surfaces. The current research focuses on investigating the role of three types of indoor latex paint, chosen based on their VOC content as normal, low, and zero VOC paints, on ozone removal and primary and secondary emission rates of freshly painted drywall. The outcomes from this work will be important to understand 
different freshly painted latex paints effect on indoor air quality especially in presence of ozone.

\subsection{Methodology}

\subsubsection{Materials tested}

In this study, three latex based paints bought from a local paint store were tested for ozone removal and carbonyl emissions. The paints were applied on new, unused gypsum board (USG, brand SHEETROCK) coated with zero VOC primer (Drywall Primer, Sherwin Williams). The primer was applied at least 24 hours before applying the latex paint for test. Edges and lower face of the boards were covered with aluminum foil to prevent ozone reaction with non-painted surfaces. Table 5.1 below shows the description and details of paints used.

Table 5.1. List of characteristics of paints investigated in this study.

\begin{tabular}{lllll}
\hline Code & Brand & Manufacturer & Color & VOC content \\
\hline Normal VOC & Enamel & Sherwin Williams & white high gloss & $176 \mathrm{gm} / \mathrm{L}$ \\
Low VOC & Emerald & Sherwin Williams & White matte & $<50 \mathrm{gm} / \mathrm{L}$ \\
Zero VOC $\%$ & ProClassic & Sherwin Williams & White satin & $<39 \mathrm{gm} / \mathrm{L}$ \\
\hline
\end{tabular}

\# as described by the manufacturer

$\%$ Code name is given based on seller store identification.

\subsubsection{Experimental Apparatus}

A schematic diagram for the experimental apparatus is shown in figure 5.1. The system consists of an air supply system that can provide pure and ozonated air with different concentrations. Two identical glass chambers with volume of 52L each constructed following ISO 16000-6 standards were used to contain the painted boards. Ozone is provided using stable ozone generator (UVP, model SOG-2), and measured using two ozone analyzers (2B Technologies, model 106-L) upstream and downstream 
the ozonated chamber. Laboratory compressed air system was used as an air supply. Purification of supply air from oil and water droplets, if exist, was warranted by using two filters. A laboratory gas dryer (Drierite, W.A. Hammond Drierite Co. Ltd.) was used to dehumidify the air before passing through an activated carbon filter to purify the air from VOCs. To readjust the air humidity to the required level, the air stream passed through a glass impinge filled with distilled water. A by-pass valve was used to control relative humidity of the supply air. Both temperature and relative humidity were measured and recorded in one-minute interval using a HOBO 12Bit sensor (Onset, model S-THB-M002) that was connected to an HOBO data logger (Onset, model H21-002). The purified air stream is then splited into two branches, one to supply the non-ozonated chamber, and the other to supply ozone generator then ozonated chamber. Each streams flow rates were controlled using mass flow controller (OMEGA, model FMA 5523). The total volatile organic compounds (TVOC) released from paint sample was measured using photo ionization detector (PID) sensor (Grey Wolf, IQ610) that is capable to detect VOC compounds that have ionization potential smaller than $10.6 \mathrm{eV}$. The list of VOCs detected using this method exceeds 350 compounds. The sensor gives a reading in parts per billion (ppb) representing a bulk concentration for compounds detected. All parts of apparatus were constructed using ozone inert material like stainless steel for valves and connectors and teflon for piping. To prevent possible air leak from outside the chambers, the pressure inside the chambers were always slightly higher than atmospheric pressure. 


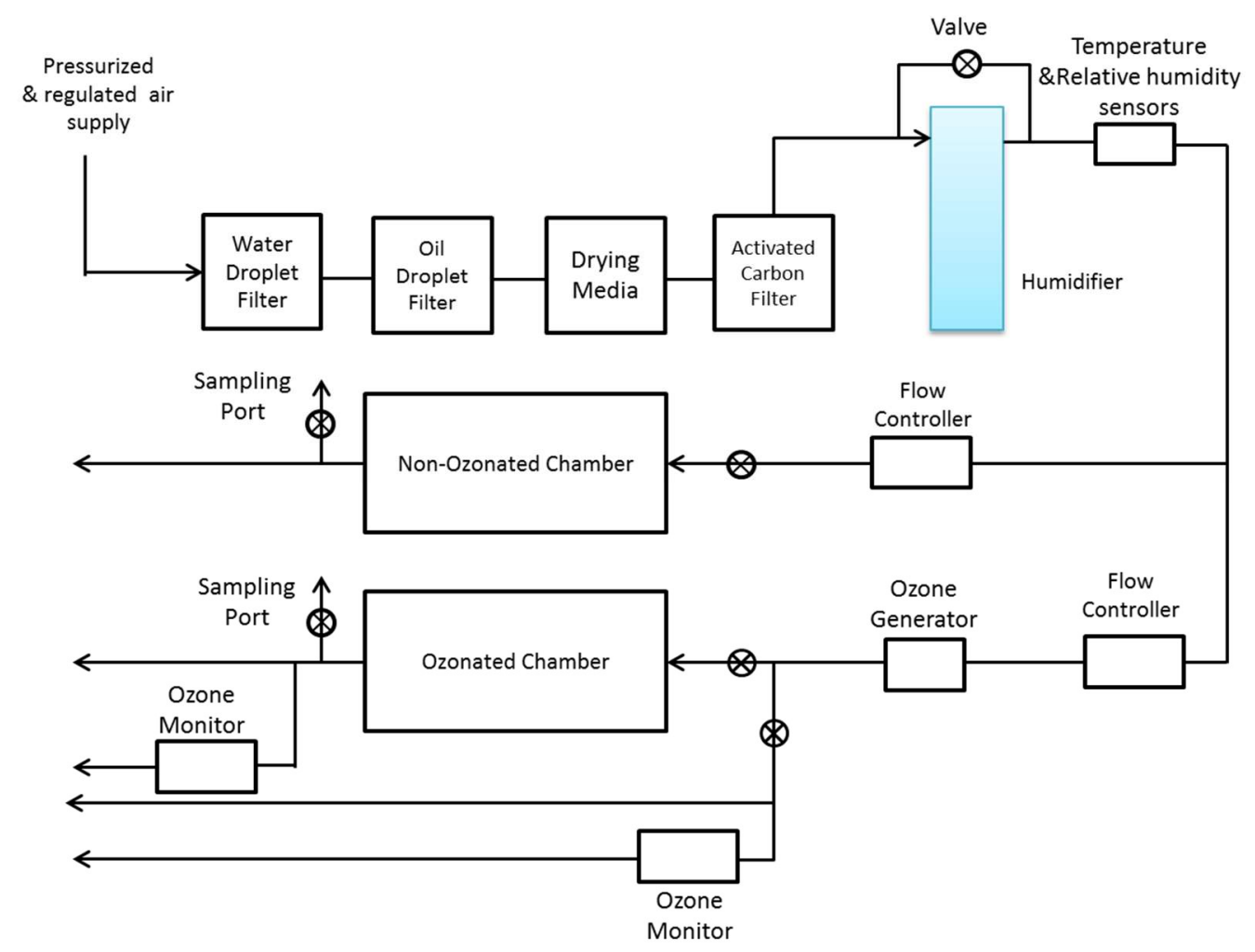

Figure 5.1. Schematic diagram of the experimental apparatus.

\subsubsection{Experimental procedure:}

Ozone removal and emission tests took place in two identical glass chambers supplied with clean air at $3.0 \pm 0.045$ air exchanges per hour and temperature of $21^{\circ} \mathrm{C} \pm$ $1{ }^{\circ} \mathrm{C}$, and the relative humidity of $50 \pm 2 \%$. One chamber is provided with pure air, and the other is supplied with pure ozonated air at $120 \pm 2 \mathrm{ppb}$. The paint was applied by roller on square gypsum board $(20 \mathrm{~cm} \times 20 \mathrm{~cm})$ that is previously covered with zero VOC primer at least 24 hours before applying the paints following the instruction of manufacturer. The backing and edges of boards were covered with aluminum foil to prevent ozone reaction with non-painted areas (CDPH 2010, Rim et al. 2016). To ensure the consistency of the mass of the paint on every board, a precision scale (VeriTas, 
S5201) was used to measure the mass of gypsum board before and after applying the paint to ensure that $4.0 \mathrm{gm}$ of paint is applied in each test. The gypsum boards were also weighted at the end of every test that lasted for 3 days to measure the paint mass loss due to evaporation. In total, 15 gypsum boards were used to cover TVOC, ozone deposition, and carbonyl emission tests. Table 5.2 show the matrix of tests conducted during this study. Test chambers were thoroughly wiped with distilled water and dried using heat gun then quenched using $350 \mathrm{ppb}$ ozone stream for $3 \mathrm{hrs}$. before conducting every new test (Abbass et. al. 2017, Coleman et. al.2008).

Table 5.2. List of paint tests and measurements made in each experiment.

\begin{tabular}{|c|c|c|c|}
\hline Test no. & Paint type & Chamber type & Measurement \\
\hline 1 & \multirow{3}{*}{ Normal VOC } & Ozonated chamber & Ozone deposition \\
\hline 2 & & Non-ozonated chamber & TVOC \\
\hline 3 & & Ozonated chamber & TVOC \\
\hline 4 & \multirow{3}{*}{ Low VOC } & Ozonated chamber & Ozone deposition \\
\hline 5 & & Non-ozonated chamber & TVOC \\
\hline 6 & & Ozonated chamber & TVOC \\
\hline 7 & \multirow{3}{*}{ Zero VOC } & Ozonated chamber & Ozone deposition \\
\hline 8 & & Non-ozonated chamber & TVOC \\
\hline 9 & & Ozonated chamber & TVOC \\
\hline 10 & \multirow{2}{*}{ Normal VOC } & Ozonated chamber & Carbonyl sampling \\
\hline 11 & & Non-ozonated chamber & Carbonyl sampling \\
\hline 12 & \multirow{2}{*}{ Low VOC } & Ozonated chamber & Carbonyl sampling \\
\hline 13 & & Non-ozonated chamber & Carbonyl sampling \\
\hline 14 & \multirow{2}{*}{ Zero VOC } & Ozonated chamber & Carbonyl sampling \\
\hline 15 & & Non-ozonated chamber & Carbonyl sampling \\
\hline
\end{tabular}

\subsubsection{Total VOC and Carbonyls sampling and analysis}

In this research, total volatile organic compounds (TVOC) were measured using portable VOC measurement sensor (Grey Wolf - model IQ-610) connected to hand held portable PC for data logging in 1-minute interval. The device provided TVOC measurements in the range of $0-20000 \mathrm{ppb}$ with resolution of $1 \mathrm{ppb}$. Two points 
Calibration with factory calibration kit was performed before starting the measurements. In addition to TVOC measurements, individual carbonyl measurements similar to compounds covered by Abbass et. al. (2017) were samples in every paint test. The 13 compounds samples are covered by EPA standard (TO-11a) (EPA 1999). The compounds included: formaldehyde, acetaldehyde, acrolein, acetone, propionaldehyde, crotonaldehyde, methacrolein, n-buteraldehyde, 2-butanone, benzeldehyde, valeraldehyde, m-tolualdehyde, and hexaldehyde. Additional five heavy aldehyde compounds were added to the method. These compounds included: cyclohexanone, heptanal, octanal, nonanal, and decanal.

Air sampling pump (SKC, model 224-PCXR8) was used to pass air at constant flow rate of $400 \mathrm{~mL} / \mathrm{min}$ for $60 \mathrm{~min}$. through a glass sampling tube (SKC, model 226-120). These tubes are packed with silica gel coated with 2,4-dinitrophenylhydrazine (DNPH) and provided with ozone scrubbing material to minimize ozone influence on sampling material. An external orifice flow meter provided with pressure transducer (OMEGA, PX653-03D5V) was used to measure air flow rate through sampling tubes.

One sample was taken from a blank tube, chamber inlet, and exits of both empty ozonated and non-ozonated chambers prior to paint tests to measure background concentrations. At the beginning of every paint test, two identical painted gypsum boards were placed in ozonated and non-ozonated chambers simultaneously. After one hour from the start of test, one air sample was taken from the non-ozonated chamber for 1-hr period. After that one 1-hr sample was taken from the ozonated chamber. In total 18 samples were collected from both chambers at the following time sequence: $1 \mathrm{hr}, 8 \mathrm{hrs}$, 16hrs, $24 \mathrm{hrs}, 48 \mathrm{hrs}$, and $72 \mathrm{hrs}$. All sampling tubes were preserved in sealed glass tubes at 
$4^{\circ} \mathrm{C}$. All tubes were desorbed and analyzed according to TO-11a instructions within two weeks of sample collection.

\subsubsection{Carbonyl analysis}

Analysis of carbonyl compounds was performed in Bioanalytical Mass Spectrometry Facility in Chemistry Department, Portland State University. A high performance liquid chromatography system coupled with a high resolution $(30,000)$ mass spectrometer (HPLC/MS, Thermo Electron LTQ XL-Orbitrap Discovery) was used to analyze the samples using negative polarity mode. The HPLC/MS photo and parameters of the device are listed in the supporting information section. The resulting mass spectral data were filtered using 5ppm theoretical mass window using Xcalibur software/ Quan browser. A Poroshell $120 \mathrm{SB}-\mathrm{C} 182.7 \mu \mathrm{m}(3 \mathrm{mmx} 150 \mathrm{~mm})$ column was installed to separate the compounds. The solvent flow rate used was $0.4 \mathrm{~mL} / \mathrm{min}$ with initial concentrations of $60 \%$ acetonitrile and $40 \%$ water. This ratio was kept constant for the first 4 minutes of each HPLC run, increased linearly to $100 \%$ acetonitrile over an 8 -minute period, kept constant for 4 minutes, and then changed back to $60 \%$ acetonitrile and kept constant for an additional 4 minutes. The total time for every sample test was 20 minutes. The data from each sample was analyzed to obtain specific carbonyl mass on the sorbent tube, which was then used to calculate gas-phase concentration of the compound during the experiment.

Calibration of HLPC/MS to every 18 carbonyls was performed before samples analyzing using a serial dilution method of a mixture of a standard solution containing the 18 organic compounds. The mixture prepared in laboratory by mixing two types of 
standard solutions. The first was a mixture of 13 compounds (Sigma Aldrich, ERA013K) matching the compounds according to TO-11a standards. The additional five compounds, cyclohexanone, heptanal, octanal, nonanal, and decanal, were obtained as individual solutions (AccuStandard Inc.). The calibration was performed to obtain a fivepoint calibration curve for every compound with all resulting $\mathrm{R}^{2}$ greater than 0.99 , similar to the procedure used by Cros et al., (2012) and Gall et al. (2013).

\subsection{Data analysis}

\subsubsection{Ozone deposition velocities}

Ozone deposition velocity is derived from a mass balance through the test chamber including chamber material. Same derivation is followed in Abbass et. al. (2017b) and Poppendieck et. al (2007):

$$
\begin{aligned}
& \frac{d C}{d t}=A E R \cdot C_{\text {inlet }}-A E R \cdot C_{\text {outlet }}-k_{g} \cdot C_{\text {outlet }} \cdot \frac{A g}{V}-k_{S} \cdot C_{\text {outlet }} \cdot \frac{A s}{V} \\
& k_{S}^{t}=\frac{V}{A_{S}} \cdot \frac{1}{C_{\text {outlet }}^{t}}\left[A E R\left(C_{\text {inlet }}^{t}-C_{\text {outlet }}^{t}\right)-k_{g} C_{\text {outlet }}^{t} \cdot \frac{A_{g}}{V}-\frac{C_{\text {outlet }}^{t}-C_{\text {outlet }}^{t+1}}{\Delta t}\right]
\end{aligned}
$$

where $\mathrm{C}_{\text {inlet }}$ and $\mathrm{C}_{\text {outlet }}$ are the concentration of ozone in the inlet and outlet of the

chamber (ppb) respectively, $\frac{d C}{d t}$ represents the change in the outlet ozone concentration (ppb per hour); AER is the air exchange rate $\left(\mathrm{h}^{-1}\right), \mathrm{V}$ is the volume of chamber $\left(\mathrm{m}^{3}\right) ; \mathrm{A}_{\mathrm{g}}$, $A_{s}$ are the internal surface areas of the glass chamber, and the sample area respectively $\left(\mathrm{m}^{2}\right) ; k_{g}$ and $k_{s}$ are ozone deposition velocities for the glass chamber material and the painted surface respectively $\left(\mathrm{m} \mathrm{h}^{-1}\right)$.

Before starting paint tests, an empty chamber ozone test was performed to calculate ozone deposition velocity for the chamber material $\left(\mathrm{kg}_{\mathrm{g}}\right)$. Both inlet and outlet ozone 
concentration values were recorded at steady-state condition defined as exit concentration change is less than 2 ppb over a 20 -minute period. These values were applied to equation (1) to calculate $\mathrm{kg}$. In paint tests, this value is used in equation 1 to calculate transient deposition velocity $\left(\mathrm{k}_{\mathrm{s}}\right)$. To facilitate the comparison of ozone deposition velocity values at steady state condition, the average of last $20 \mathrm{~min}$. of each test was calculated and graphed. Uncertainties were calculated using the propagation of error analysis incorporating uncertainties of the ozone monitors of $2 \%$ of reading and flow controllers of $1.5 \%$ of reading.

\subsubsection{Carbonyl emissions}

To quantify carbonyl emissions, the specific emission rate (SER), according to Abbass (2017) and Nicolas et al. (2007) is used:

$$
S E R=C_{\text {exit }} \cdot \frac{A E R}{A_{S} / V}
$$

where $\mathrm{C}_{\text {exit }}$ is the concentration of the specific carbonyl of interest at the exit of the chamber after removing background values in $\left(\mu \mathrm{g} \mathrm{m}^{-3}\right)$; AER is the air exchange rate $\left(\mathrm{h}^{-}\right.$ $\left.{ }^{1}\right)$; $A_{S}$ is the surface area of painted sample $\left(\mathrm{m}^{2}\right)$; and $V$ is the volume of test chamber $\left(\mathrm{m}^{3}\right)$. The uncertainty analysis based on error propagation for equation 3 was performed. The uncertainty of every compound was found using three repeated measurements for every compound in standard solution using HPLC/MS and incorporated in the uncertainty analysis. The percentage RTD of the three readings was less than $20 \%$ for all compounds. The average uncertainty for primary specific emission rates (averaged across all observed primary carbonyl emissions) was $\pm(1.62) \mu \mathrm{g} \mathrm{m}^{-2} \mathrm{~h}^{-1}$, and $\pm(3.29) \mu \mathrm{g}$ 
$\mathrm{m}^{-2} \mathrm{~h}^{-1}$ for secondary specific emission rates (averaged across all secondary carbonyl emissions).

\subsection{Results and discussion}

\subsubsection{Exit ozone concentration}

Figure 5.2 shows the change of exit ozone concentration with time for paint samples. Figure 5.2a show the change for the first $100 \mathrm{~min}$. of the test. The figure shows noticeable difference for the first hour at the beginning of tests. The low VOC test shows a slow increase in exit ozone concentration, but zero VOC paint sample test show rapid increase to more than $70 \mathrm{ppb}$ at the first $20 \mathrm{~min}$ then reduces down to about $50 \mathrm{ppb}$. The normal VOC paint curve increases faster than low VOC curve but slower than zero VOC paint. Figure $5.2 \mathrm{~b}$ show the exit ozone concentration for the whole period of tests. It can be seen that both low and zero VOC paints have similar exit ozone curves, but the normal VOC paint show continuous increase in exit ozone concentration till the end of test. Change in ozone concentration is attributed to two possible reaction mechanisms, the first is the gas phase reaction of ozone with VOCs released from paint, the second is gas-solid phase reaction of ozone with painted surfaces. So, lower ozone values refer to more reaction that consumes the ozone, and higher values will refer to less reaction by either or both mechanism. 


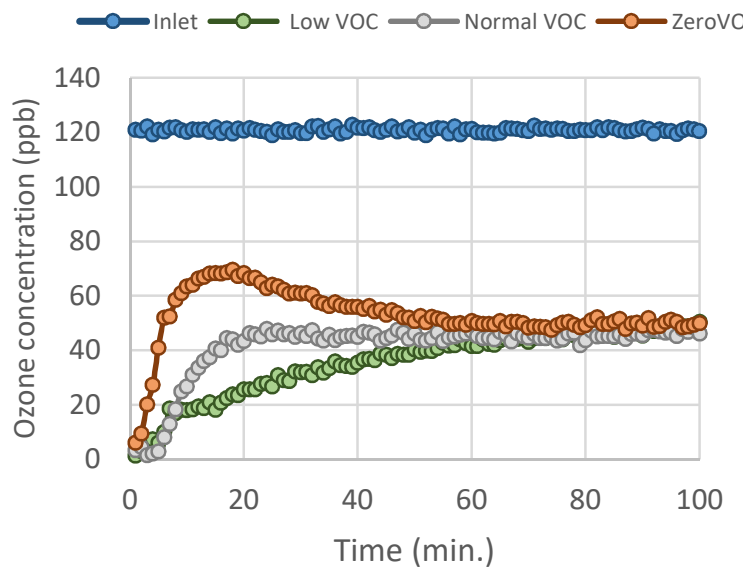

a)

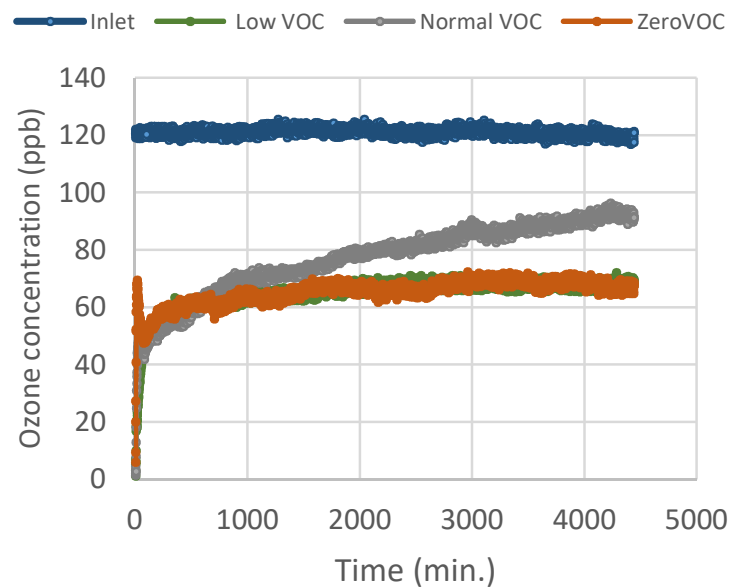

b)

Figure 5.2. Ozone concentration change with time for paint tests. a) for the first $100 \mathrm{~min}$. of paint tests. b) For tests lasted for 3days each.

\subsubsection{Ozone deposition velocity}

Transient ozone deposition velocity calculated from equation (2) is shown in figure 5.3. The figure shows high values at the beginning of every test. This is attributed to low ozone concentration inside the chamber at the beginning of tests. Gradually, the ozonated air will replace the clean air inside the chamber then chamber exit ozone values will rise till reaching a balance between ozone entering and leaving the chamber. The deposition velocity curves also show that low and zero VOC paints will reach steady ozone deposition velocity values faster than for the normal VOC paint and both have almost identical ozone deposition curves with steady state values around $2.5 \mathrm{~m} \mathrm{~h}^{-1}$. However, the deposition velocity curve for normal VOC paint continues to decrease in value till reaching about $0.7 \mathrm{~m} \mathrm{hr}^{-1}$ at the end of test. Another ozonated test was performed for the normal VOC paint to confirm this trend and the results were matching this observation. 
This behavior refers to continues reduction in reactivity of ozone with either the paint surface and/or gas phase compounds released from paint surface.

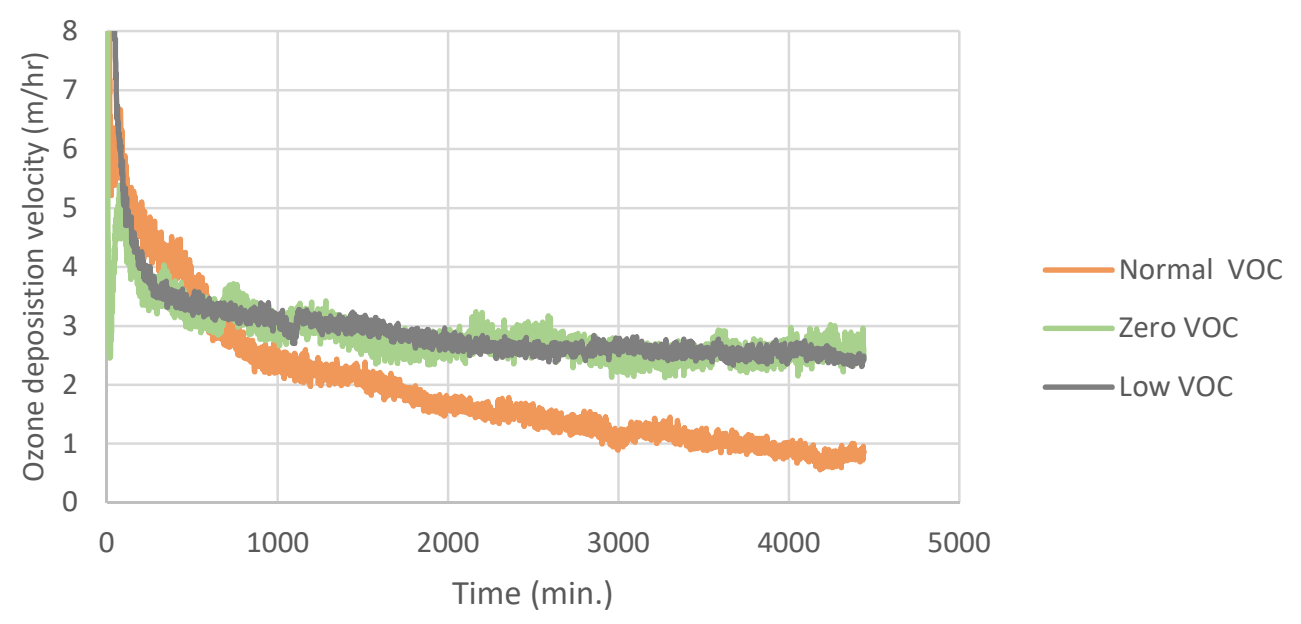

Figure 5.3. Transient ozone deposition velocity for paint samples. All tests are performed at 3 AER and inlet ozone concentration of $120 \mathrm{ppb}$.

Figure 5.4 shows steady state ozone deposition velocity calculated by averaging the values for the last 20min. of each test. As seen before, both low and zero VOC paints have close values with 2.4 , and $2.7 \mathrm{~m} \mathrm{hr}^{-1}$ respectively, and lower deposition value of about $0.8 \mathrm{~m} \mathrm{hr}^{-1}$ for the normal VOC paint. The values from these tests are within values reported by other researchers like 1.9-3.2 $\mathrm{m} \mathrm{hr}^{-1}$ by Walker et. al. (2009), $0.5-1.4 \mathrm{~m} \mathrm{hr}^{-1}$ by Cros et. al. (2012), and 0.25-0.9 $\mathrm{m} \mathrm{hr}^{-1}$ by Gall et al. (2013). However, all reported values were for painted surfaces that were few months old and not freshly painted as in the current research. 


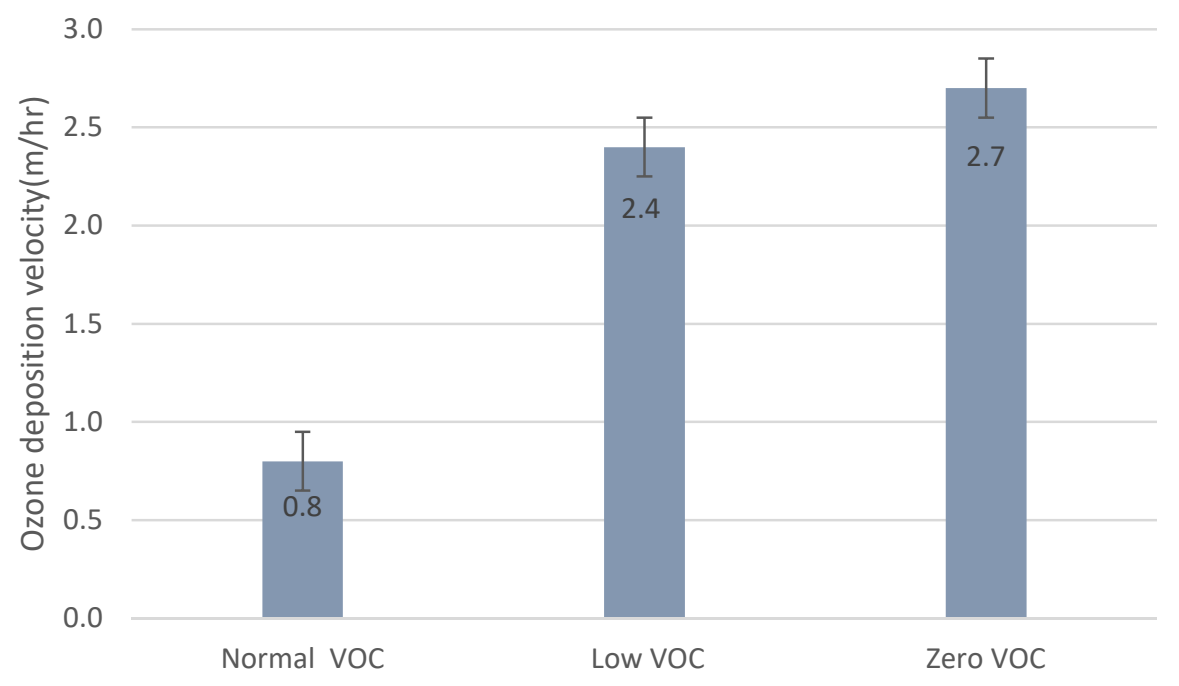

Figure 5.4. Steady state ozone deposition velocities for three paint samples. Error bars are uncertainty calculated by error propagation method using instruments uncertainties. Empty chamber had very small value of $0.013 \mathrm{~m} \mathrm{~h}^{-1}$ that is not included in graph. This value is included in the calculations of paint samples ozone deposition velocities.

\subsubsection{TVOC and carbonyl emissions}

Figure 5.5 shows the total VOC measurement using PID sensor for the three paint types in both ozonated and non-ozonated chambers. The figures show rapid increase in TVOC concentration after short time of start of all tests followed by an exponential decay. For instance, figure 5.5a show that the TVOC concentration at the exit of normal VOC non-ozonated chamber reaches about $15000 \mathrm{ppb}$ after about 3 hours then starts to decay after that. This value is about 10 times the maximum VOC recorded for low and zero VOC paints where peak TVOC are lower than 1000ppb. These data show that paints are strong source for VOCs especially during the first few hours of application.

Comparing the ozonated and non-ozonated TVOC curves show in general that TVOC concentrations in presence of ozone are significantly lower than concentrations in absence of ozone. For instance, Figures 5.5a and 5.5b show that peak TVOC for ozonated 
tests are about one tenth the peak value of non-ozonated test. This can be hypothesized as the more VOC emitted by painted surface the more ozone will react with these VOCs. This will eventually result in consumption of both VOCs and ozone as a result of gas phase reaction. By linking this hypothesis with ozone deposition velocity curves, this explanation seems reasonable for low VOC paint linking it with high ozone gas-surface reaction. However, it might not explain the lower ozone deposition velocity for normal VOC paint unless there much less ozone gas-surface reaction that cause low ozone deposition velocity for normal VOC paint. For zero VOC paint, the non-ozonated concentrations are comparably lower than other two types of paints, but ozonated test concentrations are slightly higher than low VOC paint. This could be as a result of less gas phase reaction between ozone and emitted VOCs or because of less volatile compounds released. 


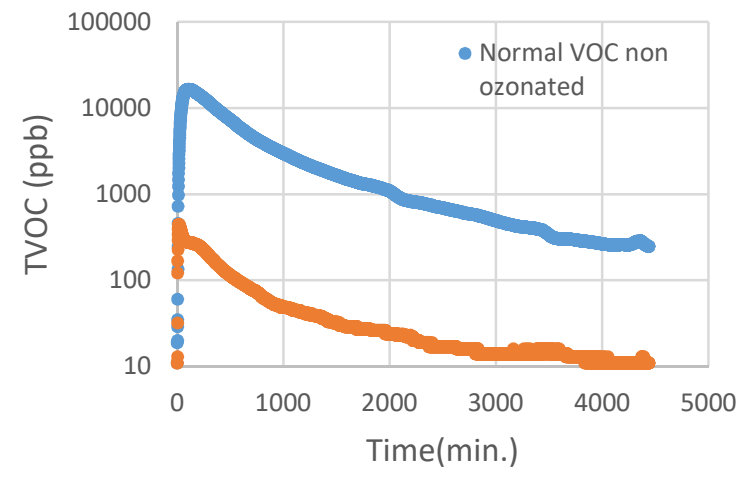

a)

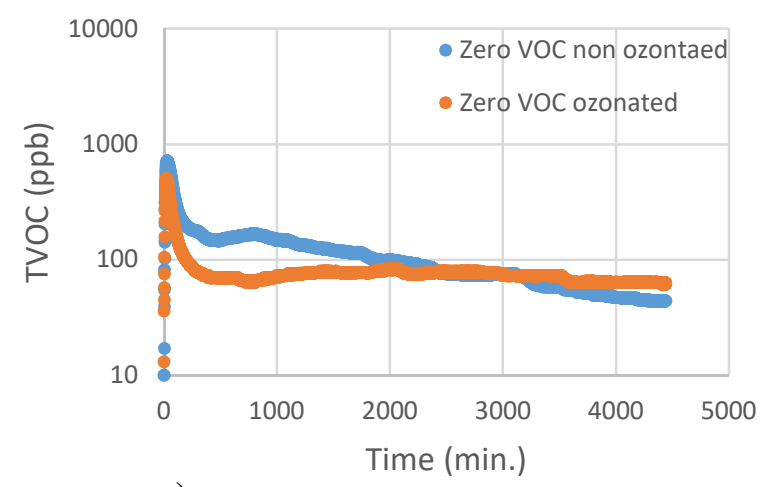

c)

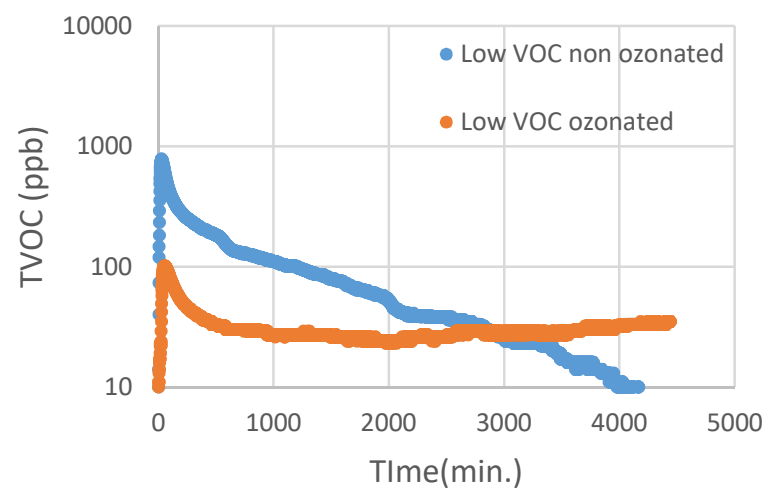

b)

Figure 5.5. Total VOC measurements change with time for ozonated and non-ozonated painted samples. Background concentrations ranged between 8-13 ppb. a) normal VOC paint. B) low VOC paint. c) zero VOC paint.

Figure 5.6 show specific emission rates for carbonyls detected in air samples taken from ozonated and non-ozonated chambers at different times during every test. The compounds detected in all tests were: acetone $\mathrm{C} 3$, hexaldehyde $\mathrm{C} 6$, heptanal $\mathrm{C}$, octanal C8 and nonanal C9. Comparing normal VOC paint emissions in figures 5.6a, and 5.6b. The figures show acetone, hexaldehyde and nonanl as the most predominate primary emissions with higher emission values at the start of non-ozonated test then decreasing gradually with time except for nonanl where concentration increase is noticed from 20 to 
about $47 \mu \mathrm{g} \mathrm{m}^{-2} \mathrm{~h}^{-1}$ as time passes. For ozonated emission, or secondary emissions, much higher values of nonanl are observed, about 10 times the primary emission values. Also, that there are secondary emissions of hexaldehyde that not presented in primary emissions. The same trend of increase in nonanl emissions with time is noticed for secondary emissions (except at time of $25 \mathrm{hrs}$ ). These data may give an indication that nonanl concentration may keep increasing even after the 3-day test period. The lower concentration values at hour 25 in ozonated test especially for nonanl, octanal, heptanal, and hexaldehyde could be attributed to many possible causes like defected sampling tube, or imperfect air flow through sampling tube during sampling or some imperfection during desorption. Figures 5.6c and 5.6d show emissions for low VOC paint. The compounds seen in primary emissions are only acetone and nonanal. The acetone concentration shows a rapid decay from peak value of about $86 \mu \mathrm{g} \mathrm{m}^{-2} \mathrm{~h}^{-1}$ at start of test to $4 \mu \mathrm{g} \mathrm{m}{ }^{-2} \mathrm{~h}^{-1}$ at the end of 3-day test. On the other hand, nonanl emissions show values varying around $20 \mu \mathrm{g} \mathrm{m}^{-2} \mathrm{~h}^{-1}$ with no obvious decay. The ozonated low VOC paint emissions show existence of hexaldehyde, heptanal, and octanal in addition to acetone and nonanal. Also that secondary nonanl emission rate is around 15 times higher than primary emissions.

Primary emission rates of zero VOC paint is shown in figure 5.6e. The graph show that predominant concentrations of nonanl that decays from about 30 to $25 \mu \mathrm{g} \mathrm{m}^{-2} \mathrm{~h}^{-1}$ and very low emissions of octanal. The ozonated emissions in figure $5.6 \mathrm{f}$ shows dramatic increase in nonanal with lower emissions of Hexaldehyde, heptanal, and octanal that were not existed in primary emissions. The above figures show an evidence that existence of ozone will increase carbonyl emissions as a result of ozone reaction with paint surface and VOCs emitted from paint. Also tis reaction may cause emission of compounds that 
are not present in absence of ozone. This conclusion agrees with the finding of Wisthaler and Weschler (2010) that ozone reaction with indoor materials, paint in our tests, might generate by-products that might be more harmful than ozone itself. 


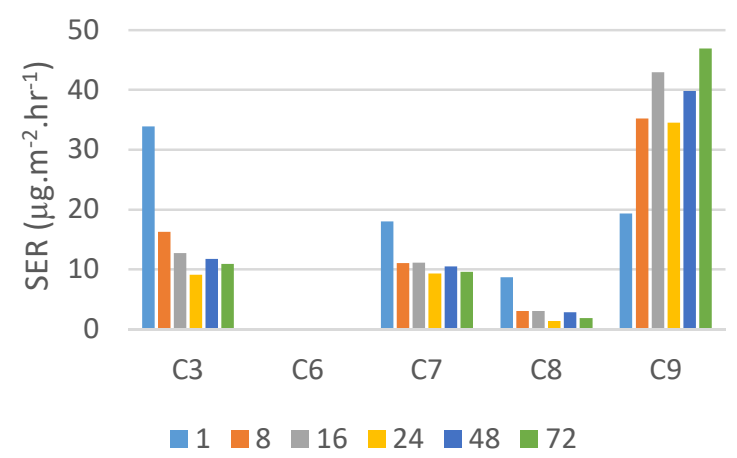

a) Normal VOC paint (Primary emissions)

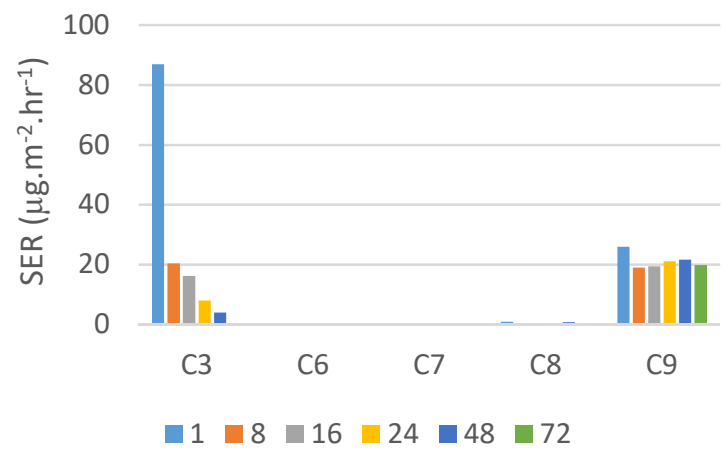

c) Low VOC paint (Primary emissions)

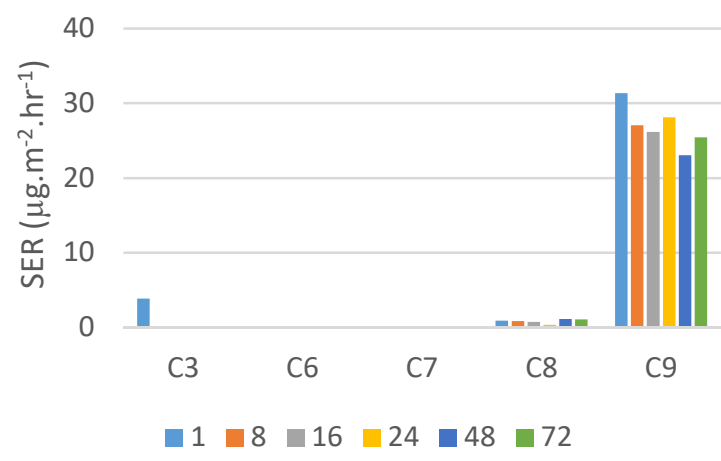

e) Zero VOC paint (Primary emissions)

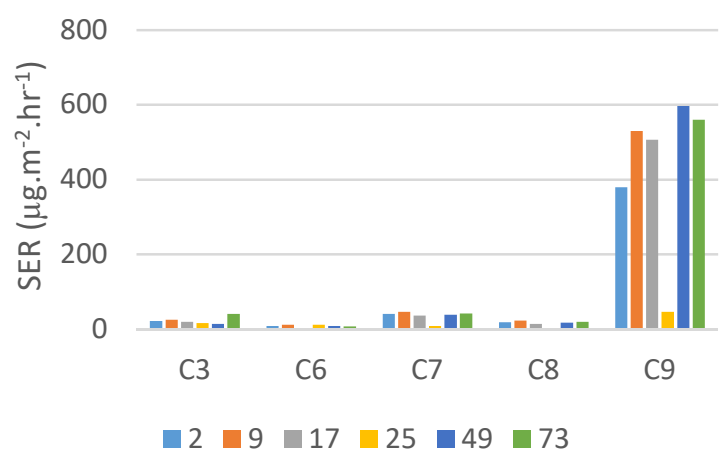

b) Normal VOC paint(Secondary emissions)

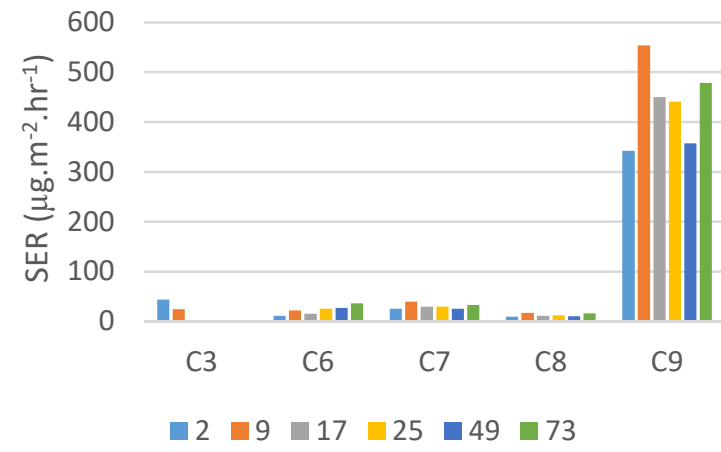

d) Low VOC paint (Secondary emissions)

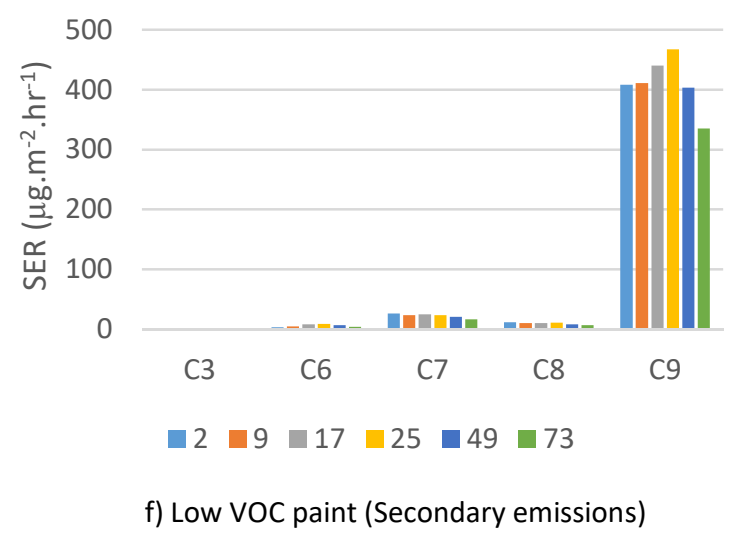

Figure 5.6. Specific emission rates change with time for all paint samples. The numbers in legend show the time when each air sample was taken in hours after the start of each test. $\mathrm{C} 3=$ acetone, $\mathrm{C} 6=$ hexaldehyde, $\mathrm{C} 7=$ heptanal, $\mathrm{C} 8=$ octanal $\mathrm{C} 9=$ nonanal. Average uncertainty using propagation of error for primary emissions was (1.62) $\mu \mathrm{g} \mathrm{m}^{-2} \mathrm{~h}^{-1}$ and for secondary emissions (3.29) $\mu \mathrm{g} \mathrm{m}^{-2} \mathrm{~h}^{-1}$. 
Figure 5.7 shows the average specific emission rates for VOCs measured during the period of study. The figure allows the comparison of individual VOC and their primary and secondary emission rates, in absence and presence of ozone. Figures $5.7 \mathrm{a}$ and $5.7 \mathrm{~b}$ show that for normal VOC paint, secondary emissions for all compounds detected are higher than primary emissions. The smallest increase was in acetone $\mathrm{C} 3$ with $7 \mu \mathrm{g} \mathrm{m}^{-2} \mathrm{~h}^{-1}$ and maximum increase is noticed for nonanal C9 with $401 \mu \mathrm{g} \mathrm{m}^{-2} \mathrm{~h}^{-1}$. For low VOC paint, figures $5.7 \mathrm{c}$ and $5.7 \mathrm{~d}$ show no primary emissions for hexaldehyde and heptanal C6, C7 and very small value for octanal. However, higher primary emissions of both acetone $\mathrm{C} 3$ and nonanal C9. For secondary emissions there is a reduction in acetone by $11 \mu \mathrm{g} \mathrm{m}^{-2}$ $\mathrm{h}^{-1}$, but strong secondary emissions for all other compounds especially nonanal with a value of $416 \mu \mathrm{g} \mathrm{m}^{-2} \mathrm{~h}^{-1}$. For zero VOC paint. Figures $5.7 \mathrm{e}$ and $5.7 \mathrm{f}$ show that no or negligible primary emissions for all compounds except primary emission of nonanal with value of $27 \mu \mathrm{g} \mathrm{m}^{-2} \mathrm{~h}^{-1}$. Secondary emissions are much lower than what is seen for normal and low VOC paints with lower secondary emission of acetone and higher secondary emissions of nonanal with about $437 \mu \mathrm{g} \mathrm{m}^{-2} \mathrm{~h}^{-1}$. These graphs show in general that normal VOC paint has much more primary emissions than other two paints. Also, zero VOC paint is the least emitter. Also, acetone, and nonanl are the main two compounds existed in normal and low VOC paints. Also, exposure to ozone will generally increase the concentrations of existed compounds and stimulate the emission of compounds that were not existed in non-ozonated tests. 


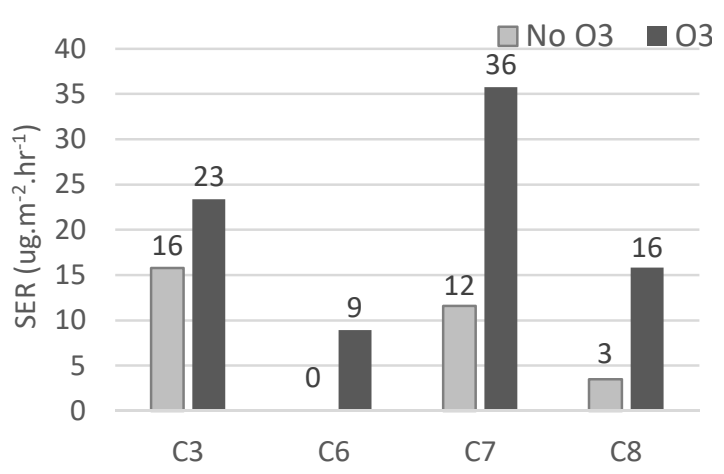

a)

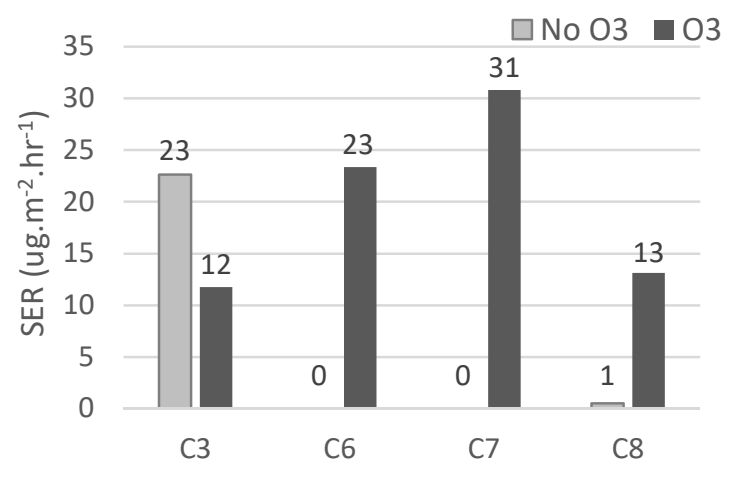

c)

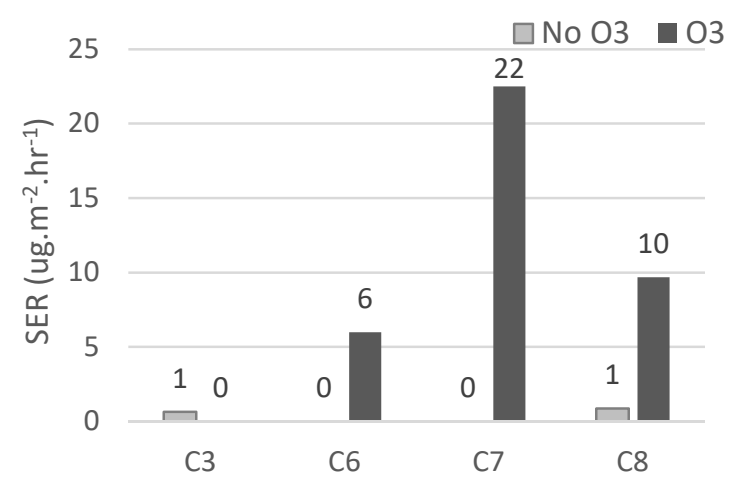

e)

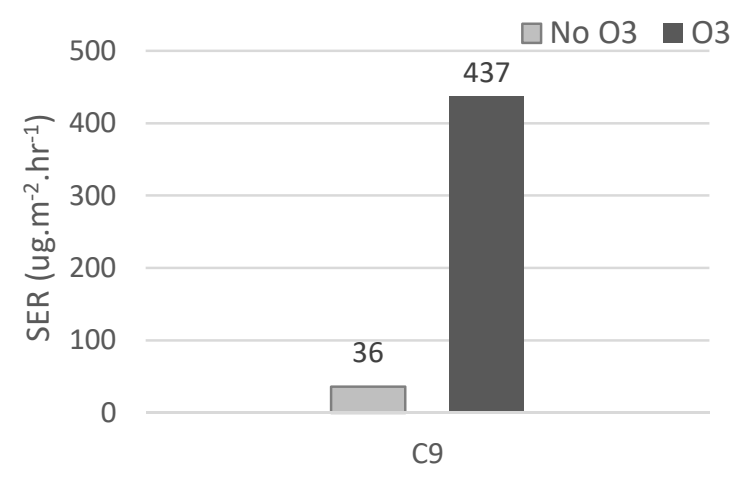

b)

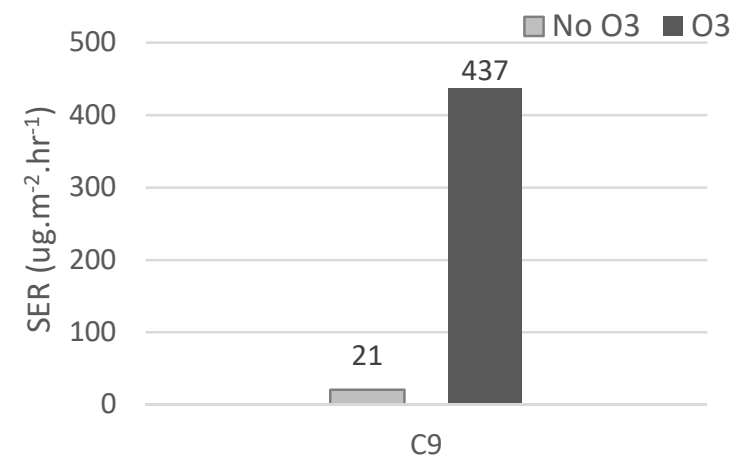

d)

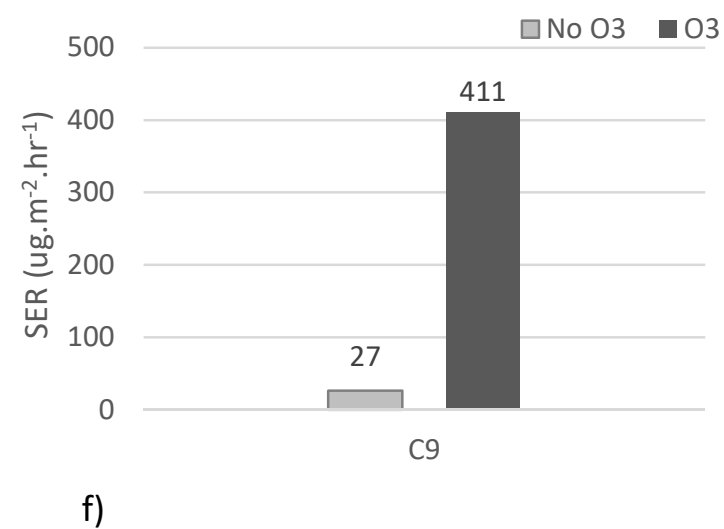

Figure 5.7. Average specific emission rates for all paint samples. $\mathrm{C} 3=$ acetone, $\mathrm{C} 6=$ hexaldehyde, $\mathrm{C} 7=$ heptanal, $\mathrm{C} 8=$ octanal $\mathrm{C} 9=$ nonanal. Figures a and $\mathrm{b}$ : normal VOC paint, figures c and d: low VOC paint, figures e and f: zero VOC paint. Average uncertainty using propagation of error for primary emissions was (1.62) $\mu \mathrm{g} \mathrm{m}^{-2} \mathrm{~h}^{-1}$ and for secondary emissions (3.29) $\mu \mathrm{g} \mathrm{m}^{-2} \mathrm{~h}^{-1}$. 


\subsection{Conclusions}

In this research, three freshly latex painted surfaces were tested to calculate the ozone deposition velocity, TVOC, and specific carbonyl emissions. The results show that ozone deposition velocity is changing with time at the start of test then gets steady state values after about 24 hours for low and zero VOC paint. For normal VOC paint, ozone deposition velocity continues to drop slowly till the end of 3 day tests. Zero VOC paint have the highest deposition value of $2.7 \mathrm{~m} \mathrm{~h}^{-1}$ whereas the low, and normal VOC paints have the values of 2.4 and $0.8 \mathrm{~m} \mathrm{~h}^{-1}$ respectively. Emission tests using both PID TVOC sensor and carbonyl analysis using HPLC-MS show that all paint types are strong emitters for different VOCs especially acetone and nonanal. However, lower emissions are noticed for low VOC paint than normal VOC paint and much less values are detected for zero VOC paint. Total VOC measurements show that all paints are strong VOC emitters for the first few hours after applying the paint, then an exponential decay is seen during 3 days. Same behavior is noticed for individual carbonyls starting with peak value at the start of test then decaying with time except for nonanal in both normal and low VOC paint where emissions were increasing gradually till the end of test.

Total VOC measurements made by PID sensor for ozonated chamber show less TVOC concentrations for ozonated chamber than non-ozonated one especially for normal and low VOC paints. However, individual carbonyl measurements show increase in secondary carbonyl emissions especially acetone and nonanal. Combining conclusions from both ozone deposition velocity and VOC emission data suggests that zero VOC paint is the best sink for ozone and the least VOC and carbonyls emitter. 


\section{References}

Abbass, O. A., Sailor, D. J., \& Gall, E. T. (2017). Effect of fiber material on ozone removal and carbonyl production from carpets. Atmospheric Environment, 148, 42-48.

Abbass, O. A., Sailor, D. J., \& Gall, E. T. (2017b). Effectiveness of indoor plants for passive removal of indoor ozone. Building and Environment, 119, 62-70.

CDPH, (2010). Standard method for the testing and evaluation of volatile organic chemical emissions from indoor sources using environmental chambers. Version 1.1. California department of public health. Feb. 2010.

Chang, J., Fortmann, R., Roache, N., \& Lao, H. C. (1999). Evaluation of Low-VOC Latex Paints. Indoor Air, 9(4), 253-258.

Chang, J., Tichenor, B. A., Guo, Z., \& Krebs, K. A. (1997). Substrate effects on VOC emissions from a latex paint. Indoor Air, 7(4), 241-247.

Coleman BK, Destaillats H, Hodgson AT, Nazaroff WW, (2008). Ozone consumption and volatile byproduct formation from surface reactions with aircraft cabin materials and clothing fabrics. Atmospheric Environment 42, 642-654.

Corsi, R. L., \& Lin, C. C. (2009). Emissions of 2, 2, 4-trimethyl-1, 3-pentanediol monoisobutyrate (TMPD-MIB) from latex paint: a critical review. Critical Reviews in Environmental Science and Technology, 39(12), 1052-1080.

Cros CJ, Morrison GC, Siegel JA, Corsi RL, (2012). Long-term performance of passive materials for removal of ozone from indoor air. Indoor Air 22 (1), 43-53.

Davis, J. M., \& Speckman, P. (1999). A model for predicting maximum and 8 h average ozone in Houston. Atmospheric Environment, 33(16), 2487-2500.

EPA, (1999). Compendium Method TO-11A. Determination of Formaldehyde in Ambient Air Using Adsorbent Cartridge Followed by High Performance Liquid Chromatography (HPLC) [Active Sampling Methodology]. Center for Environmental Research Information. Office of Research and Development U.S. Environmental Protection Agency. Cincinnati, OH 45268.

Gall ET, Darling E, Siegel J, Morrison G, Corsi R, (2013). Evaluation of three common green building materials for ozone removal, and primary and secondary emissions of aldehydes. Atmospheric Environment 77, 910-918.

Hansen, M. K., Larsen, M., \& Cohr, K. H. (1987). Waterborne paints: a review of their chemistry and toxicology and the results of determinations made during their use.

Scandinavian journal of work, environment \& health, 473-485.

Klepeis NE, Nelson WC, Ott WR, Robinson JP, Tsang AM, Switzer P, Behar JV, Hern SC, Engelmann WH, (2001). The National Human Activity Pattern Survey (NHAP): a 
resource for assessing exposure to environmental pollutants. J. Expo Anal Environ Epidemiol, 11 (3), 231-52.

Ling, Z. H., \& Guo, H. (2014). Contribution of VOC sources to photochemical ozone formation and its control policy implication in Hong Kong. Environmental science \& policy, 38, 180-191.

Nicolas M, Ramalho O, Maupetit F, (2007). Reactions between ozone and building products: Impact on primary and secondary emissions, Atmospheric Environment, 41 (15), 3129-3138.

Poppendieck, D., Hubbard, H., Ward, M., Weschler, C., \& Corsi, R. L. (2007). Ozone reactions with indoor materials during building disinfection. Atmospheric Environment, 41(15), 3166-3176.

Reiss, R., Ryan, P. B., Koutrakis, P., \& Tibbetts, S. J. (1995). Ozone reactive chemistry on interior latex paint. Environmental science \& technology, 29(8), 1906-1912.

Rim D, Gall ET, Maddalena RL, Nazaroff WW, (2016). Ozone reaction with interior building materials: Influence of diurnal ozone variation, temperature and humidity, Atmospheric Environment, 125A, 15-23.

Sparks, L. E., Guo, Z., Chang, J. C., \& Tichenor, B. A. (1999). Volatile organic compound emissions from latex paint-Part 1. Chamber experiments and source model development. Indoor Air, 9(1), 10-17.

Segalin, B., Kumar, P., Micadei, K., Fornaro, A., \& Gonçalves, F. L. (2017). Sizesegregated particulate matter inside residences of elderly in the Metropolitan Area of São Paulo, Brazil. Atmospheric Environment, 148, 139-151.

Taha, H., \& Sailor, D. (2010). Evaluating the Effects of Radiative Forcing Feedback in Modelling Urban Ozone Air Quality in Portland, Oregon: Two-Way Coupled MM5CMAQ Numerical Model Simulations. Boundary-layer meteorology, 137(2), 291-305. Doi: $10.1007 / \mathrm{s} 10546-010-9533-9$

United States Department of Commerce. (2006). Paint and Allied Products: 2005. Economic and Statistics Administration, U.S. Census Bureau, MA325F(05)-1.

Walker IS, Sherman, M, Nazaroff W, (2009). Ozone Reductions Using Residential Building Envelopes. Report LBNL-5889E. Ernest Orlando Lawrence Berkeley National Laboratory, Berkeley, CA (US).

Wisthaler A, Weschler CJ, (2010). Reactions of ozone with human skin lipids: sources of carbonyls, dicarbonyls, and hydroxycarbonyls in indoor air. Proceedings of the National Academy of Sciences of the United States of America 107 (15), 6568-6575. 


\section{Supporting Information for Chapter 5:}

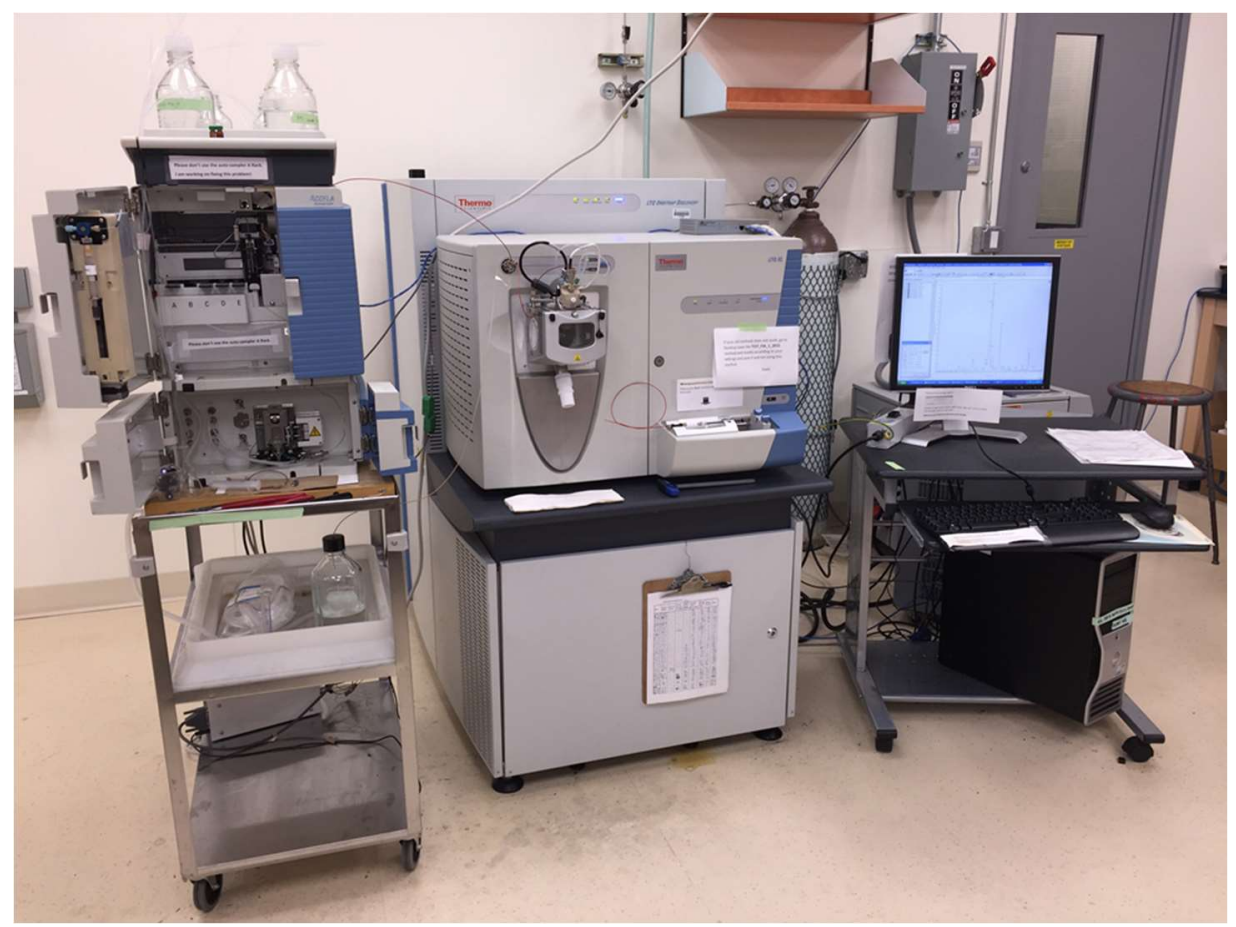

Figure 5.8. Photo of high pressure liquid chromatography / Mass spectroscopy (HPLC/MS) used to analyze air samples for carbonyl compounds.

\section{Parameters of mass spectrometry used in carbonyls detection:}

The Mass spectrometry was set on negative polarity method with following parameters:

Tune file values:

Source Type: ESI

Capillary Temp (C) : 400.00

Sheath Gas Flow () : 10.00

Source Voltage $(\mathrm{kV}): \quad 4.5$

Capillary Voltage (V): -40.00

Tube Lens(V) $\quad: \quad-80.00$ 


\section{Chapter 6}

\section{Conclusions}

In this dissertation, four different studies were performed to investigate the impact of different indoor building materials, such as carpets, indoor plants, HVAC filters, and indoor latex paints on indoor air quality by studying ozone removal and carbonyl emissions. In the first study, the effect of carpet fiber type on ozone removal and carbonyl emissions was investigated. The results from this study show that carpet fiber types have significant effect on ozone removal. Ozone deposition velocity values for six carpet types ranged between 2 to $6 \mathrm{~m} \mathrm{~h}^{-1}$. This indicates that carpets have good capacity in harmful ozone removal. However, elevated by-product emissions are observed in the presence of ozone. For ozone removal, nylon carpet fiber showed the least effectiveness in ozone removal, but was also one of the least aldehyde emitters. This makes it a reasonable choice for areas that has less elevated ozone exposures. On the other hand, polyester fiber carpet had the lowest ozone deposition velocity of around $2 \mathrm{~m} \mathrm{~h}^{-1}$, but had the highest carbonyl emissions when exposed to ozone which makes it less than optimal choice for carpet type for high ozonated regions. Wool and poly-propylene carpet had the highest ozone deposition velocity values, which is a favorable point. Also, have the least heavy aldehyde emissions. However, they are both within high light carbonyl emitters, especially poly-propylene fiber carpet. Trixta-type carpet fibers had a higher ozone deposition velocity, around $5 \mathrm{~m} \mathrm{~h}^{-1}$, and is one of the least light carbonyl emitters. They did, however, have higher heavy aldehyde primary emissions. Also, this type of carpet had moderate secondary emissions which make it a second choice compared to the nylon carpet fiber. 
In the second study of this dissertation, five common indoor plants were tested for ozone removal and the effect of light variations on ozone deposition velocity. The indoor plants showed wide range of ozone deposition velocity values ranging between $0.5-5.5$ $\mathrm{m} \mathrm{h}^{-1}$, depending on the type of plant, and numbers of exposure to ozone. Golden Pothos plant was the highest ozone removal plant within the species tested, and Peace lily was the least. The indoor plants tested showed substantial differences in responding to changes in light levels. Whereas Dieffenbachia was the lease responsive to light with increase of a factor of 1.7, Peace lily was the highest light responsive with increases of ozone deposition velocity by a factor of 4.7. Ozone removal effectiveness calculations were based on hypothetical indoor space, assuming a reasonable number of plants per volume. This model showed modest contributions to ozone removal by indoor plants of about $0.9-9 \%$. This is primarily due to the small ratio of leaf surface area to the total volume of space where plants may be located.

In the third study, ozone removal efficiency of three HVAC filters was investigated. The first type of filter was new and unused, while the two others were installed in air handling units located on green and white membrane roofs of a local commercial building. Ozone levels of 40ppb and 120ppb, at a relative humidity of $30 \%$ and $70 \%$, were tested. The outcomes of this research show that the green roof filter had more ozone removal efficiency than the white membrane roof filter. Efficiencies of about $25 \%$ at $40 \mathrm{ppb}$ ozone inlet and around $10 \%$ at $120 \mathrm{ppb}$ ozone levels were observed. Also, the unused filter had slightly better ozone removal than the white membrane roof filter at about $15 \%$ vs $10 \%$. The results also show that changes in relative humidity had a minor effect on ozone removal efficiency. As relative humidity increased from 30 to $70 \%$, the 
green roof filter, showed about a 5\% improvement in ozone removal efficiency over the white membrane roof filter and unused filters. Scanning electron microscope images show that heavy deposits on the green roof filter originating from the surrounding vegetation layer on the roof is the primary reason behind its high ozone removal efficiency. Also, the surface morphology difference between the new and white membrane roof filter fibers is the most likely cause for better ozone removal by the unused filter.

The fourth part of this dissertation has investigated ozone removal, TVOC, and carbonyl emissions from gypsum boards freshly painted with normal, low, and zero VOC indoor latex paints. Ozone deposition velocity testes show that both low VOC and zero VOC paints have ozone deposition values around $2.5 \mathrm{~m} \mathrm{~h}^{-1}$. Also, that normal VOC paint has much less ozone deposition velocity value of about $0.8 \mathrm{~m} \mathrm{~h}^{-1}$. Total VOC measurements show that freshly painted surfaces are strong VOC sources especially during the first 24 hours of paint application. Both low and zero VOC paints showed much lower peak TVOC values compared to normal VOC paint. For carbonyl emissions, acetone and nonanal were the most dominant compounds detected in primary emissions from normal and low VOC paints, also only nonanal was the compound detected, with small concentrations of heptanal, for zero VOC paint. When exposed to ozone, nonanal concentrations for all paints increased substantially to about 10 times the initial concentrations. Other heavy aldehydes were also generated as a result of exposure to ozone. Combining conclusions from both ozone deposition velocities and VOC emissions data suggests that zero VOC paint is the best sink for ozone and the least likely to emit VOCs and carbonyls. 
The outcomes from different research conducted in this dissertation suggest that indoor building materials have a significant impact on indoor air quality. Also, selection of these materials should be based on a careful review of the results of specialized research, as introduced in this dissertation, to ensure that different building materials will not negatively impact the indoor environment with the emission of toxic compounds.

Instead, building materials will enhance the safety and health of the occupants by removing harmful pollutants from their indoor living and work spaces. 


\section{References}

Abbass, O. A., Sailor, D. J., \& Gall, E. T. (2017). Effect of fiber material on ozone removal and carbonyl production from carpets. Atmospheric Environment, 148, 42-48. http://dx.doi.org/10.1016/j.atmosenv.2016.10.034

Abbass, O. A., Sailor, D. J., \& Gall, E. T. (2017b). Effectiveness of indoor plants for passive removal of indoor ozone. Building and Environment, 119, 62-70.

Allen, R. J., Wadden, R. A., \& Ross, E. D. (1978). Characterization of potential indoor sources of ozone. The American Industrial Hygiene Association Journal, 39(6), 466-471.

ASHRAE 2011, Ozone and Indoor Chemistry. Environmental Health Committee (EHC) Emerging Issue Report. Retrieved online on Jan. (2017) from:

https://www.ashrae.org/File\%20Library/docLib/Committees/EHC/Emerginglssues/EHC_Emergin g_Issue-OzoneandIndoorAirChemistry.pdf

Beig, G., Gunthe, S., \& Jadhav, D. B. (2007). Simultaneous measurements of ozone and its precursors on a diurnal scale at a semi urban site in India. Journal of Atmospheric Chemistry, 57(3), 239-253. doi: 10.1007/s10874-007-9068-8

Bekö, G., Clausen, G., \& Weschler, C. J. (2007). Further studies of oxidation processes on filter surfaces: Evidence for oxidation products and the influence of time in service. Atmospheric Environment, 41(25), 5202-5212.

Bell, M. L., Peng, R.D., Cominici, F. (2006). The exposure-response curve for ozone and risk of mortality and the adequacy of current ozone regulations. Environmental Health Perspectives 114(4): 532-536.

Bentayeb, M., Billionnet, C., Baiz, N., Derbez, M., Kirchner, S., \& Annesi-Maesano, I. (2013). Higher prevalence of breathlessness in elderly exposed to indoor aldehydes and VOCs in a representative sample of French dwellings. Respiratory medicine, 107(10), 1598-1607.

Berardi, U., GhaffarianHoseini, A., \& GhaffarianHoseini, A. (2014). State-of-the-art analysis of the environmental benefits of green roofs. Applied Energy, 115, 411-428.

Blondeau, P., Iordache, V., Poupard, O., Genin, D. and Allard, F. (2005), Relationship between outdoor and indoor air quality in eight French schools. Indoor Air, 15: 2-12. doi:10.1111/j.1600-0668.2004. 00263.x

Boelter, K. J., \& Davidson, J. H. (1997). Ozone generation by indoor, electrostatic air cleaners. Aerosol Science and Technology, 27(6), 689-708.

Brauer, M., \& Brook, J. R. (1997). Ozone personal exposures and health effects for selected groups residing in the Fraser Valley. Atmospheric Environment, 31(14), $2113-$ 2121. http://dx.doi.org/10.1016/S1352-2310(96)00129-X 
Calfapietra, C., Morani, A., Sgrigna, G., Di Giovanni, S., Muzzini, V., Pallozzi, E., ... \& Fares, S. (2016). Removal of ozone by urban and peri-urban forests: Evidence from laboratory, field, and modeling approaches. Journal of environmental quality, 45(1), 224233. doi:10.2134/jeq2015.01.0061

California Department of Resources Recycling and Recovery (CalRecycle), (2016). Carpet Construction and Demolition Recycling. http://www.calrecycle.ca.gov/ConDemo/Carpet/, accessed Sept 4, 2016.

CDPH, (2010). Standard method for the testing and evaluation of volatile organic chemical emissions from indoor sources using environmental chambers. Version 1.1. California department of public health. Feb. 2010.

Chang, J., Fortmann, R., Roache, N., \& Lao, H. C. (1999). Evaluation of Low-VOC Latex Paints. Indoor Air, 9(4), 253-258.

Chang, J., Tichenor, B. A., Guo, Z., \& Krebs, K. A. (1997). Substrate effects on VOC emissions from a latex paint. Indoor Air, 7(4), 241-247.

Coleman BK, Destaillats H, Hodgson AT, Nazaroff WW, (2008). Ozone consumption and volatile byproduct formation from surface reactions with aircraft cabin materials and clothing fabrics. Atmospheric Environment 42, 642-654.

Corsi, R. L., \& Lin, C. C. (2009). Emissions of 2, 2, 4-trimethyl-1, 3-pentanediol monoisobutyrate (TMPD-MIB) from latex paint: a critical review. Critical Reviews in Environmental Science and Technology, 39(12), 1052-1080.

Crawshaw C, Simpson W S, (2002). Wool: Sience and Technology. Woodhead Publishing. 62.

Cros CJ, Morrison GC, Siegel J, Corsi R, (2011). Removal of indoor ozone by green building materials, 12th International Conference on Indoor Air Quality and Climate 2011.

Cros CJ, Morrison GC, Siegel JA, Corsi RL, (2012). Long-term performance of passive materials for removal of ozone from indoor air. Indoor Air 22 (1), 43-53.

Davis, J. M., \& Speckman, P. (1999). A model for predicting maximum and 8h average ozone in Houston. Atmospheric Environment, 33(16), 2487-2500.

De Smedt, F., De Gendt, S., Heyns, M. M., \& Vinckier, C. (2001, January). Materials compatibility and organic build-up during ozone-based cleaning of semiconductor devices. In DIFFUSION AND DEFECT DATA PART B SOLID STATE PHENOMENA (pp. 63-66). Scitec Publications; 1999.

Destaillats, H., Chen, W., Apte, M. G., Li, N., Spears, M., Almosni, J., ... \& Fisk, W. J. (2011). Secondary pollutants from ozone reactions with ventilation filters and degradation of filter media additives. Atmospheric environment, 45(21), 3561-3568. 
EPA, (1999). Compendium Method TO-11A. Determination of Formaldehyde in Ambient Air Using Adsorbent Cartridge Followed by High Performance Liquid Chromatography (HPLC) [Active Sampling Methodology]. Center for Environmental Research Information. Office of Research and Development U.S. Environmental Protection Agency. Cincinnati, OH 45268.

EPA, (2015). NAAQS Table. An online content from U.S. Environmental Protection Agency website. Retrieved online on Dec. (2016) from: https://www.epa.gov/criteria-airpollutants/naaqs-table

EPA, (2017). Ozone Pollution. An online content from U.S. Environmental Protection Agency website. Retrieved online on Jun (2017) from: https://www.epa.gov/ozonepollution

Fares, S., Goldstein, A., \& Loreto, F. (2010). Determinants of ozone fluxes and metrics for ozone risk assessment in plants. Journal of Experimental Botany, 61(3), 629-633.

Fick J, Nilsson C, Andersson B, (2004). Formation of oxidation products in a ventilation system. Atmospheric Environment 38, 5895-2599.

Gall, E. T. (2013). Ozone transport to and removal in porous materials with applications for low-energy indoor air purification. PhD. dissertation. University of Texas at Austin. Online retrieved from:

https://repositories.lib.utexas.edu/bitstream/handle/2152/21927/GALL-

DISSERTATION-2013.pdf? sequence $=1 \&$ isAllowed $=\mathrm{y}$

Gall ET, Corsi RL, Siegel JA, (2011). Barriers and opportunities for passive removal of indoor ozone. Atmospheric Environment 45 (19), 3338-3341.

Gall ET, Darling E, Siegel J, Morrison G, Corsi R, (2013). Evaluation of three common green building materials for ozone removal, and primary and secondary emissions of aldehydes. Atmospheric Environment 77, 910-918.

Grøntoft T, Raychaudhuri M, (2004). Compilation of tables of surface deposition velocities for $\mathrm{O} 3, \mathrm{NO} 2$ and $\mathrm{SO} 2$ to a range of indoor surfaces. Atmospheric Environment $38,533-544$.

Gryparis, A., Forsberg, B., Katsouyanni, K., Analitis, A., Touloumi, G., Schwartz, J., ... \& Wichmann, H. E. (2004). Acute effects of ozone on mortality from the "air pollution and health: A European approach" project. American journal of respiratory and critical care medicine, 170(10), 1080-1087.

Hansen, M. K., Larsen, M., \& Cohr, K. H. (1987). Waterborne paints: a review of their chemistry and toxicology and the results of determinations made during their use. Scandinavian journal of work, environment \& health, 473-485. 
Hill, A. C. (1971). Vegetation: a sink for atmospheric pollutants. Journal of the Air Pollution Control Association, 21(6), 341-346.

Hoang C, Kinney KA, Corsi RL, (2009). Ozone removal by green building materials. Building and Environment 44 (8), 1627-1633.

Hyttinen, M., Pasanen, P., \& Kalliokoski, P. (2006). Removal of ozone on clean, dusty and sooty supply air filters. Atmospheric Environment, 40(2), 315-325.

Iain Walker, Max Sherman and William W. Nazaroff. (2009). "Ozone Reductions Using Residential Building Envelopes.” A report prepared by: Lawrence Berkeley National Laboratory.

Indoor Air Quality Guide Best Practices for Design, Construction, and Commissioning. (2009). American Society of Heating, Refrigerating and Air-Conditioning Engineers (ASHRAE). Online article retrieved from: https://www.ashrae.org/resources-publications/bookstore/indoor-air-quality-guide

ISO, (2006). International Standard ISO 16000-9. Indoor air- Part 9: Determination of the emission of volatile organic compounds from building products and Furnishing-Emission test chamber method.

Jenkins, P. L. and Nazaroff, W. W. "Activity patterns of Californians: Use of and proximity to indoor pollutant sources", Atmospheric Environment. (1992) Vol. 26, pp. 2141-2148

Kerstiens, G., \& Lendzian, K. J. (1989). Interactions between ozone and plant cuticles. New Phytologist, 112(1), 21-27.

Kim, K.J., Jeong, M.I., Lee, D.W., Song, J.S., Kim, H.D., Yoo, E.H., Jeong, S.J., Han, S.W., Kays, S.J., Lim, Y.-W., Kim, H.-H., (2010). Variation in formaldehyde removal efficiency among indoor plant species. Hort Science 45, 1489- 1495.

Klepeis NE, Nelson WC, Ott WR, Robinson JP, Tsang AM, Switzer P, Behar JV, Hern SC, Engelmann WH, (2001). The National Human Activity Pattern Survey (NHAP): a resource for assessing exposure to environmental pollutants. J. Expo Anal Environ Epidemiol, 11 (3), 231-52.

Kozlowski, T. T. (1980). Responses of shade trees to pollution. Journal of Arboriculture, 6(2) 29-40.

Kunkel, D. A., Gall, E. T., Siegel, J. A., Novoselac, A., Morrison, G. C., \& Corsi, R. L. (2010). Passive reduction of human exposure to indoor ozone. Building and Environment, 45(2), 445-452.

Lambers, H., Chapin III, F. S., \& Pons, T. L. (2008). Photosynthesis. In Plant physiological ecology (pp. 11-99). Springer New York. 
Lamble, S. P. (2011). Ozone uptake rates and secondary product emissions of green building materials. Master Thesis, Missouri University of Science and Technology. Paper 4926.

Lamble SP, Corsi RI, Morrison GC, (2011). Ozone deposition velocities, reaction probabilities and product yields for green building materials. Atmospheric Environment 45, 6965-6972.

Lee, P., \& Davidson, J. (1999). Evaluation of activated carbon filters for removal of ozone at the ppb level. American Industrial Hygiene Association Journal, 60(5), 589-600.

Lee, K., Vallarino, J., Dumyahn, T., Ozkaynak, H., Spengler, J.D., (1999). Ozone decay rates in residences. Journal of the Air and Waste Management Association 49 (10), 12381244.

Lei, W., Foy, B. D., Zavala, M., Volkamer, R., \& Molina, L. T. (2007). Characterizing ozone production in the Mexico City Metropolitan Area: a case study using a chemical transport model. Atmospheric Chemistry and Physics, 7(5), 1347-1366.

Lin, C. C., \& Chen, H. Y. (2014). Impact of HVAC filter on indoor air quality in terms of ozone removal and carbonyls generation. Atmospheric Environment, 89, 29-34.

Ling, Z. H., \& Guo, H. (2014). Contribution of VOC sources to photochemical ozone formation and its control policy implication in Hong Kong. Environmental science \& policy, 38, 180-191.

Lippmann, M. (1989). Health effects of ozone a critical review. Journal of the Air Pollution Control Association, 39(5), 672-695.

Morrison GC, Nazzarof WW, (2002). Ozone Interaction with Carpet: Secondary Emissions of Aldehydes, Environmental Science and Technology, 36, 2185-2192.

Morrison GC, Nazaroff WW, Cano-Ruiz JA, Hodgson AT, Modera MP, (1998). Indoor air quality impacts of ventilation ducts: ozone removal and emissions of volatile organic compounds. Journal of the Air \& Waste Management Association 48 (10), 941-952.

Nazaroff WW, Gadgil, AJ, Weschler CJ, (1993). Critique of the Use of Deposition Velocity in Modeling Indoor Air Quality, ASTM International, 81-103.

Nicolas M, Ramalho O, Maupetit F, (2007). Reactions between ozone and building products: Impact on primary and secondary emissions, Atmospheric Environment, 41 (15), 3129-3138.

Oleson, K. W., Bonan, G. B., \& Feddema, J. (2010). Effects of white roofs on urban temperature in a global climate model. Geophysical Research Letters, 37(3). 
Orwell, R.L., Wood, R.L., Tarran, J., Torpy, F., Burchett, M.D., (2004). Removal of benzene by the indoor plant/substrate microcosm and implications for air quality. Water. Air. Soil Pollut. 157, 193-207. doi:10.1023/B: WATE.0000038896.55713.5b

Pandrangi, L. S., \& Morrison, G. C. (2008). Ozone interactions with human hair: ozone uptake rates and product formation. Atmospheric Environment, 42(20), 5079-5089.

Papinchak, H. L., Holcomb, E. J., Best, T. O., \& Decoteau, D. R. (2009). Effectiveness of houseplants in reducing the indoor air pollutant ozone. HortTechnology, 19(2), 286-290.

Poppendieck D, Hubbard H, Ward M, Weschler C, Corsi RL, (2007). Ozone reactions with indoor materials during building disinfection. Atmospheric Environment 41 (15), 3166-3176. http://dx.doi.org/10.1016/j.atmosenv.2006.06.060

Pudasainee, D., Sapkota, B., Shrestha, M. L., Kaga, A., Kondo, A., \& Inoue, Y. (2006). Ground level ozone concentrations and its association with NOx and meteorological parameters in Kathmandu valley, Nepal. Atmospheric environment, 40(40), 8081-8087.

Reiss, R., Ryan, P. B., Koutrakis, P., \& Tibbetts, S. J. (1995). Ozone reactive chemistry on interior latex paint. Environmental science \& technology, 29(8), 1906-1912.

Rim D, Gall ET, Maddalena RL, Nazaroff WW, (2016). Ozone reaction with interior building materials: Influence of diurnal ozone variation, temperature and humidity, Atmospheric Environment, 125A, 15-23.

Russell, J.A., Hu, Y., Chau, L., Pauliushchyk, M., Anastopoulos, I., Anandan, S., Waring, M.S. (2014). Indoor-biofilter growth and exposure to airborne chemicals drive similar changes in plant root bacterial communities. Applied Environmental Microbiology, 80(16): 4805-4813.

Sailor, D. J. (2008). A green roof model for building energy simulation programs. Energy and buildings, 40(8), 1466-1478.

Sailor, D. J., Elley, T. B., \& Gibson, M. (2012). Exploring the building energy impacts of green roof design decisions-a modeling study of buildings in four distinct climates. Journal of Building Physics, 35(4), 372-391.

Segalin, B., Kumar, P., Micadei, K., Fornaro, A., \& Gonçalves, F. L. (2017). Sizesegregated particulate matter inside residences of elderly in the Metropolitan Area of São Paulo, Brazil. Atmospheric Environment, 148, 139-151.

Shao, M., Lu, S., Liu, Y., Xie, X., Chang, C., Huang, S., \& Chen, Z. (2009). Volatile organic compounds measured in summer in Beijing and their role in ground-level ozone formation. Journal of Geophysical Research: Atmospheres, 114(D2).

Shields, H. C., Weschler, C. J., \& Naik, D. V. (1999). Ozone removal by charcoal filters after continuous extensive use (5 to 8 years). Indoor Air, 99, 49-54. 
Sparks, L. E., Guo, Z., Chang, J. C., \& Tichenor, B. A. (1999). Volatile organic compound emissions from latex paint-Part 1. Chamber experiments and source model development. Indoor Air, 9(1), 10-17.

Standard 55 (2013). Thermal Environmental Conditions for Human Occupancy (ANSI Approved). Retrieved from:

http://www.techstreet.com/ashrae/products/1868610?utm_source=promotion\&utm_medi

um=landingpage\&utm_campaign $=86179 \& u t m \_t e r m=86179 \& u t m \_$content $=86179 \&$ ashra e_auth_token=

Stephens, B., Gall, ET, Siegel JA, (2012). Measuring the penetration of ambient ozone into residential buildings, Environmental Science and Technology, 46 929-936.

Szinyei, D. (2014). Modelling and evaluation of ozone dry deposition (Doctoral dissertation, Freie Universität Berlin).

Taha, H., \& Sailor, D. (2010). Evaluating the Effects of Radiative Forcing Feedback in Modelling Urban Ozone Air Quality in Portland, Oregon: Two-Way Coupled MM5CMAQ Numerical Model Simulations. Boundary-layer meteorology, 137(2), 291-305. Doi: 10.1007/s10546-010-9533-9

Tuomi, T., Engström, B., Niemelä, R., Svinhufvud, J., \& Reijula, K. (2000). Emission of ozone and organic volatiles from a selection of laser printers and photocopiers. Applied Occupational and Environmental Hygiene, 15(8), 629-634.

Uhde E, Salthammer T, (2007). Impact of reaction products from building materials and furnishings on indoor air quality - A review of recent advances in indoor chemistry, Atmospheric Environment, 41 (15), 3111-3128.

United States Department of Commerce. (2006). Paint and Allied Products: 2005. Economic and Statistics Administration, U.S. Census Bureau, MA325F(05)-1.

U.S. Environmental Protection Agency (1997): An Office Building Occupant's Guide to Indoor Air Quality, Office of Research and Development Washington. DC, (EPA/402/K97/003aF).

Walker IS, Sherman, M, Nazaroff W, (2009). Ozone Reductions Using Residential Building Envelopes. Report LBNL-5889E. Ernest Orlando Lawrence Berkeley National Laboratory, Berkeley, CA (US).

Wang H, Morrison GC, (2006). Ozone-initiated secondary emission rates of aldehydes from indoor surfaces in four homes. Environmental Science \& Technology 40 (17), 52635268.

Wang H, Morrison GC, (2010). Ozone-surface reactions in five homes: Surface reaction probabilities, aldehyde yields, and trends. Indoor Air, 224-234. 
Waring MS, Siegel JA, (2013). Indoor Secondary Organic Aerosol Formation Initiated from Reactions between Ozone and Surface-Sorbed d-Limonene, Environmental Science and Technology, 47 (12), 6341-6348.

Weschler CJ, (2000). Ozone in Indoor Environments: Concentration and Chemistry, Indoor Air, 10, 269-288.

Weschler CJ, (2006). Ozone's Impact on Public Health: Contributions from Indoor Exposures to Ozone and Products of Ozone-Initiated Chemistry. Environ Health Prospect. 114, 1489-1496.

Weschler CJ, (2009). Changes in indoor pollutants since the 1950s. Atmospheric Environment 43 (1), 153-169.

Wechsler C, Hodgson, AT, Wooley, JD, (1992). Indoor chemistry: Ozone, Volatile Organic Compounds, and Carpets. Environmental Science and Technology, 26 23712377.

Weschler, C. J., Shields, H. C., \& Naik, D. V. (1994). Ozone-removal efficiencies of activated carbon filters after more than three years of continuous service. ASHRAE transactions, 100(2), 1121-1129.

Wisthaler, A., \& Weschler, C. J. (2010). Reactions of ozone with human skin lipids: sources of carbonyls, dicarbonyls, and hydroxycarbonyls in indoor air. Proceedings of the National Academy of Sciences, 107(15), 6568-6575.

Wolverton, B. Johnson, A. Bounds, K. (1989). "Interior Landscape Plants for Indoor Air Pollution Abatement". Final report. National Aeronautics and Space Administration. Report number: NASA -TM-101768.

Wood R.A., Burchett M.D., Alquezar R., Orwell R.L., Tarran J., Torpy F. (2006). The potted-plant microcosm substantially reduces indoor air VOC pollution: I. Office fieldstudy. Water Air Soil Pollution 175:163-180. doi: 10.1007/s11270-006-9124-z

Yamamoto, N., Shendell, D. G., Winer, A. M., \& Zhang, J. (2010). Residential air exchange rates in three major US metropolitan areas: results from the Relationship Among Indoor, Outdoor, and Personal Air Study 1999-2001. Indoor Air, 20(1), 85-90. doi: 10.1111/j.1600-0668.2009.00622.x

Zhao, P., Siegel, J. A., \& Corsi, R. L. (2007). Ozone removal by HVAC filters. Atmospheric Environment, 41(15), 3151-3160.

Zhao, P. (2006). Ozone interactions with HVAC filters (Doctoral dissertation). University of Texas at Austin. Retrieved online from:

https://repositories.lib.utexas.edu/bitstream/handle/2152/2965/zhaod81284.pdf 